

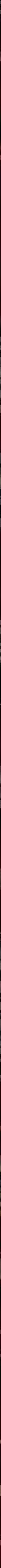




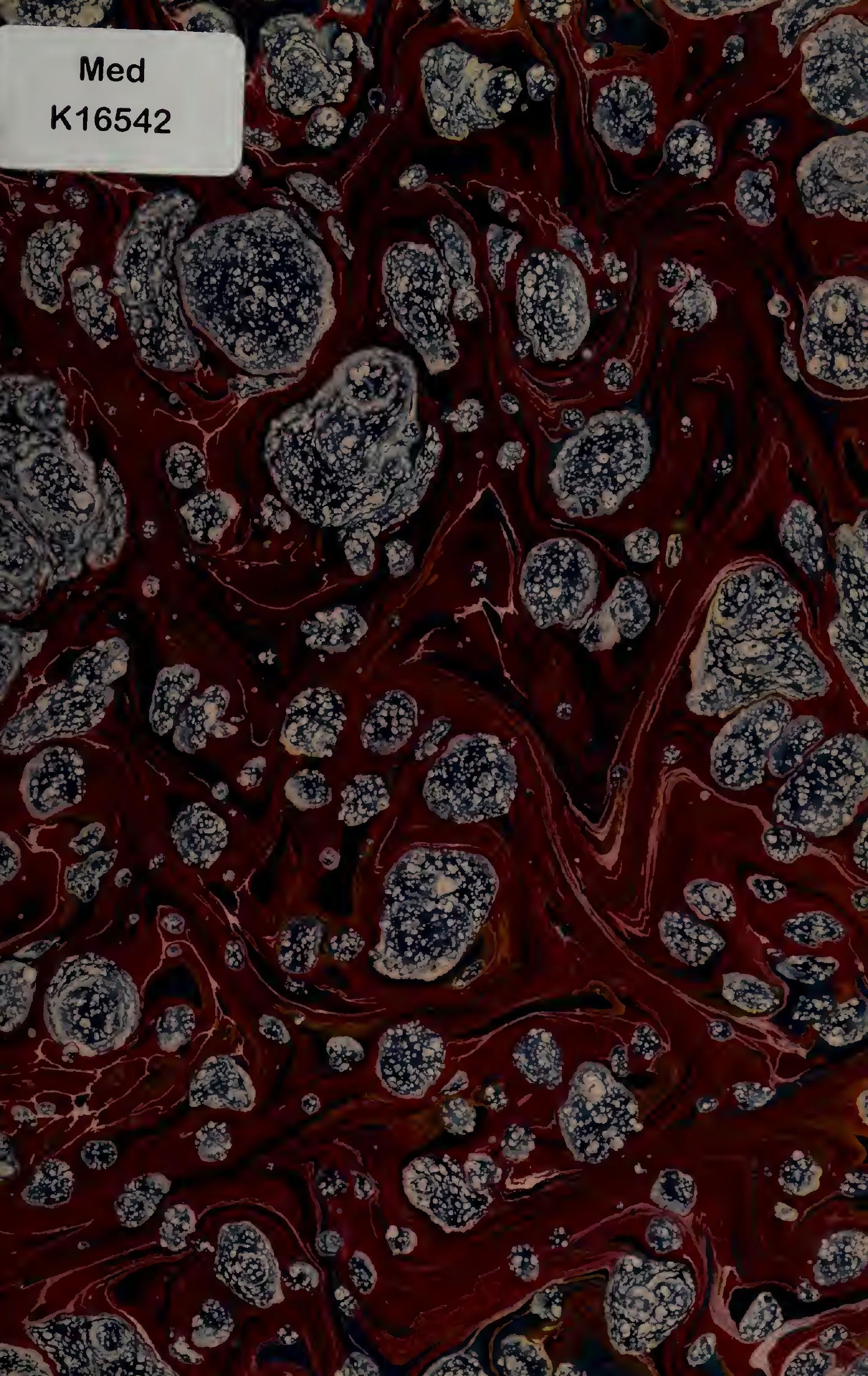





DIE

\section{MIKROSKOPISCHEN THIERE}

DES

\section{SÜSSW ASSER-AQUARIUMS.}

FÜF FREUNDE

DES MIKROSKOPES UND DER NATURWISSENSCHAFTEN,

SYSTEYATSCH DARGESTELLT

VON

\section{GUSTAV SCHOCH.}

I. $\mathrm{BUCH}$.

\section{DIE URTHIERE.}

MIT ACHT LITHOGRAPHIRTEN TAFELN.

\section{LEIPZIG.}

VERLAG VON ARTHUR FELIX.

1868. 


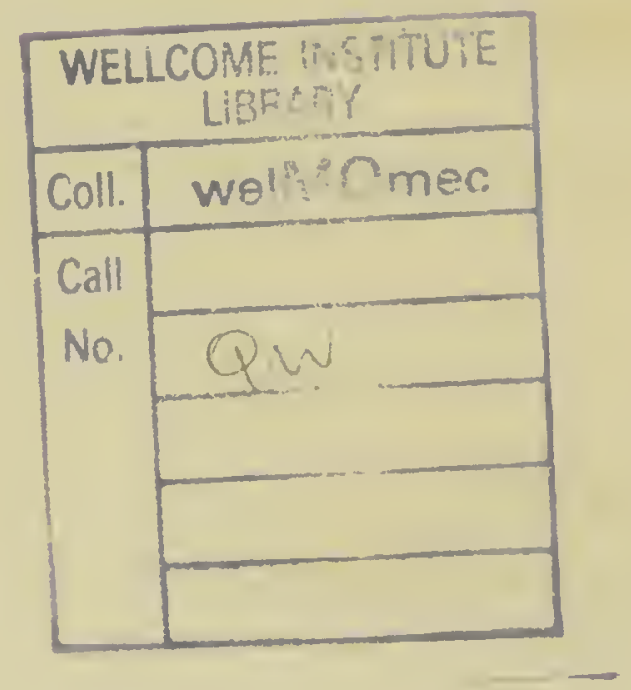




\section{Vorwort.}

Es scheint eine allgemein inenschliche Eigenschaft zu sein, dass Naturerscheinungen uns gewöhnlich nur so lange beschäftigen, unsere Bewunderung nur so lange erregen, als sie uns neu sind, und dass, sobald das Object der Betrachtung in das Bereich des Alltäglichen übergeht, unser Interesse erlischt. Nur selten wird nachhaltiger Wissenstrieb geweckt. Wer zum erstenmal an ein Mikroskop kommt, wünscht etwa ein Blatt, ein Haar, einen Floh, oder sonst etwas seinem Geschmacke Zusagendes zu sehen, und geht in der Regel damit befriedigt von dem Glase hinweg.

Das Mikroskop, das ein Gemeingut der Gebildeten sein sollte, hat wohl meist aus diesem Grunde noch nicht die verdiente Verbreitung gefunden. Und doch, wie reichlich lohnt sich die mässige Ausgabe für cin Instrument, das uns eine so unerschöpfliche Fundgrube des Wunderbaren öffuet; wie oft wird für Spielereien untergeordneter Art unbedenklich eine gleiche Summe verwendet; theure Aquarien werden als Staffage in Salons eingerichtet, die nach kurzer Zeit dem Besitzer, dem nicht ein Mikroskop zu Gebote steht, gleichgültig werden.

Freilich ist es mit dem Instrumente allcin nicht gethan; es muss zugegeben werden, dass der Gebrauch desselben dem Laien wesentlich erschwert ist durch den Mangel an billigen, populiiren und doch planmässigen Schriften, woraus auch der Ungeübtere schöpfen kann. Dieser letzten Erwägung verdankt unser Versuch einer Anleitung zur Deutung des Gesehenen seine Entstehung. 
Bewohner des Binnenlandes halten wir uns bei Betrachtung' der niedrigsten 'Thierformen mit voller Absicht ausschliesslich an die des süssen Wassers, die unsere Bäche und Gräben fuillen, ja zu Hunderten in jerlem Tropfen sumpfigen Wassers wimmeln.

Das bescheidenste Aquarium, ein Glas Wasser aus irgend einem Sumpfe, bildet das Areal, worauf wir sammeh und beobachten; die nöthigen Hülfswerkzeuge bestehen aus einem flachen Uhrghas, einigen Glasscherbẹn und den Deckgläschen. Wir halten uns ferne von theoretischen Discussionen über Pflanzen- oder Thiernatur eines Geschöpfes; diese vermeiden wir nicht nur desshalb, weil die Entscheidung bei Anwendung mässiger Vergrösserungen äusserst unsicher wird, sondern weil wir überhaupt beherzigen, dass viele neuere Forscher für die niedrigsten Stufen des organischen Lebens den Unterschied zwischen Thier und Pflanze als gar nicht vorhanden erklären, und dass, mit genauerem Studium des thierisehen und pflanzlichen Protoplasma die beiden organischen Reiche wirklich enge mit einander verbunden erscheinen.

Der Hauptzweck dieser Blätter ist viehnehr, dem Anfänger im Mikroskopiren eine Anleitung zur Bestimmung dessen zu geben, was er unter dem Vergrösserungsglase sieht, ihn aufmerksan zu machen darauf, wo er suchen soll, und ihm in gedrängter Form zu melden, was von geübten Forschern mit vorzüglichen Instrumenten bisher entdeckt worden ist. Sollte daher die vorliegende Arbeit, die aus eignem Redürfniss hervorgegangen, den Einen zum planmässigen Studium anregen, dem Andern ein Wegweiser in der unermesslichen Formenmenge werden, so ist ihr 'Zweck vollkommen erfüllt. 


\section{Inhaltsverzeichniss.}

Vorwort.

Seite.

Vurbemerkung . . . . . . . . . . . . . . . . . . . 1

Urthiere, allgemeiner Theil. Einleitung . . . . . . . . . . 2

Specieller Theil . . . . . . . . . . . . . . . . . . 7

IVurzelfüsser . . . . . . . . . . . . . . . . 7

Proteïla . . . . . . . . . . . . . . . . 9

Actinophryida . . . . . . . . . . . . . . . 12

Arcellida . . . . . . . . . . . . . 13

Infusorien . . . . . . . . . . . . . 16

Flagellata . . . . . . . . . . . . . 24

Cilio-Flagellata . . . . . . . . . . . 31

Ciliata . . . . . . . . . . 32

Holotricha .............. . . 34

Heterotricha . . . . . . . . . . . . . . 41

Hypotricha . . . . . . . . . . . . 43

Peritricha . . . . . . . . . . . 46

Suctoria . . . . . . . . . . . . . . 54

Entwickelungsgeschichte der Infusorien . . . . . . . . 57

\section{Index generum.}

Acineta . . . . . . . 57 Carchesium . . . . . 51

Actinophrys . . . . . . . 12 Ceratium . . . . . . . . 31

Amiba . . . . . . . . . 9 Cercomonas . . . . . . 26

Amphileptus . . . . . . . 38 Chilodon . . . . . . . 43

Anthophysa . . . . . . 27 Chilomonas. . . . . . 26

Arcella . . . . . . . . 14 Chlamydumonas . . . . 29

Aspidisca . . . . . . . 45 Coleps . . . . . . . . 38

Astasia . . . . . . . . . 28 Colpoda . . . . . . . . 40

Balantidium . . . . . . 41 Cothurnia . . . . . . 53

Botryocystis . . . . . . 29 Cryptoglena . . . . . . 29

Bursaria . . . . . . . . 42 Cryptomonas . . . . . . 29 
Seite.

Seitc.

Cyclidium . . . . . . 26. 40

Petalopus .. . . . . . 12

1)ifflugia . . . . . . . 14

Phacus . . . . . . . 28

1)inobryon . . . . . . 28

Phascolodon . . . . . . 43

Diselmis . . . . . . . 29

Phialina . . . . . . 37

Echinopyxis . . . . . 14

Plagiophrys . . . . . 13

Enchelyodon . . . . . . 37

Plagiotoma . . . . . 41

Enchelys . . . . . . 37

Ploesconia . . . . . 45

Epistylis . . . . . . . 51

Poclophrya . . . . . . 56

Ervilia . . . . . . . 43

Podostoma . . . . . 12

Euglena . . . . . . 28

Prorodon . . . . . . 37

Euglypha . . . . . . 15

Euplotes . . . . . . . . 45

Proteus . . . . . . . 9

Glaucoma . . . . . . 41

Gonium . . . . . . 27

Gromia . . . . . . . 15

Haematococcus . . . . . 29

Halteria . . . . . . . 46

Heteromita . . . . . . . 26

Hexamita . . . . . . 26

Holophrya . . . . . . . 37

Kerona . . . . . . . 45

Lacrymaria . . . . . . . 36

Lagenophrys . . . . . . 53

Lembadium . . . . . . 41

Leucophrys . . . . . . . 42

Loxodes . . . . . . . 38

Loxophyllum . . . . . . 38

Metopus . . . . . . . 41

Monas . . . . . . . 25

Nassula . . . . . . 39

Opalina . . . . . . . 85

Protococcus . . . . . 29

Scyphidia . . . . . . 51

Solenophrya . . . . . 57

Sphaerophrya . . . . . 56

Spirostomum . . . . . 41

Stentor . . . . . . 42

Stichochaeta . . . . 45

Stichotricha . . . . 15

Strombidium . . . . . 46

Stylonỵchia . . . . . . 45

Thecamonas . . . . . 29

Trachelius . . . . . . . 38

Trachelophyllum . . . . 37

Trepomonas . . . . . . 26

Trichodina . . . . . . 50

Trichodiscus . . . . . 13

'Trichomonas . . . . . . 26

Trinema . . . . . . 15

Urocentrum . . . . . 47

Uvella . . . . . . . 27

Opercularia....... . 51 Vaginicola ...... 53

Ophrydium ....... . 53 Volvox........ 27

Oxytricha . . . . . . 45 Vorticella ....... 52

Paramecium ....... . 40 Zoothamnium . . . . . 52

Peridinium . . . . . . 31 


\section{Vorbemerking.}

In dem ersten Tropfen schlammigen Wassers, welchen der Anfänger mit diesem Buche zur Seite untersucht, wird der erstaunte Beobachter viele Gebilde finden, von deren Natur er sich keine Rechenschaft geben kann, von denen er nicht weiss, sind es Thiere oder Pflanzen, sind es Urthiere, oder gehören sie einer andern Kilasse des animalen Reichs an. Wir wollen ihm daher die bekanntesten und häufigsten dieser Formen, welche er entweder ihrer Bewegung, oder ilhrer eigenthümlichen Gestaltung wegen für Urthiere halten möchte, denunciren, damit er sie nicht vergebens im vorliegenden Systeme suche, ohnc uns übrigens um dic Bercchtigung zu streiten, mit welcher wir sie entweder dem Pflanzenreiche, oder andern Thierklassen zurechnen.

Wir erwähnen also als Pflanzen, die schon zu den Infusorien gezählt worden sind, und deren Bewegung uns den Eindruck eines thierischen Wesens machen könnte, die Diatomeen, Desmidiaceen und alle jene einzelligen Algen, wovon Fig. 1-10 die gewöhnlichsten darstellen; ferner die schwankenden und schlängelnden Bacterien, Vibrionen und Spirillen (Fig. 11. 12, 13).

Unter den thierischen Gebilden, die vielfach zu den Urthieren gerechnet worden sind, trennen wir von diesen $a b$, die parasitisch im Darmcanal von Insecten lebenden Gregarinen (Fig. 14), das Wasserä̈lchen (Anguillula) und die Räderthiere, welche wir in einem den mikroskopischen Würmern und Krebsthierchen gewid- 
meten Buche besprechen werden. Die mit unbewaffnetem Auge leicht erkennbaren Wasserthierchen, wie z. B. der Süsswasserpolyp, die kleinen Krebsarten und Insectenlarven sind schwerlich einer Verwechselung ausgesetzt.

\section{Urthiere (Protozoa).}

\section{Allgemeiner Theil.}

Kein Urthier kann von blossem Auge erkannt werden, nur von sehr Wenigen bekommt man eine Idee ihrer Existenz, wenn sie sich als unendlich kleine Pünctchen, oder als feiner, schimmelähnlicher Ueberzug auf Wasserpflanzen zeigen. Es ist daher begreiflich, dass die Kenntniss dieser Thiere mit der Erfindung des Mikroskops und dessen Vervollkommnung innig rerbunden ist.

Die erste ordentliche Beschreibung von Urthieren erschien gegen Ende des letzten Jahrhunderts von Otтo Friedrich Müllir. Aber nur nach wesentlicher Verbesserung unserer optischen Hilfsmittel war es möglich, die unendliche Menge ron Formen genauer zu studiren und zu ordnen, und so trat denn erst zu Anfang der dreissiger Jahre das riesenhafte Werk von EHRExberg über die Infusionsthiere in's Leben, welches die ganze gelehrte Welt lange mit Bewunderung erfüllte, ob der reichhaltigen Menge ron Thieren und ihrer merkwürdigen Organisation, von der bisher Niemand eine Ahnung gehabt hatte. Wenn wir ein Urthier betrachten, so sehen wir in der wasserhellen Körpersubstanz desselben gewöhnlich eine Reihe verschiedenartig gefärbter Kügelchen oder Bläschen. Diese Kügelchen bestehen meist aus den Speisetheilen, die das Thier gefressen hat. EHREnberg behauptet nun, dass jedes dieser Kügelchen einem eigenen, schon vorher im Thier existirenden Magen entspreche, und dass diese Magen durch einen oft verzweigten Darmcanal (Fig. 26 I.) im Zusammenhange stünden. Er nennt 
daher die Urthiere schlechtweg Magenthiere (Polygastrica). Andere eigenthümliche Körper im Innern dieser 'Thiere (Kern, contractile Blase) erklärt er für Geschlechtsorgane u. s. w.

Gegen Ende der dreissiger Jahre schon wurde aber ein guter Theil dieser Wunder durch einen französischen Forscher (DuJARDIN) der staunenden Welt wieder entzogen, indem er die phantasiereichen Hypothesen Ehrexberc's über die complicirte Organisation rerwarf und annahm, dass die Urthiere möglichst einfach organisirt seien. Nach ihm bestehen diese Geschöpfe aus einem gleichmässigen Schleim, der ron einer feinen Hülle umgeben ist; bei einigen sogar fehlt auch diese Hülle. Alle einzelnen Theile dieses Schleimkörpers haben dieselbe Bedeutung, die nämliche physiologische Dignität; einzelne helle Blasen oder festere Körper im Innern derselben wären zufällige Elemente, und nicht als Organe des Thieres anzusehn. Die Körpersubstanz der Urthiere erhielt ron Dujardis den Namen Sarcode, und zeichnet sich aus durch ihre grosse Dehnbarkeit und die Fähigkeit in ihrem Innern Blasen zu bilden. Fremde Körper werden in dieselbe aufgenommen, durch ihre $\mathrm{Zu}$ sammenziehung in fortschreitende Bewegung rersetzt und endlich verändert und verdaut wieder ausgestossen.

Diese Anschauung wurde von deutschen Forschern, besonders von MEYEx, noch weiter ausgebildet, indem sie die Urthiere mit der einfachen Zelle verglichen. Dieselben sind nach dieser Ansicht bloss ein verschiedenartig gestalteter Zellensack mit homogenem Schleime gefüllt, worin ein Zellenkern schwimmt.

Doch auch eine solche Vorstellung musste nach und nach verlassen werden, nachdem Lifberkühx, Coins, Steix, Balbiasi, Lachmaxi und Cuapariene die Physiologie der Urthiere genauer studirt hatten, und einen höhern Grad von Organisation fanden, als ihn die Idee cines homogenen Schleimes (Sarcode), oder die der einfachen Zelle zulïsst. So interessant diese physiologischen Studien sind, so dürfen wir uns hier nicht so sehr in die Einzelheiten einlassen und begnügen uns vorläufig mit folgender Vorstellung. Jedes Urthier hat eine sehr dehnbare festere Körpermasse, das $\mathrm{K}$ orperparenchym, an welcher oft eine derbe, mit Bewegungsorganen versehene Haut deutlich zu erkennen, oft aber kein Unterschied zwisclen Körper und Haut wahrnehmbar ist. Die innere 
Partie des Körperparenchyms scheint von dünnerer Consistenz zu scin, theilt aber die Contractionsfähigkeit vollkommen mit dem festen äusseren Parcnchym. In den meisten Fällen ist der Uebergang dieser zwei Schichten in einander ein ganz allmählicher; oft aber erscheint der Innenraum der Urthiere schärfer von dem äussern, resistenten Parenchym getrennt, und bildet alsdann eine mit schleimiger Flüssigkeit gefüllte Höhle, worin sich vorzugsweise die Speiscballen anhäufen.

In der obeflächlichen Schicht des Körperparenchyms liegt eine (oder mehrere) mit wasserheller Flüssigkeit gefüllte contractile Blase eingebettet, die sich in regelmässigen Zeiträumen zusammenzieht und wieder füllt. Sic fehlt allen entschieden pflanzlichen Gebilden, und kann also mit Recht als rein thierisches Organ betrachtet werden, während niedere Organismen, wo sie nicht entdeckt wurde, heute noch eine unbestimmte Stellung zwischen Thier- und Pflanzenreich einnehmen. Bei einzelnen Arten hat man sogar Anfänge von einem Gefässsystcm beobachtet, das mit dieser Blase in Verbindung steht. Ebenso befindet sich im äussern Korperparenchym eine festere Stelle, Kern (Nucleus) genannt, welche bei der Fortpflanzung eine wesentliche Rolle spielt.

Die Urthiere sind alle an das Wasser gebunden, aber ihr Vorkommen ist sehr verschiedenartig. Nicht in allen Flüssigkeiten findet man sie. Vergebens wird man in Jauche und ganz faulen Pfützen darnach suchen; auch ist es eine arge Uebertreibung, wenn behauptet wird, in jedem Tropfen Trinkwassers werden Tausende dieser Geschöpfe verschlungen. In frischem Regen - oder Quellwasser wird die Beute kaum die Mühe des Suchens lohnen, während Sumpfwasser oder langsam fliessende Bäche eine unendliche Fülle von Urthieren beherbergen; überhaupt wo Wasserpflanzen vorkommen, ist immer eine reiche Ausbeute zu gewärtigen.

In demselben Bache, in dem nämlichen Teiche kann man je nach dem Standpunct der Thiere ganz verschiedenartige Faunen sammeln. Oft verräth ein staubiger Ueberzug, eine leichte Trübung des Wassers die massenhafte Anhäufung schwimmender Infusorien; festsitzende erblickt schon das blosse Ange als schimmelartige Bedeckung auf Wasserpflanzen, Insectenlarven und Schnecken; die zahlreichsten Formen der Freischwimmenden findet man im 
Blattwerke von Wasserpflanzen, während die kriechenden Wurzelfüssler häufiger in Schlamm und Bodensatz der Gewässer getroffen werden.

Von besondcrem Interesse ist das Erscheinen von Urthieren in Aufgüssen (Infusionen), woher ja die Infusorien ihren Namen haben (Aufgussthiere). Wenn man irgend eine organische Substanz z. B. Heu, Brod, Fleisch u. s. f. mit Wasser übergiesst, und diese Infusion einige Zeit dem Licht und der Luft aussetzt, so wird man darin bald zahlreiche mikroskopische Wesen sich bilden sehen, die sich anfangs vcrmehren, dann aber wieder abnehmen, um neuen Formen Platy zu machen. Geht der Aufguss allmählich in Fäulniss über, so sterben die Infusorien ab, und nur wenige pilzartige Pflanzen finden jetzt noch einen ihrer Entwickelung günstigen Boden.

Schon nach wenigen Stunden des Bestehens einer Infusion, fängt die Oberfläche des Wassers an, sieh staubig zu trüben, und unter dem Mikroskop löst sich dieser Staub in eine Menge winziger Wesen auf, die ihrer schwankenden und schlängelnden Bewegung wegen früher für Aufgussthiere gegolten haben; es sind Vibrionen und Bacillarien (Fig. 11. 12.13 I.). Dann erscheinen rasch herumfahrende Kügelchen oder Pünctchen, Monaden, über deren pflanzliche oder thierische Natur noch viele Zweifel obwalten; nach einigen Tagen findet man vielleicht eine Menge von Pantoffelthierchen oder ähnlichen Infusorien, und noeh später erseheinen die festsitzenden Glockenthierchen und verwandte Formen. Je nach dem Stoffe, der zur Infusion benutzt worden, und je nach der 'Temperatur entwiekeln sich diese oder jene Thierarten, und geht die Aufeinanderfolge dieser Gebilde rascher oder langsamer von statten; aber bisher sind diese Beziehungen noch wenig erforscht. Es ist daher auch für den Anfänger ein dankbares Gebiet, die Progression der Thierformen für versehiedene Infusionen zu studircn.

Wenden wir uns nun zur Systematik, um die zahlreichen Formen, denen wir im Kreise der Urthiere begegnen, zu sichten, so müssen wir vorab ein leicht entdeckbares Princip der Eintheilung suchen, da die innere Organisation, oder die eigentlich physiologischen Merkmale zu fein sind, um praktiseh verwerthet werden zu können; hiebei leistet uns die Besehaffenheit der Körperoberfläche, und die daran angebrachten Bewegungsorgane den meisten 
Vorschub; nach diesen können wir die Urthiere vorerst in zwei grosse Gruppen oder Klassen bringen.

Die eine Kilasse besteht aus Urthieren mit deutlicher Haut, die fester, resistenter ist, als das weiche Körperparenchym. Hieran sitzen feine Häärchen, die durch ihre flimmernde Bewegung das 'Thier weiter treiben; oder es finden sich Borsten, Stacheln oder Dornen, oder wenigstens entdeckt man ein langes haarähnliches Anhängsel, das durch seine peitschenartigen Schwingungen die Ortsbewegung des Thieres vermittelt; oder endlich besitzen sie gar keine Bewegungsorgane, sondern sind mit langen Saugröhren oder Tentakeln bewaffnet. Diese Thiere bilden die Klasse der In $\mathrm{u}$ sorien.

Eine zweite Klasse der Urthiere, die Wurzelfüisser, lassen keine scharf contourirte, festere Haut erkennen, und zeigen keinerlei äussere Bewegungsorgane, keine Haare, keine Borsten, sondern rermitteln ilıre Ortsveränderung nur durch das Ausfliessen ihrer Körpermasse nach dieser oder jener Seite hin. Bald strömt das Körperparenchym in dünnen Strahlen aus, bald heben sich breite Lappen wellenartig ab und kriechen, den Rest nachschleppend, so auf dem Boden dahin, daher der Name Wurzelfüsser (Rhizopoda).

Diese zweite Gruppe ist im süssen Wasser in viel geringerer Zahl rertreten, während im Meerwasser die Wurzelfüssser an Mannichfaltigkeit und Artenzahl die eigentlichen Infusorien übertreffen. Immerhin sind letztere durchweg höher organisirt nnd wir beginnen daher, ron unten aufsteigend, mit der Klasse der Wurzelfüsser die specielle Betrachtung niedrigster Thierformen. 


\section{Specieller Theil.}

\section{Klasse. (Wurzelfüsser).}

\section{Rhizopoda.}

Die Wrurzelfüsser oder Rhizopoden stehen an der untersten Grenze des Thierrcichs. Wic schwierig es sein mag, die einzclnen Thierformen in eine ihrer Organisation entsprechende Stellung oder Reihenfolge zu bringen, wie unzulänglich auch unsere gegenwärtigen Systeme die Verwandtschaft der einzelncn Organismen zu cinander ausdrücken; darüber herrscht wohl kcin Zweifel, dass die einfachsten und niedrigsten Geschöpfe der Klasse der Wurzclfüsser angehören.

Ihr Körper besteht aus einer eigenthümlichen, dchnbaren gallertartigen Substanz mit eingestrcuten, festcn Körnchen, welche man Sarcode oder Protoplasma genannt hat. Durch Ausstülpungen derselben entstehen Fortsätze (Pseudopoden), stumpfe Lappen, oder fadenförmige Ausläufer, welche die Bewegung des Thieres vermitteln. In Innern befindet sich eine Körperhöhle, die mit zäher Flüssigkeit und Nahrungsstoffen gefüllt ist. Die Verbindung zwischen dieser Kïorperhöhle und der Oberfläche ist noch ganz unbekannt.

Kein Wurzelfüsser hat einen Mund; flüssige Stoffe scheinen durch das Körperparenchym aufgesogen zu werden, festere werden dadurch aufgenommen, dass der Schleimkörper sich um den Nahrungsstoff herumlegt, gleichsam um ihn herumfliesst und ihn an einer bcliebigen Stelle in sein Gewebe aufnimmt. Dort wird er nach einiger Zeit aufgelöst oder verdaut und das Zurückbleibende auf ähnliche Weise irgendwo ausgestossen. So wird oft ein grösserer Gegenstand aufgenommen als das Thicr selbst ist, sodass dieses nur als schlcimiger Ueberzug des gefressenen Gegenstandes erscheint.

Von übrigen Organen bemerkt man bei den Wurzelfüssern nichts, als eine oder mehrere wasserhelle Blasen im Körpcrparenchym, die sich periodisclı zusammenzielın und dann wieder füllen. 
Ferner beobachtet man ebenfalls in der Körpersubstanz einen festen Kern, der mit der Fortpflanzung dieser Thiere in Verbindung steht. Eigentliche Geschlechtsorgane hat man nie beobachtet, sondern dieWurzelfüsser vermehren sich durch 'Theilung.

Trotz der einfachen Organisation und trotz der schwankenden Körperform lassen sich die Wurzelfüsser doch leicht in scharf getrennte Gruppen theilen. Man hat zwei Ordnungen errichtet, deren erste von einzeln lebenden Thieren gebildet wird (Monosomatia, Einleibige) und deren zweite aus colonieen weise zusammenhängenden Thieren besteht (Polythalamia, Vielkammerige). Letztere gehören aber ausschliesslich dem Meere an, während die Einleibigen sich in grosser Menge im Bodensatz unserer süssen Gewässer finden und daher näher besprochen werden sollen.

Die Wurzelfüsser unseres Süsswassers zerfallen in drei wesentliche Gruppen.

1) In ganz nackte Thiere von sehr weichem Körper, welcher an seiner Oberfläche in beständig wellenförmiger Bewegung ist, Fortsätze nach allen Seiten hin treibt, und sich dadurch kriechend fortbewegt; diese bilden die unterste Familie des Thierreichs, die sogenannten We chselthierchen (Proteïda).

2) Bei einer zweiten Familie, den Sonnenthier chen (Actinophryida) besteht der Körper aus einer festern, körnigen Substanz und ist strahlenförmig mit einer Menge äusserst feiner, langer Ausläufer umgeben, die unbeweglich nach allen Richtungen hinstarren.

3) Die dritte Gruppe der Wurzelfüsser endlich zeichnet sich aus durch das Vorhandensein einer festen, lederartigen oder hornigen Schale, die das schleimige Thier theilweise umhüllt, und ron ihn ausgeschieden wird, ähnlich wie das Schneckenhaus von der Schnecke. Diese Thiere wurden daher anfänglich unter die Schnecken gezählt, bis genauere Untersuchungen die einfache Organisation ihres Körpers und den Mangel innerer Organe mit Bestimntheit darlegten. Sie bilden die Familie der K apselthiere (Arcellida), die je nach der Form ihrer Schale und der Art ihrer Ausläufer in eine Reihe von Gattungen zerfallen. 


\section{Fam. Proteïda.}

1. Gen. Amiba (von $\alpha_{\mu} \varepsilon i(\beta)$ ), Wechselthierchen. Spec. dif- I. 16. $f l$ uens. Das gemeine Wechselthierchen wurde früher seiner stets sich ändernden Form wegen Proteus genannt. Denke dir ein winziges Klümpchen durchsichtigen Schleimes, in dessen Mitte zahlreiche feine Körner angehäuft sind, so hast du einen ungefähren Begriff von der Form des ruhenden Thieres. Nun beginnt an irgend einer Stelle des äusserst zarten, wasserhellen Randsaumes eine wellenartige Berwegung; der Saum buchtet sich aus, das Thier scheint zerfiiessen zu wollen; die helle Umklcidung des centralen Körnerhäufchens wird an eincr Stelle breiter, und dchnt sich in einen länglichen Fortsatr, aus. Dann fliessen die Körnchen langsam in die Ausstiilpung hinein bis nahe an den Randsaum, berühren aber denselben nie ganz. Dieser helle Rand stellt das eigentliche Körperparenchym vor, während die gekörntc Masse im Innern sich in einem Hohlraum mit dünnerem Medinm zu befinden scheint. Dic begonnene Bewegung schreitet wellenförmig um den ganzen Körperumfang fort; zwei, drei und mehr Lappen fliessen aus, heften sich am Glase des Objectträgers fest und zichen das übrige Thier langsam nach sich. Mit Ausnahme der Wimperbewegung einiger grosscr Rïderthiere gibt es kaum eine eleganterc Bcwegung unter dem Mikroskop, als dieses bestïndig fliessende Hcrumkriechen des Proteus. Oft scheint sich das ganzc Thier um seine Axe zu rollen: cs zeigt sich abcr bei genauerer Beobachtung doch, dass es immer auf derselben Flächc kriecht, also eine Bauch - und Rückenseite unterscheiden lässt. Man kann sich von der Art seines Vorrückens einen annähernden Begriff machen, wenn man zwischen zwei Glasscherben cinen Wassertropfen behutsam zusammenpresst. Auch hier buchten sich die Wassertheilchen vielfältig aus, dehnen sich odcr ziehen sich zurück, je nachdem der Druck zu- odcr abnimmt. Gewöhnlich findct man im Innern des Proteus mehrere contractile Blasen die sich hie und da zusammenziehn oder erweitern.

Unser Proteus stösst jetzt auf einen fremden Körper, z. B. auf eine Navicula, jene kalınförmigen, einzelligen Pflänzchen, die alle Wassergräben und Sümpfe beleben. Langsam unflicsst er das kleine 
Schiffchen und drückt dasselbe nach und nach in seine weiche Körpermasse hinein. Die Pflanze bleibt längere Zeit in seinem Innern und wird auf allen Reisen des Thierchens mitgeschleppt, bis sie an irgend einer beliebigen Körperstelle wieder verändert ausgestossen wird. Der Proteus hat sie gefressen, verdaut und wieder ausgeschieden.

Es sind meistens mikroskopische einzellige Pfänzchen, welche unserm 'Thierchen zur Nahrung dienen; man kann dasselbe aber auch mit Farbstoffen z. B. mit fein zertheiltem Carmin oder Indigo eigentlich füttern, und findet es dann oft damit rollgestopft.

Der Proteus erreicht eine Grösse von $1 / 200$ bis $1 / 50$ " und findet sich ziemlich häufig im Bodensatze von Sümpfen oder langsam fliessenden Bächen und Gräben; ofst trifft man ihn massenhaft in Blumenvasen, deren Wasser lange nicht erneuert wurde etc. Bei mechanischer Erschütterung zicht das Thier seine Ausläufer ein, und nimmt eine unregelmässig rundliche Form ein. Dasselbe geschieht auf chemischen oder elektrischen Reiz, z. B. durch Zusatz ron Säuren oder Salzen, oder bei Leitung eines galranischen Stromes durch das Wasser. Ist der Reiz zu stark, so wird der Rand des Thieres schärfer markirt, deutlich doppelt contourirt und die ganze Körpermasse trübt sich, vielleicht in Folge einer oberflächlichen Gerinnung der Sarcode. Endlich platzt das Klümpchen, die Kürner trcten in's Wasser und der Leib zerfliesst spurlos. Dasselbe findet statt, wenn das Wasser allmählich auf dem Objectträger eintrocknet. Wenn sich die Sarcode einmal getrübt hat, der Rand scharf contourirt ist, so ist das Thier todt und kommt nicht mehr zum Leben, wenn auch der Reiz aufhört.

Man hat mchrere Arten ron Amiba unterschicden, je nach der Form und Anzahl ihrer Ausläufer; indess zeigen alle dieselben Lebenserscheinungen, und ist dic Begrenzung der einzelnen Species noch sehr schwankend; wir erwähnen daher nur die Amiba diffuens (Fig. 16 I.) mit stumpfen, kurzen Lappen und Ausläufern und die Amiba radiosa (Fig. 17 I.) mit zahlreichen feinen langen Fortsïtzen, in welche keine Körner eindringen.

Anhang. Neuere Forschungen haben den Proteus, diess einfachste Urthier zu hoher Wichtigkeit gebracht. Man kennt n̈̈mlich seit längerer Zeit pflanzliche Gebilde, welche ganz diesel- 
ben Bewegungserscheinungen darbieten, wie das Wechselthierchen: Pilzbildungen aus der Familie der Monomyceten (Didymium serpula, Aethalium septicum) bestehen grossentheils aus schleimigen Zellen, die in beständiger Bewegung sind, Ausläufer nach allen Seiten hinaussenden und wieder einziehn, sich mit den Fortsätzen netzförmig verbinden und ähnliche Reactionserscheinungen zeigen, wie die Amiben, wenn sie chemischen oder elektrischen Reizungen ausgesetzt werden. Im Innern der Staubfadenhaare der Tradescantia virginica, einer lilienartigen Blume, findet man ähnliche Gebilde, die mit ihren langen Ausläufern an den Zellenwandungen des Haares herumkriechen, wie eine Amiba radios auf den Objectträger. Es ist sehr wahrscheinlich, dass in nächster Zeit solche Formen als viel verbreitet in der Pflanzenwelt entdeckt werden. Aber von noch grösserer Wichtigkeit und Bedeutung für die Physiologie des thierischen Körpers ist das Auffinden solch Amiba-ähnlicher Zellen (Amoeboidzellen) in höhern Thieren. In dem Zellengefüge der Hornhaut hat man bei Fröschen, Fischen und sogar bei Sïugethieren freie bewegliche Zellen gefunden, welche sich wie unser Proteus geberden, sich dehnen, zusammenziehn, zwischen andern festgeformten Zellen eigentlich herumkriechen, und, was das Merkwïrdigste ist, mit Nervenelementen in einer gewissen Verbindung zu stehn scheinen. Dieselben beweglichen Zellen hat man auch im Bindegewe be vielfach verbreitet gefunden, ja sogar eine schon längst bekannte Zellenform, die farblosen Blutkörperchen, sollen bei einer gewissen Temperatur wie, Amiben zwischen den ruhig liegenden rothen Blutzellen herumkriechen. Zweifelsohne werden diese Entdeckungen modificirt und vermehrt werden müssen, um zu einer genügenden Verwerthung für die Physiologie zu kommen; immerhin aber bezeichnen sie einen Wendepunct in der Lehre der gesammten organischen Schöpfung; und so hat unser unscheinbares Thierchen durch Verkettung mit ähnlichen Wesen eine Bedeutung erlangt, die weit über das gewöhnliche Interesse hinausgeht, welches blosse Neugier an der wechselnden Form desselben nehmen kann.

I)er Vollständigkeit wegen erwähnen wir noch in Kürze zwei rerwandte Gattungen :

2. Gen. Podostoma. Spec. filigerum. Das Thierchen 1. 18. erscheint oft als einfache Amiba, bildet einen Kilumpen, treibt 
flache Fortsätze, die sich rasch verlängern, sodass es der Amiba radiosa gleicht, nur sind seine Bewegungen viel lebhafter. Dann sieht man plötzlich an einem der Ausläufer ein langes, peitschendes Haar ausgehen, ganz ähnlich wie die Peitschenhaare der Flagellaten. Dies Organ dient nicht zur Fortbewegung sondern zum Ergreifen der Nahrung. Fremde Körper in der Nähe des Haares drehen sich rasch um dasselbe herum. Dann wird es kräftig in Spiralform zurückgezogen und der damit gefischte Körper verschwindet in einer löffelartigen Aushöhlung des Lappens, aus dem das Peitschenhaar hervorgekommen war.

1. 19. 3. Gen. Petalopus. Spec. diffluens. Der Petalopus ist eine cylindrische Amibe, die nur an einem Ende feine fadenförmige Ausläufer entsendet, aber diese Auslïufer können sich an ihrer Spitze kolbig aufblähen, oder in flache Lappen ausfliessen.

\section{Fam. Actinophryida.}

I. 20. 4. Gen. Actinophrys. Spec. Sol. Das Sonnenthierchen, der einzige Repräsentant dieser Familie, den wir näher betrachten wollen, ist das gerade Gegentheil der stets wechselnden Amiba. Leicht würde man dasselbe beim ersten Anblick unter dem Mikroskop für todt, oder für ein pflanzliches Gebilde halten, so steif und unbeweglich liegt er vor uns. Ein kugelförmiger Körper von etwa $1 / 50$ " Grösse ist ringsum mit äusserst feinen langen Strahlen bekleidet, welche ihm seinen Namen rerschafft haben, da sie wie ein Heiligenschein das Thier umgeben. Lange kann man dasselbe fixiren und man bemerkt keine Aenderung, keine Bewegung; hie und da verschwinden einzelne Strahlen, andere scheinen auszutreten, aber das geht so unmerklich, dass man sich getäuscht glaubt. Und doch ist diess unberwegliche Geschöpf ein arges Raubthicr: Ein kleines, schnellschwimmendes Infusorium fährt unvorsichtigerweise in den Strahlenkranz, welcher das Sonnenthier umstarrt und bleibt darin hängen, wie eine Fliege in Spinngewebe. Der Gefangene zuckt noch zwei bis drei Secunden, und dann ist er todt. Es ist. wie wenn durch diese Strahlen ein 
rasch betäubendes Gift auf das Infusorium einwirken würde. Die Fortsätze legen sich nun fester an die Beute an, der Körper buchtet sich etwas gegen das getödtete Thier aus, dann ziehen sich die dasselbe umschliessenden Strahlen langsam mit sammt der Beute ein, und nur der Mangel an Strahlen lässt die Stelle erkennen, wo der fremde Körper eingeführt wurde. Bald ist der dcfecte Fadenkranz wieder ergïnzt. und so frisst das Thier in kurzer Zeit mehr, als sein eigenes Volumen beträgt, wodurch es etwas unregelmässig aufgetrieben wird.

Bei genügender Nalırung sieht man dasselbe bald eine biscuitahnnliche Gestalt annehmen. Die Mitte schnürt sich immer mehr ein, wodurch eine Theilung eingeleitet und rasch rollzogen wird. Nach wenigen Stunden sind zwei Stücke nur noch durch einen glashellen Streifen verbunden, der nach und nach nicht mehr ron einem gewöhnlichen Strahle zu unterscheiden ist; endlich reisst auch dieser durch, und die beiden Individuen entfernen sich unmerklich von einander.

Ein der Theilung entgegengesetzter Process, die Copulation, wird bci diesem Thier häufig bcobachtet, wobei zwei, drei und noch mehr Sonnenthierchen zu einem Individuum zusammenschmelzen. Die Bedeutung dicser Verschmelzung ist bisher noch unbekannt.

Man hat je nach der Körperform mehrere Artcn unterschieden, die wir hicr übergehen, und wir erwähnen nur noch kurz zwei verwandte Gattungen.

5. Gen. Trichodiscus, bei welchem die Strahlen in einem einfachen Krcise des Körperumfangs abgehen, und

6. Gen. Plagiophrys, wo die Strahlen nur ron einer beschränkten Stelle auslaufen.

\section{Fam. Arcellida.}

Die Kapselthierchen sind leicht kenntlich durch eine feste lederartige oder hornige Schale von regelmässigem Bau. Sie finden sich häufig im Bodensatz aller sumpfigen Gowässer und kriechen wie Schnecken an Wasserpflanzen herum. Ihre Nahrung besteht, wie die der Amiben, aus einzelligen Algen und zersctzten Pflanzentheilen. Die zierliche Gestalt und grosse Regelmässigkeit 
der Schalen scheint für eine complicirte Structur, die uns bis jetzt räthselhaft geblicben ist, zu sprechen.

Bei der Vertheilung in Gattungen nehmen wir zuerst Rücksicht auf die Form ihrer Ausliufer und hernach auf die Gestaltung ihrer Schalen.

\section{Erste Gruppe.}

Die Ausläufer (Pseudopoden) sind flache Lappen oder Bänder, wie bei den Amiben. Die Bewegungen der Thiere sind in Verhältniss zur zweiten Gruppe lebhaft zu nennen.

I. 21. 7. Gen. Arcella. Spec. vulgaris. Im Schlamme von Sümpfen und an Wasserpflanzen, wie Potamogeton, Chara, Ceratophyllum etc. findet man häufig eine braune halbkugelige Schale, die scheibenartig zu sein scheint. Nach einiger Zeit hat sich die Schale vielleicht etwas gedreht und zeigt die topfähnliche Seitenansicht. Sie ist glatt und äusserst fein facettirt. Da alle Kapselthierchen wahre Faulthiere sind, sich nur äusserst langsam bewegen, so braucht es etwas Geduld, die Lebenserscheinungen derselben zu beobachten. Die hornige Schale ist ziemlich hart und wird durch einen Druck auf das Deckblatt leicht zersprengt. In der Mitte ist eine grosse rundliche Oeffnung, aus welcher der körnige Leib des 'Thieres beim Kriechen etwas hervortritt und flache oder bandartige hyaline Ausläufer treibt. Im Unkreis der Oeffnung bemerkt man eine Anzahl contractiler Blasen.

Fine andere Art A. patens hat eine uhrglasförmige Schale, deren Oeffnung den ganzen Rand umfasst.

Bei einer dritten Species A. a culeata hat der Umkreis der Schale höckrige Erhebungen, die durchbrochen scheinen, da das Thier daraus sehr feine Ausläufcr entsenden kamn; man hat daher aus diescr Art die Gattung Echinopyxis gebildet.

1. 22. 8. Gen. Difflugia. Die Thiere dieser Gattung unterscheiden sich von dem socben beschriebenen Kapsclthierchen bloss dadurch, dass ihre mehr flaschen - oder birnförmige Schale nie glatt, sondern stets mit frcmden Körpern (feinen Sandtheilchen) bedeckt ist. An dem vordern Ende der ovalen Hülle strömen die glashellen bandartigen Ausläufer nach allen Seiten hinaus. (Zahlreiche Arten.) 


\section{Zweite Gruppe.}

Die Pseudopoden bilden feine, selten verzweigte Strahlen, nie aber Lappen oder Bänder. Die Bewegung der Thiere ist eine äusserst langsame.

9. Gen. Euglypha. Häufig findet man im stehenden und fliessenden Gewässer eiförmige, meist aschgraue Schalen, die aus mosaikartigen Stückchen sehr regelmässig zusammengesetzt scheinen. Von oben betrachtet erscheinen sie natïrlich als rundliche Scheiben; sie sind ziemlich durchsichtig und weniger spröd, als die Kapseln ron Arcellu. Darin sitzt das schleimige Thier, das an seiner vordern Seite die feinen Ausläufer entsendet, in welche keine Körnchen von der Körpersubstanz eintreten. Spec. tu bercul os a.

Für die Euglyphen, die ihre Ausläufer aus einer seitlichen Oeffnung treiben, hat man das Gen. Trinema errichtet.

\section{Dritte Gruppe.}

Die Ausläufer dieser Thiere bilden äusserst feine Körperausstrahlungen, die rielfach mit einander verschmelzen und Anastomosen bilden.

10. Gen. Gromia. Spec. flu viatilis. Die rundliche, bräun- I. 25. liche Schale dieses Thieres findet sich häufig auf Wasserpflanzen in schwach fliessenden Gewässern. Die äusserst zarten Pseudopoden strömen wie fliessendes Wachs langsam aus der Körpermasse hervor, und unendlich feine Körnchen rinnen in die langen Strahlen, die sich oft verzweigen und netzförmig mit einander verbinden. Hat sich ein solcher Ausläufer festgesetzt, so zieht er schwerfällig, wie an einem Tau, das ganze Thier nach.

Neuere Forscher haben mit Recht die Genera Arcella und Difflugic mit den Amiben vereint, Euglypha hingegen in eine eigene Gruppe zum Sonnenthierchen gebracht, und aus dem Gen. Gromia eine selbstständige Familie gebildet. Gründe rein praktischer Natur verhindern uns, diesem Beispiel zu folgen. 


\section{Klasse.}

\section{Infusorien.}

Dic Infusorien sind Urthicre mit einer deutlichen, scharf contourirten, festcrn Oberhaut (Cuticula od. Epidermis), welche die weiche Körpermasse umflicsst. Darin ist der wcscntlichstc Unterschied derselben von der vorigen Klasse zu suchen. Die Rcsistenz. dieser Haut und ihre Dehnbarkeit ist zwar sehr verschiedenartig, aber nirgends finden wir solche, welche z. B. an jeder beliebigen Körperstelle feste Nahrung aufnehmen können, oder vcrdautc Reste ausstossen; es sind, wo überhaupt Mund und After sichtbar werden, stets ganz bcstimmte, oft mit eigenen Wimpern versehene Oeffnungen, die in das Innere des Körpers führen. Ein ferncrer wesentlicher Unterschied diescr beiden Klassen bildet dic Art ihrer Bewegung. Nirgends findet man bei den Infusorien das Ausfliessen der Körpersubstanz zu Lappenbildung oder Fortsätzen, die als Bewegungsorgane dienten; sie besitzen vielmehr dcutliche Anhängsel der Haut, welche die Bewegung vermitteln. Keinem Infusorium fehlen solche gänzlich, wenn sie auch mit geringen Vergrösserungen nicht immer leicht zu sehen sind.

Dicse Bewegungsorgane geben uns den sichersten Anhaltspunct für die Systematik, da sie am leichtesten beobachtet werden, und für jetzt wenigstens viel natürlichere Gruppen unterschciden lassen, als problematische Untersuchungen über Mund und Aftcr, oder über einen complicirten innern Organismus, dessen Existenz noch sehr zweifclhaft ist.

Es war früher cine nahclicgende Anschauung, diese einfachsten thierischen Geschöpfe mit den Elementartheilen höherer Organismen zu vergleichen, sie also bloss für belebtc Zcllen zu halten, und diese Anschauungsweise wirkt gegenwärtig anch vielfach mit.

Genaucre Untcrsuchung zeigt uns aber in den Infusorien doch mehr, als cin mit homogenem Schleim gefülltes Bläschen. Auch hier können wir, wie bei den Wurzelfüssern, meist ein etwas derberes äusseres, und ein inneres flüssigeres Körperparenchym 
erkennen, deren Uebergang ineinander indess ein ganz allmühlicher ist.

In der äusscrn Körpersubstanz eingebettet liegt das co n tractile Orga n, welches sich in bestimnten Zwisehenräumen kräftig zusammenzieht und alsdann dem Auge verschwindet, um sich nach und nach wieder mit Flüssigkeit zu füllen. Die einfachste Form dieses eigenthümlichen Organes besteht in einer oder mehreren wasserhcllen Blasen. Wo nur eine einzige vorhanden ist, liegt sie gewöhnlich in der Nähe ron Mund oder After. Sind mehrere solcher Blasen da, so bilden sie oft eine regelmässige Reihe, oft aber sind sie unregelmässig durch den ganzen Körper zerstreut, aber stets im Rindenparenchym gelegen. Wahrscheinlich besitzen sie keine besondere Membran : oft rereinigen sich mehrere nümlich in einen schlauchförmigen Canal. Bei andern Infusorien hat das System überhaupt nur die Form eines Schlauches, ohne rundliche Blasen zu bilden; wieder bei andern verläuft ein Canal durch die ganze Lïnge des Thicres und mündet in seinem vordern oder hintern Ende in eine grössere Blase, oder es ist eine solche in scinem Verlaufc eingesehaltet. Oft sieht man kleine Wassertröpfchen sich im Innern des Thierkörpcrs ausscheiden, mit einander zu grössern Tropfen rersehmelzen und auf cinem bestimmten Wege gegen die contraetile Blase hinstreben, wodureh diese allmählich gefüllt wird. Kommt die Bildung solcher Wassertröpfchen erst in der Nühe der Jlase zu Stande, so erhält das System einc rosettenartige Form. Oft aber führen vou allen Seiten wirkliche feine Canïlehen in den centralen Sanmler und dann entsteht eine sternförmige Zeichnung, deren Ausläufer bei der Contraction der Blase aufgctrieben werden, während sie sieh bei Füllung derselben zusammenziehn.

Ueber die eigentliche Bedeutung dieses contractilen Systems, das nur wenigen Infusorien fehlt, ist man noch nicht ganz im Kilaren: Während Fhrixberg dasselbe ganz ohne Grund als Fortpflanzungsorgan erklärte, halten cs neuere Forscher (Lachuaxx und Claparìde) für ein rudimentäres Circulationssystem, das die Mischung der Sïfte zum Zwecke hättc. Die bedeutendste Autorititt in diesem Gebiete, Sterr, erklïrt dasselbe für ein Wassergefüsssystem, dessen Zweck sei, das mit der Nahrung in den Körper 
aufgenommene Wasser wieder auszuscheiden. Hiefür scheint wirklich die meist peripherische Lage des Organs zu sprechen, und bei einigen Infusorien ist auch in der That eine directe Verbindung desselben mit dem Mund oder After, oder mit der Körperoberfläche entdeckt worden. Auffallend und nur von diesem Gesichtspuncte erklärlich ist der Umstand, dass die marinen Infusorien viel langsamere Contractionen zeigen, als die des süssen Wassers.

Ebenfalls im äussern Körperparenchym liegt der sogenannte Kern (Nucleus), der oft mehrfach ist und sich bei der Vermehrung wesentlich betheiligt. Er besteht aus einer körnigen Substanz, die etwas fester und resistenter ist, als die ïbrige Körpermasse und beim Tode des Thieres nicht so rasch zerfliesst; durch Zusatz von ganz verdünnter Essigsäure tritt er deutlicher hervor und wird schärfer contourirt. Seine Form ist je nach den einzelnen Gattungen verschieden, im Ganzen meist rundlich, oval oder bandartig ausgezogen und gekrümmt, nur selten vielfach verästelt. Meist sind am Kern ein oder zwei Kernkörper chen ( $N^{\prime}$ ucleolus) bemerkbar, die in seinem Innern, oder aber auch an seiner Aussenfläche als kleine bläschenartige Gebilde erscheinen. Ein so allgemein verbreitetes Organ muss auch eine wesentliche Function erfüllen. Heute sieht man den Nucleus durchweg für das Fortpflanzungsorgan der Infusorien an, und wir kommen auf seine Bedeutung sofort zu sprechen.

1. 15. Die gewöhnlichste Art der Vermehrung erfolgt nämlich auf dem Wege der Theilung und zwar theilen sich die Infusorien entweder in die Quere, oder der Länge nach, oder nach einer schiefen Linie. Zuerst erweitert sich das 'Thier in der Richtung, welche senkrecht zur Theilungslinie steht, d. h. bei der Längstheilung wächst es in die Breite, bei der Quertheilung in die Länge. Alsdann schnürt sich sein Tiörper von beiden Seiten, oder von vorn nach hinten ein, und auch am Kerne tritt eine entsprechende Einbuchtung zu Tage. Dieser Process dauert fort bis zwei annähernd gleiche Hälften entstanden sind, welche zwei gleichen Thieren den Ursprung geben.

Eine andere Art der Vermehrung geschieht auf dem Wege der Knospung. Das Thier treibt hiebei einen seitlichen Wulst hervor, der durch sein Wachsthum nach und nach die Form der Mutter annimmt. Entweder bleibt dieses neue Individuum bestän- 
dig uit dem alten Thier verbunden, wodurch Colonicen entstehen, oder es trennt sich als selbständiges Geschöpf los.

Die Sprösslinge, welche aus dem Knospungsprocess hervorgehen, sind indess viel kleiner, als die durch Theilung entstandenen, und wachsen erst allmählich zur Grösse des Mutterthieres aus. Ein fernerer wesentlieher Unterschied der Knospen- und der Theilungssprösslinge besteht darin, dass sich der Nucleus des Mutterthieres bei der Knospentheilung gar nicht betheiligt, sondern jede Knospe einen eignen Kern entwiekelt.

Eine letzte Art von Vermelirung endlicl geschieht durch Bildung von Embryonen, die dem Mutterthier unähnlich sind, und deren weitere Entwicklung bisher noch nicht hat beobachtet werden können. Man hat mit dieser Embryonenbildung Vorgänge in Verbindung gebracht, die vielfach an die geschlechtliche Fortpflanzung höherer Thiere erinnern. Vorerst erwähnen wir hier die Conjugation (Zygose), die in einem Verschmelzungsprocess von zwei oder mehreren Mutterthieren derselben Art besteht, bisher aber 11 u. bei wenig Infusorien beobaehtet worden ist. Aber auch ohne vorhergehenden Versehmelzungsprocess hat man bei einigen Infusorien eine Art geschlechtlicher Function entdeckt. Man fand nïmlich, dass das oben beschriebene Kernkörperchen, sich in winzige, lebhaft schwingende Theilchen auflöse, welche, ähnlich den Spermatozoen höherer Thiere, in die Substanz des Kernes eindringe. Alsdann entwickeln sich aus dem Nucleus jene eigenthümlichen, dcm Mutterthier unïhnlichen Embryonen, die nach einiger Zeit durch eine Oeffnung in's Freie gelangen und sich selbständig herumtreiben. Den speciellen Vorgang wollen wir im Anhang näher betrachten.

Von der grössten Wichtigkeit für uns sind die äussern Hautorgane, auf deren Gestaltung die jetzige Eintheilung der Infusorien beruht, und die wir daher in ihren Hauptformen näher erörtern wollen.

Bewegungsorgane. Eine Reihe von Infusorien, sowie auch einige rein pflanzliche Gebilde vcrmitteln ihre Bewcgung 
durch ein oder mehrere haarförmige Anhängsel '(Flagellum) von äusserster Feinheit, deren Länge die des Thieres gewöhnlich bedeutend übertrifft. Durch die wellenförmigen Peitschenschläge dieses Organes wird das Thierchen fortgetrieben. Diese Peitschellhaare haben aber nicht immer dieselbe Function: Es gibt solche, die sich in ihrer ganzen Länge biegen und winden, andere sind an der Basis steifer, kräftiger und haben nur in ihrem äussern Ende die volle Beweglichkeit; endlich kommen stärkere, steife Haare vor, die vom Thiere oft träg nachgeschleppt werden; oft aber heften diese sich mit ihrer Spitze fest an fremden Gegenständen an, und schnellen, das 'Thier nachziehend lebhaft zusammen.

Die grosse Mehrzahl von Infusorien bewegt sich vermittelst feiner, kurzer Wimperhä̈̈rchen (Ciliae), die in stetem Flimmern begriffen sind und nie die Länge des Thieres erreichen. Bei vielen ist damit der ganze Körper gleichmässig bedeckt, bei andern stehen diese Wimperhaare in bestimmten Reihen, oder bekleiden nur einzelne Stellen, z. B. die Mundöffnung oder die Bauchseite, und alsdann sind sie gewöhnlich fester und krältiger.

Einige Infusorien besitzen viel stïrkere Wimpern, eigentliche Stacheln, Borsten, Haken, die ihnen eine laufende Bewegung ermöglichen. Sie sind weiter nichts als ein Bündel zusammengewachsener, feinerer Haare und spalten sich an ihren Enden oft in ihre Elementartheile:

Ein ferneres eigenthümliches Bewegungsmittel besitzen einige Infusorien in der Form äusserst feiner, langer und steifer Seidenhare; damit machen sie sehr rasche, schnellende Bewegungen, und diese Geschöpfe sind ihrer grossen Sprünge wegen sehr schwierig zu studiren. Endlich gibt es eine Klasse von Infusorien, die keine eigentlichen Bewegungsorgane haben, wohl aber an verschiedenen Stellen ihres Körperumfanges feine, geknöpfte Tentakeln oder Saugröhrchen tragen. Mit diesen Organen heften sie sich an andern Infusorien fest, und saugen den Inhalt derselben aus.

? Endlich müssen wir hier noch kurz gewisser stäbcheı̈̈hnlicher Gebilde erwähnen (Trichocysten), die im Parenchym einiger Infusorien zerstreut liegen. Diese werden von einigen Forschern als Nesselorgane bezeichnet, in denen ein spiraligaufgerollter und aus- 
schnellbarer Faden liege. Andere halten diese festen Stäbchen für eine Art Tastorgan: sie nehmen an, dass ein, auf das solide Gebilde wirkender Druck dadurch der schleimigen Masse des Infusorienleibes deutlicher mitgetheilt werde.

Die Lebensweise dieser winzigen Geschöpfe, von denen wenige die Grösse einer zehntel Linie erreichen, einzelne aber unter $1 / 1000$ "' herabgehen, ist sehr verschieden. Einige scheinen ihre Nahrung nur in flüssiger Form durch die Haut aufzunehmen; nie findet man in ihrem Innern feste fremde Bestandtheile, nirgends bemerkt man eine deutliche Mundöffnung. Die grosse Mehrzahl aber hat einen deutlichen $\mathbf{M}$ und, der oft mit eigens gestellten Wimperhaaren bekleidet ist, oft auch mit einer schlauchförmigen $\mathrm{Schlingröhre} \mathrm{(Oesophagus),} \mathrm{welche} \mathrm{in} \mathrm{die} \mathrm{Körperhöhlung} \mathrm{führt,}$ in Verbindung steht. Oft existirt bald in der Nähe des Mundes, bald ihm gegenüber eine Stelle für den Auswurf der verdauten Nahrungsstoffe; ein eigentlicher After. Häufig aber sind diese Theile von einer Kleinheit, dass sie nur mit den stärksten Gläserin beobachtet werden können.

Wem dies nicht rergönnt ist, der wird auf die Gegenwart eines Mundes oder Afters schliessen, wenn er fremde Körper, z. B. pflanzliche Abfülle, einzellige Algen, oder fein zertheilte Farbstoffe, wie Indigo und Carmin, mit denen man viele Infusorien eigentlich füttern kann, im Innern der Thiere bemerkt; oder wenn er sieht, wie ein solches Infusionsthierchen sich plötzlich eines 'Theiles seines Inhaltes entledigt.

Bisher ist es noch nie gelungen, einen zusammenhängenden Darmcanal durch das ganze Thier zu entdecken. Die Speisetheilchen werden erst in körnigen Massen durch den Mund eingeführt, wo nicht ein gröberer Körper verschlungen worden ist; bald aber ballen șich die Körnchen durch die Thätigkeit des Oesophagus in dessen hintern Theil zu kleinen Kugeln zusammen, die auf unbekannten Wegen in die innere Leibeshöhle weiter befördert werden, um nach einiger Zeit veründert und verdaut durch den After auszutreten. In dem dünnerflüssigen Innenparenchym befinden sich dann diese Speiseballen in einer regelmässig rotirenden Bewegung, über deren Erzeugung man noch im Unklaren ist.

Viele Infusorien sind Raubthiere, die kleinere verschlingen, 
die meisten leben ron zersetzten Pflanzentheilen, die sie entweder direct aufnehmen, oder die ihnen vermittelst eines Wimperapparates zugeführt werden, indem sie in ihrer Ungebung damit einen kreisförmigen Strudel erzeugen.

Alle Infusorien sind an das Wasser gebunden, die meisten schwimmen frei darin herum. Natürlich wird durch das Mikroskop nicht nur ihr Körper, sondern aueh die Schnelligkeit ihrer Bewegungen vergrössert, was eine genaue Betrachtung der dnrch einander wimmelnden Gesehöpfe vielfach erschwert. Einige wenige leben als Schmarotzer im Innern höherer Thiere, und sterben, in's Wasser gebracht, sehnell ab. Einige leben gesellschaftlich, Colonieen bildend, sitzen die grösste Zeit ihres Lebens auf andern Körpern festgeheftet und verlassen diesen Standpunct nur in einem kurzen Stadium der Entwicklung. Wir sehen daher in dieser Klasse fast alle Lebensformen der übrigen Thierwelt rertreten.

Wenn das Wasser, in welchem Infusoricn sich befinden, zu rerdunsten anfängt, oder sich zersetzt, oder wenn aus irgend einem Grunde die Lebensbedingungen den 'Thierchen nieht mehr günstig sind, so schwellen sie gewöhnlieh etwas an, und es bilden sich in ihrem Innern grosse wasserhelle Blasen (Tacuolen). Theilweise wird der Körperinhalt an irgend einer Stelle als zäher Schleim ausgestossen, die Bewregungen hören auf, und das Thier zerfliesst allmählich spurlos. Bei einigen Arten mit derberer Hülle widersteht diese der Zersetzung noch längere Zeit, bei den meisten aber zerfliesst die Hülle sammt dem Inhalt. Nicht immer aber sterben die Infusorien auf solehe Weise aus, sondern in den meisten Fällen langsamer Verdunstung des Wassers kapseln sie sich ein. Zu diesem Behufe dreht sich das Thier gewöhnlich auf derselben Stelle längere Zeit um seine Axe, seine Formen werden naeh und nach abgerundet, und man sieht immer deutlieher eine rundliehe oder ovale, anfangs schleimige. bald aber erstarrende Hülle um den unkenntlichen Thierklumpen entstehen. In dieser Form widerstehen sie der gänzlichen Austroeknung, oder allzugrosser Kälte beim Gefrieren des Wassers, und werden ron jedem Luftzuge als feinste Stäubchen überallhin verweht, um, ihre Kapsel sprengend, wieder ein neues Leben zu führen, wenn sie der Zufall an Orte bringt, dic ihrer Existenz günstig sind. Auf dem Process der Einkapse- 
lung beruht die allgemeine Verbreitung der Infusorien und ihr Auftreten in Infusionen. Die Millionen Sonnenstäubchen, welche alle Luft erfüllen, bestehen theilweise aus solchen winzigen Cysten, die überall hin verweht werden, und so in die Infusionsflüssigkeit gelangen. Gerade dic Arten mit grosser Incystirungsfähigkeit erscheinen am häufigsten in Infusionen, während andre Arten, bei denen der. Einkapselungsproccss noch nicht beobachtet wurde, oder deren Cysten rerhältnissmässig gross sind, nie in künstliclien Infusionen auftreten. Uebrigens hat man ron einzelnen Formen ihre Verbreitung im Cystenzustand direct nachweisen können: Ein sehr vcrbreitetes Infusorium z. B., das Heuthierchen (Colpoda), entsteht massenhaft in Infusionen ron Heu. Stammt das Heu aus einem nassen Jahrgang, so bilden sich in dcr Infusion desselben viel zahlreichere Colpoden, als durch Uebergiessung von trocken gewachsenem Heu. Die starken Landregen, welche die Wiese theilweisc unter Wasser setzten, gaben deu am Grasstengel hängcndon Cysten dic Gelegenheit, ihrc Hülle zu sprengen; in kurzer Zeit vervielfälfültigten sich durch Theilung die ausgebrochenen Colpoden in's Unendliche, und beim Verdunsten des Wassers haben wir wieder ebenso viele Cysten, die auf eine neue Gelegenheit zum Auskriechen harren. Man braucht daher zur Erklärung der allgemeinen Verbreitung von Infusorien gar nicht zu der sonderbaren Hypothese der Urzeugung Zuflucht zu nehmen, sondern nur die Verhältnisse, wie sie uns klar vor Augen liegen, einer genügenden Würdigung zu unterziehn.

Gehen wir nun zur Systematik der Infusorien über, so treten uns, je nach den Bcwegungsorganen rorerst drei grosse Hauptgruppen deutlich entgegen, welche die drei Ordnungen dieser Klasse bilden. Die crste Ordnung und zugleich die niedrigste ist diejenige der Flagellaten oder Geisselthierchen. Alle die hierher gehörenden Infusorien bewegen sich vermittelst eines oder mehrerer peitschenartiger Haare (Flagella), welche die Länge des 
Körpers gewöhnlich bedeutend übertreffen. Eine zweite Ordnung bilden die Ciliaten (Wimperthierchen), deren Körper ganz oder theilweise mit feinern oder gröbern Wimpern (Ciliae) bedeckt ist, die ihnen zur Fortbewegung dienen. Die dritte Ordnung endlich bilden die Suctorien (Sa uginfusorien), die auf dem sonst nackten Körper feine, mit einem Knopf endigende Sangröhren besitzen, womit sie andre Thiere aussangen.

\section{Ordnung.}

\section{Flagellata.}

Als Bewegungsorgane dienen ein oder mehrere fadenförmige Anhängsel (Peitschenhaare), die lünger als der grösste Durchmesser des Leibes sind.

Diese Gruppe zerfällt vorerst in zwei Unterordnungen, von denen die erste ganz der gegebenen Definition entspricht, indem sie nackte Thiere mit einem oder mehreren Peitschenhaaren umfasst, und die Unterordnung der eigentlichen Flagellaten bildet. Bei der zweiten Unterordnung, den Cilio-Flagellaten, ist der Körper meist mit einem festen Panzer bedeckt und zeichnet sich aus durch eine Reihe feinerer Cilien, die neben dem Peitschenhaar zur Fortbewegung dienen.

Wir wollen die eigentlichen Flagellaten in zwei Familien tren$\mathrm{n} € n$, von denen die erste 'Thiere mit verhältnissmässig steifem, wenig dehnbarem Körper bilden: Mon a den (_Monadida); die zweite Familie hingegen, die der A end e r linge (Astasida), zeichnet sich durch die grosse Dehnbarkeit und die stete Formveränderung ihres Körpers aus. Beide Familien zerfallen ferner je nachdem sie aus vereinzelten Thieren, oder aus colonicenweis zusammenhängenden Induviduen bestehen, wieder in zwei Unterfamilien, nämlich in einfache und gesellige Monaden oder Aenderlinge.

\section{Fan. Monaden.}

Die Monaden gehören zu den kleinsten aller Infusorien, viele stehen an der Grenze unsers Auffassungsvermögens: sie gehen auf $1 / 2000$ "' herab. Man trifft sie in allen süssen Gewässern, bald ver- 
einzelt, bald massenhaft. Fast in allen Infusionen erscheinen sie zuerst in grosser Menge. Bei geringer Vergrösserung von 100 bis $300 \mathrm{Mal}$ sieht man die meisten als Pünctchen oder rundliche Bläschen rasch durch das Sehfeld ziehn; schwerlich erkennt man die Schwänze oder rüsselförmigen Anhängsel und noch weniger den Mund. Der fadenformige Anhang ist rorn, d. h. die Bewegung des Thieres ist derart, dass dasselbe mit diesem Faden wie mit einer Peitsche herumschlägt, und ihm nachfolgt, also nicht, wie man es vermuthen möchte, den Anhang als Schwanz zum Fortstossen braucht.

Die Geschichte der monadenartigen Infusorien ist derzeit so verwickelt, so eng mit Ersclieinungen des pflanzlichen Lebens verbunden, dass die ganze Ordnung der Flagellaten der Auflösung nahe ist. Bis wir hierüber volle Sicherheit erlangt haben, beschäftigen wir uns mit den wesentlichen Typen dieser Thierchen, um sie später wieder zu erkennen, wenn glückliche und geduldige Forscher ihnen ihre wahre Stellung werden angewiesen haben. Diese Blïtter, wir müssen es nochmals wiederholen, dienen eben nicht dazu, einem wissbegierigen Publicum die Quintessenz des gegenwärtigen Standpunctes der Infusorienlehre als Lectüre zu bieten, sie sollen vielmehr für den Besitzer eines Mikroskops den Leitfaden bilden, der ihn mit den zahllosen Formen niederster Thiere vertraut macht.

Die Monaden scheinen von pflanzlichem Detritus zu leben; oft lassen sie sich mit feinzertheilten Farbstoffen füttern, und zeigen dann in ihrem Innern die Molekule derselben. Wer nicht über sehr starke Vergrösserung verfügen kann, wird diese Familie überlaupt etwas stiefmütterlrch behandeln müssen; indess gibt es auch grössere Formen, die leicht zu beobachten sind.

Unterfamilie Monadida.

Meist kleine, wenig dehnbare Thiere, mit einem oder mehreren Peitschenhaaren, der übrige Kö̈rper nackt.

\section{a. Einzelnlebende Monaden.}

1. Gatt. Monas. Ein rundliches Kügelchen schwimmt mit einem langen feinen Peitschenhaar, an dessen Grunde der Mund sitzt, fast in allen Infusionen herum. Es ist die L in senmon ade (.H. lens). Bei schwacher Vergrösserung findet man selten den peitschenden Faden, aber man erräth seine Gegenwart, wenn die 
feinen Molecule auf dem Objecträger vor dem Thierchen in Bewegung kommen. Dieses 'Thierchen ron etwa $1 / 500$ "' Grösse, ist der Typus einer Monade.

Seine Bewegungen sind gleichmässig und sehr rasch. Die zahlreichen Arten dieser Gattung sind einander so ähnlich, dass die Anführung dieser Einen genügt.

11. 2. 2. Gatt. Cyclidium. Diese Gattung unterscheidet sich ron der rorigen nur dadurch, dass bei ihr das Peitschenhaar an der Basis dicker und steif ist und nur an seiner Spitze schwingende Bewegungen macht. Das Thierchen rückt daher viel langsamer und regelmässiger vorwärts als die Monade.

11. 3. 3. Gatt. Cercomonas. Eine fernere Gattung hat einen länglichen Körper, der vorn mit einem langen Peitschenhaar bewaffnet ist, hinten sich aber in einen dehnbaren Fortsatz auszieht, mit welchem die 'Thiere sich oft anzuheften pflegen.

11. 4. 4. Gatt. Chilomonas. Ein ähnlicher Fortsatz ist bei der vierten Gattung am andern Körperende angebracht, neben welchem das Peitschenhaar abgeht. Körper länglich. Sie erscheinen oft in unzählbarer Menge in faulendem Wasser, das sie wolkig trüben.

11. 5. 5. Gatt. Trichomonas. Nebst dem haarförmigen Rüssel besitzen diese Thiere noch sehr feine, liurze Wimperhaare, welche die Bewegung rermitteln helfen.

11. 6. 6. Gatt. Trepomonas. Hat zwei Filamente, das eine vorn, das andre hinten, durch deren Bewegung der S förmig gekrümmte Körper sich um seine Längsaxe dreht.

11. 7. 7. Gatt. Heteromita. Die zwei fadenförmigen Anhängsel dieses Thieres haben verschiedene Dignität; während das feine Peitschenhaar am vordern Ende sich lebhaft schlängelt, wird das viel dickere, steife, zweite Haar, das ebenfalls vorn entspringt, beim Schwimmen träg nachgeschleppt. Hiemit kann sich das Thier an fremden Körpern festsetzen, und macht häufig durch heftige Contractionen des Schlepphaares erzeugte Zuckungen.

11. 8. 8. Gatt. Hexamita endlich, hat sechs Filamente, wovon vier vorn, und zwei hinten peitschenartig schlagen.

Alle diese Monaden sind grösser als die eigentliche Gattung Monas, einzelne erreichen die Grösse von $1 / 50{ }^{\prime \prime}$. Bei allen hat man in ihrem Innern eine contractile Blase entdeckt. 


\section{b. Gesellige Monaden.}

9. Gatt. Anthophrysa. Oft trifft man auf einem baumförmig II. 9. verzweigten Stiele ron äusserster Zarthcit Knäuel ron runalichen, kleinen Monaden, ähnlich der Linsenmonade, die mit ihren langen Peitschenhaaren im Wasser einen Wirbel crzeugcn. Diese Thicrgruppen sind durch Theilung entstanden, und die unregelmässige Verzweigung des Stammes, welcher von der Monadencolonie abgesondert wird, rührt ron cincr Thcilung der ganzen Colonic ler. Der Stamm sclbst ist an der Basis gewöhnlich bräunlich, an den Enden aber hyalin. Durch Erschütterung lassen sich die Monadenbündcl leicht rom Zweige trcnnen, und schwimmen dann, ähnlich der folgenden Gattung frei im Wasser herum.

10. Gatt. Uvella. Es ist zweifclhaft, ob dicse Gattung eine II. 10. selbstständige ist. Auch hier sind 12-24 runde Monaden zu einem Knäuel verbunden, jede hat 1 oder 2 Wimperhaare, wodurch die ganze Colonie sich rollend im Wasser fortbewcgt.

11. Gatt. Volvox. Das Kugelthicrchen ist ron jcher als eincs der interessantesten, aber auch schwierigsten Räthsel ron den Mikroskopikern betrachtet worden. Denke dir eine wasserhelle gclatinöse Kugel, ron etwa $1 / 2$ "' Durchmesser, die durch feine Wimpern in rollcnde Bewegung versetzt wird. Ueber die ganze Oberflächc der Hülle sind kleine grünc Kügclchen zerstreut, von deren jedem zwei fcine Peitschenhaare ausgehn. welche die erwähnte Bewimperung rorstellen. Im Innern der Kugcl findet man meist 5 bis $S$ grössere, grüne Kugeln. Es fragt sich, als was diese einzelnen Elemente anzuschen sind. Offenbar ist das ganze Geschöpf eine Colonie zahlreicher, grüner Monaden; die kleinen, doppeltbewimperten Körperchen stellen die Individuen dar, und sind miteinander durch feine Ausläufer netzförmig vcrbunden, während die grössern grünen Kugeln im Innern, junge Colonieen rorstellen, die dann durch einen Riss hcraustreten und als eine neue Colonie frei im Wasser herumschwimmen. Spec. globator.

12. Gatt. Gonium. Aehnlich der rorigen Gattung sind auch hier ovale grüne Monaden in einer gelatinösen Masse eingebettct, welche viereckige Platten bildct, und sich langsam im Wasser fortbewegt. Spec. pectoralc. 
An hang.

II. 15. 13. Gatt. Phacus. Die schönen, grossen Monaden sind von zwei Seiten blattartig zusammengedrückt. Sie schwimmen vermittelst eines langen Peitschenhaares, langsam sich um ihre Längsaxe drehend, durch das Wasser und erreichen eine beträchtliche Grösse. Gewöhnlich sind sie intensiv grün gefärbt und haben in der Nähe des Peitschenhaares oft einen rothen Pigmentfleck. Man hat die Arten, deren hintres Ende schwanzartig ausgezogen ist, in die Gattung Phacus gebracht, für die mit abgerundetem Ende die Gattung Crumenula errichtet.

\section{Fam. Astasida (Aenderlinge).}

Diese Familie wird gebildet durch meist grössere Thiere, mit einem langen Peitschenhaar, deren Körper äusserst dehnbar ist und beständig seine Form verändert.

\section{a. Freie Aenderlinge.}

II.12.13. 14. Gatt. Euglena. Wenn wir uns einen Proteus in lebhafter Bewegung mit einem Peitschenhaar versehen denken, so haben wir das Bild einer Euglena. Allerdings ist hier die Haut deutlich doppelt contourirt und kann nicht an jeder beliebigen Stelle Nahrung aufgenommen werden. Man hat bisher bei diesen T'hieren keinen Mund entdeckt. Sie kriechen langsam auf pflanzlichem Detritus herum, und scheinen eigenthümliche Metamorphosen durchzumachen. Die einen dieser Thiere sind intensir grün gefärbt, und haben in der Nähe des Peitschenhares einen röthlichen Punct. Diese bilden das Gen. Euglena nach Ehrexbera: welcher den Pigmentfleck für ein Auge hielt. Andere Arten sind ungefürbt und ohne Augenpunct, sie bilden die Gattung Astasia. E. viridis ist oft so häufig, dass sie das Wasser der Grïben grün färbt.

\section{b. Bepanzerte Aenderlinge.}

II. 14. 15. Gatt. Dinobryon. Diese Gattung stellt gesellig lebende, meist grünliche Infusorien dar, die mit einem langen Peitschenhaar versehen sind und in urnenförmigen Schalen sitzen. Eine Colonie solcher Thiere gleicht einem Büumchen ron ineinandergesteckten 
Pfeifenköpfen. In jedem solchen pfeifenkopfähnlichen, wasserhellen Gebilde steckt ein grünliches Schleimklümpchen, welches ein langes Peitschenhaar zur Oeffnung herausstreckt.

Bei allen Aenderlingen hat man in der Nähe des Peitschenhaares eine contractiłe Blase nachgewiesen, was für uns Beweis ihrer thierischen Natur ist.

\section{An hang.}

Neuere Untersuchungen haben in der Ordnung der Flagellaten vielfache Veränderungen herrorgerufen. Von besonderer Wichtigkeit ist die Entwicklung der $\mathrm{Regen-M}$ on ade geworden. Eine ganze Reihe ron Formen, die bisher eigene Gattungen bildeten (Thecamonas, Chlamydomonas, Protococcus, Hacmatococcus, Diselmis, Euglena, Botryocystis etc.) sind als Entwicklungsstadien einiger weniger Thierchen erkannt worden.

Die Regen mon ad e (Chlamydomonas pluvisculus $E$. oder Di-II. 16. selmis viridis Duj. zeigt sich oft als Euglena-ähnliches Thierchen, mit zwei langen Peitschenhaaren, grünlichem, dehnbarem Körper, und kriccht im Wasser von Gräben und Tümpeln herum, welches sie hie und da durch ihre Menge grün färbt. In der Nähe der Peitschenhaare bemerkt man zwei alternirend sich zusammenziehende Blasen. Bald sondert sich das Thierchen eine gelatinöse zarte Hülle aus (Cryptomonas). Dann verliert es nach einiger Zeit seine Filamente und kapselt sich cin (Botryocystis). In dieser Cyste theilt sich das Thier in 2, 4, 8, 16 etc. Kügelchen, welche bei Zerreissung der Schale austreten, und sich wiederum mit zwei Peitschenhaaren bewaffnen, womit sie herumschwimmen. Diese Sprösslinge sind viel kleiner und rundlich, gleichen also der ursprünglichen Form nicht ganz.

Einen ähnlichen Process macht die Cryptoglena durch. Es ist II. 18. dies eine nit Chlorophyll gefüllte Zelle mit einem Flagellum, die in einer zarten, flaschenförmigen Hülle ron Cellulose sitzt. Anfangs füllt sie die Schale ganz aus; dann rerliert sie ihr Peitschenhaar und zieht sich kugelig zusammen. Nun beginnt in der Hülle ein beständiges Drängen und Drehen, bis diese endlich springt, woraus die nackte Cryptoglena hervorkriecht, wie eine Euglena, die ihr Peit- 
schenhaar verloren hat. Oder sie zieht sich in der Hülle in einen Klumpen zusammen, in dem der oben beschriebene Theilungsprocess rorgeht.

Auch von Euglena viriclis ist die Entwickelung näher bekannt worden : sie ist nicht immer beweglich, sondern hat einen Ruhezustand, wie der Protococcus plurialis. Sie ballt sich zur Kugel und incystirt mit einer durchsichtigen festen Kapsel (Microcystis). Darin geht eine binäre Theilung nach dem Schema 2, 4, S, 16, 32, ror; dann springt die Kapsel und daraus treten sehr kleine birnförmige Körperchen mit einem Nucleus und Peitschenhaar herror, die wahrscheinlich wieder zu Euglenen auswachsen.

Eigenthümlich ist die Entwicklung ron Volvox globator. Die grössern, grünen Ballen im Innern des merkwürdigen Kugelwesens sind, wie wir oben gesehen haben, junge Thiercolonieen, die ihr Entstehen der binären Theilung eines einzelnen Individuums rerdanken; aber es gibt noch eine andere Art der Vermehrung beim Kugelthierchen. Oft werden nämlich einzelne Individuen, ohne sich zu theilen sehr gross, so dass sie fast das Volumen einer jungen Colonie erreichen; die einen derselben zerfallen durch fortgesetzte Theilung in eine Menge winziger, lebhaft vibrirender Körperchen, die ähnlich den Spermatozoen in die übrigen vergrösserten Kugelthierchen eindringen. Darauf kapseln sich diese letztern im Innern der Muttercolonie ein, indem sie sich mit einer gelatinösen Hülle überziehn, welche conische Wülste an ihrer Oberflïche zeigt, und als Volvox stellutus beschrieben worden ist. Wenn die Muttercolonie zu Grunde geht, so bleiben diese höckrigen Kapseln am Boden des Gewässers liegen und dienen zur Erhaltung der Art. Diese Fortpflanzungsweise scheint rorzüglich bei grosser Hitze, welche das Sumpfwasser verdunsten macht, oder in Spätherbst ror dem Gefrieren desselben rorzukommen. Das weitere Schicksal des Volvox stellatus ist aber noch unbekannt. Jedenfalls hat man es hier mit einer geschlechtlichen Fortpflanzung zu thun, deren Endproduct aber dem Mutterthier unähnliche Embryonen liefert, wie wir solches später bei andern Infusorien werden kennen lernen.

Ueberhaupt zeigen die Entwicklungsrorgänge bei den Flagellaten die grösste Aehnlichkeit mit der Fortpflanzung vieler Algen, und wir reihen diese Geschöpfe nur desshalb unbedenklich dem 
Thierreiche $\mathrm{zu}$, weil bei den meisten eine deutliche contractile Blase entdeckt worden ist, die wir als rein thierisches Organ betrach ten müssen.

\section{Unter-Ordnung.}

\section{Cilio - Flagellata.}

Die Ordnung der Cilio-Fagellaten bildet nur dic einzige Familie der Peridinien, und besteht aus meist bepanzerten Thieren, die nebst einem langen Peitschenhaar noch einen transversalen Kranz feinerer Wimperhaare als Bewegungsmittel haben. Sie halten ungefähr die Mitte zwischen den Ciliaten und Flagellaten, sind aber mit den Letztcrn näher verwandt. Noch nie hat man einen deutlichen Mund oder fremde Körper in ihrem Innern entdeckt. Ebenso fehlt ihnen die contractile Blase, hingegen besitzen sie einen Nucleus. Sie haben eine feste, der Verwesung widerstehende Schale, und nackte Formen sind wahrseheinlich nur Entwicklungsphasen der Bepanzerten. Ihrer kalkigen Schale verdanken sie es, dass sic bisher die einzigen Infusorien sind, welche fossil aufgefunden wurden. Die grosse Mehrzahl belebt dic Meere, und nur zwei Gattungen sind im süssen Wasser spïrlich vertreten.

1. Gatt. Ceratium. Der Panzer ist mit hornförmigen AnhängII. 19. seln bewaffnet. Spec. cornutum. Wie bei allen Peridinien ist auch bei dieser Art die Schale durch eine etwas schieflaufende Querfurche, an deren Rändern die Cilien stehn, in zwei Hälften getheilt. Die rordere Hälfte des vierseitigen, zusammengedrückten Körpers trägt zwei gerade Hörner, die hintere nur eins.

2. Gatt. Peridinium. Der Panzer rundlich, ohne hornförII. 20. mige Arhängsel. Ein rother Fleek dieser Thierchen ist kein Auge, sondern nur ein gefärbter Tropfen öliger Flüssigkeit. Spec. ta bulatum. Der Panzer scheint aus grossen polygonalen Stïcken zusammengesetzt, wodurch eine netzförmige Zeichnung entsteht. Die Transversalfurehe ist wenig schief zur Axe geneigt. Spec. cinctum. Kleiner als das rorige, oval, Panzer ganz glatt.

Auch die Peridinien rermehren sich durch Theilung, indess haben sie noch eine andere Verwandlung. Oft verlicren sie nämlich 
ihr Peitschenhaar und den Cilienkranz und ballen sich in der Schale zu einer unbeweglichen Kugel zusammen, dann fallen die zwei Schalenstücke ab, und die nackte Kugel incystirt sich mit einer merkwürdigen, halbmondförmigen, hyalinen Hülle. Was weiter daraus wird, weiss man nicht.

\section{Ordnung.}

\section{Ciliata.}

Weitaus die grösste Anzahl der Infusorien gehört dieser Ordnung an, die durch kurze Wimperhaare, welche die Thiere ganz oder theilweise bekleiden, charakterisirt ist. Vermittelst dieser Winpern machen sie gewöhnlich rasche Bewegungen durch das Wasser. Aber nicht inmer brauchen sie die Flimmerhaare zur Ortsbewegung: die festsitzenden z. B. bewegen sich zuckend, rermittelst eines musculösen Stieles, und die Cilien derselben dienen nur zur Herbeiführung der Nahrung, indem sie in der Lmgebung des Mundes einen Strudel erzeugen. Bei vielen ist nur der Mund mit Wimperhaaren bewaffnet, und alsdann bilden sie einen Fangapparat, oder dienen zum Festhalten erfasster Körper. Viele haben oft dickere Borsten odcr Stacheln und Haken, die ebenfalls beweglich sind, und die sie wie Füsse zum Gehen benutzen.

Mit Ausnalıme einer einzigen Familie (Opalinida), die wir rorab trennen, haben alle Ciliaten einen Mund und After. Ersterer ist oft mit einem kräftigeren Cilienkranz ungeben und endet gewöhnlich in eine mehr oder weniger lange Schlingröhre (Oesopha$g u s)$, welche die Spcisetheile in das Innere des Körpers führt. Bei den einen ist der Mund und Oesophagus bewimpert und auch im ruhenden Zustande weit offen stehend, aber alsdann wenig dehnbar. Man nennt die verschieden gestalteten Ränder der Mundhöhle Peristom und die Form und die Bekleidurig desselben ist ron grosser Bedeutung für die Systematik der Infusorien. Bei andern ist der Mund und Oesophagus in der Ruhe fest geschlossen und alsdann nicht sichtbar, aber beim Fressen können sich diese Oeffumngen stark erweitern, sind aber nie bewimpert. Wir müssen hier noch ein eigenthümliches Organ erwïhnen, das bei einigen Infusorien in 
den Oesophagus eingesehaltet, dessen Bedeutung aber für den Schlingproeess noeh nieht hinlänglich ermittelt ist: Der sogenannte Re ussen-oder Stäbchenapparat nämlieh besteht in einer regelmässigen Gruppirung solider Stäbchen um den eylindrischen Oesophagus. Oft sind diese Stäbehen sehr fein und lang und seheinen dann nur regelmässige Erhärtungen des Sehlingrohres darzustellen, oder sie sind der Ausdruck der Fältelung des Sehlundkopfes; oft sind sie kürzer und ziemlieh diek, und bilden ein solides Sieb in Oesophagus, dureh welches die Nahrungstheilchen passiren müssen.

Andere eigenthümliehe Gestaltungen des Peristoms und Oesophagus wollen wir bei den einzelnen Fanilien näher betrachten und nun zur Systematik der zahlreichen Formen von Ciliaten übergehn。

Wenn wir die Form nnd Vertheilung der ('ilien zum Anhaltspuncte einer Systematik nehmen, so zerfallen uns die Ciliuten in vier grosse Unterordnungen: die erste derselben wird von allen den Ciliaten gebildet, deren Körper ganz mit gleichmässigen, feinen Wimperhaaren bedeekt ist: 1. Holotrich. Hine zweite Unterordnung zeight ebenfalls einen von gleichmässig feinen Wimperhaaren bedeckten Körper, aber in Umkreis des Mundes steht eine Spirale von viel stärkern, kräftigeren Wimpern, die theils zur Fortberegung. theils zur Ergreifung der Nahrung dicnen. Der Verschiedenartigkeit dieser Cilien wegen hat man die Unterordnung 2. Heterotricha genannt. Rei einer dritten Unterordnung, 3. Hypotricha, sind nur auf der (untern) Bauehseite entweder feine Cilien oder stärkere Borsten und Haken angebracht; die (obere) Rïekenseite dieser Infusorien ist gan\% nackt und glatt. Wine vierte Unterordnung endlich, 4. Peritricha, umfasst drehrunde Infusorien, deren Körperoberfliiche gan\% naekt ist und die nur um den Mund einen Kreis starker Wimperhaare tragen. In einigen Fïllen existirt noeh eine zweite Wimpernzone um den Tïrper.

Bei der Eintheilung dieser Unterordnungen in Familien werden nebst der Vertheilung der Cilien noch andere Eigensehaften zu Rathe gezogen.

Die Holotrichen können wir in drei Familien bringen. 1. Fam. Opalinida, wird von den oben genannten inundlosen Ciliaten gebildet. Alle die hierher gehörenden Thiere leben parasitisch in Darmeanal von Würmern, Insecten, Amphibien etc. Alle übrigen Ciliaten 
haben einen deutlichen Mund. Eine zw e it e F a mil i e, Trachelina, umfasst gleichmässig bewimperte Infusoricn von verschiedener Körpergestalt, deren Mund und Oesophagus in der Ruhe geschlossen sind, und nur bcim Fressen, wenn sie sich stark erweitern, sichtbar werden. Die Cilien ziehen sich nie bis in den Oesophagus hinein. Bei einer dritten Familie endlich, Colpodina, liegen Mund und Oesophagus stets gcöffnet in ciner seitlichen Einbuchtung des Körpers. Für dic zweite Unterordnung der Heterotrichen wollen wir nur eine Familie, Bursarina, annehmen. Die dritte Unterordnung der Hypotrichen zerfällt in zwei Familicn, von denen die erste, Chilodina, auf der Bauchseite mit feinen Wimperhaaren bekleidet ist und in ihrem Oesophagus einen Reussenapparat eingeschachtelt hat, während die zweite Familie gar keine feinern Cilien besitzt, sondern auf ihrer Bauchseitc stärkere Borsten und Hackenfüssc trägt, und um den seitlichen Mund eine langgezogene Spiralc kräftiger Cilien besitzt. Die Unterordnung der Peritrichen endlich zerfällt wiederum in zwei Familien, deren erste, Strombidina, durch einen einfachen Kranz starker Mundwimpern charakterisirt ist, während bei der zweiten Familie, Vorticellina, Mund und After in einer gemeinsamen Grube liegen, die von einem eigenthümlichen, conischen Wimperapparat bedeckt wird. Die meisten Vorticellinen sitzen auf Stielen an fremden Körpern fest.

Es ergibt sich also folgende Uebersicht: 


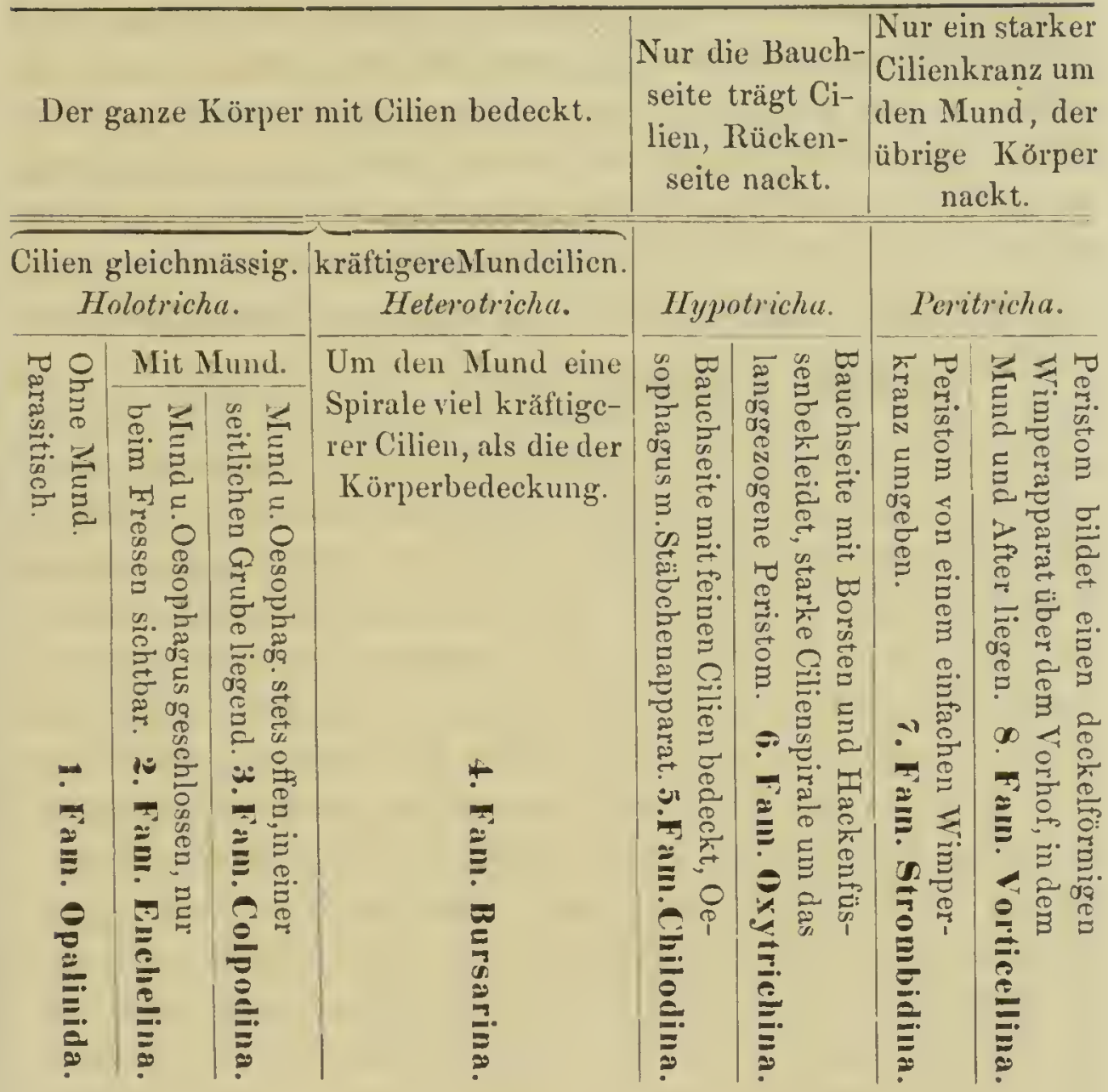

I. Unterordnung. Holotricha.

\section{a. Mundlose Infusorien.}

\section{Fam. Opalinida.}

Gatt. 0palina, Glasthierchen. Alle hierher gehörigen III. 1. 2. Thierchen sind sehr durchsichtig, wesshalb das gänzliche Fehlen ron Mund und After verhältnissmässig leicht zu constatiren ist; auch findet man nie fremde Körper in ihrem Innern. Feine Cilien stehen in regehmässigen Längsreihen, wie auf kleinen Wärzchen über den oralen, comprimirten Körper rerbreitet. Hiemit wïlzen sich diese Schmarotzer langsam im Darmschleim höherer Thiere herum. Von einigen Beobachtern werden die Opalinen für Larvenzustïnde von Eingeweidewürmern gehalten, auch scheinen wirklich 
nicht alle Formen in dieselbe Familie zu passen, da einzelne Arten mit deutlichem Kern und einer contractilen Blase versehen sind, bei andern blos der Kern und einige nicht contractile Vacuolen getroffen werden. Ihr Aufenthalt ist ausschliesslich der Darm von Würmern, Insecten und Amphibien und sic sterben rasch, wenn sie in reines Wasser versetzt werden. Einige der häufigsten Arten sind: O. ranarum in Froschdarm, O.lumbrici in den Eingeweiden des Regenwurmes etc.

I1. Fam. Fuchelina. Wa ze n thierchén.

Diese Familie besteht aus ziemlich grossen, länglichen Infusorien, mit sehr dehnbarem Körper, der gleichmässig mit äusserst feinen Flimmerhaaren bedeckt ist. Oft hält es schwer, diesen feinen Wimperüberzug zu erkennen. Sie haben keine auffallend stärkere Cilienbekleidung des Mundes, keine Borsten, keine Hackenfüsse, und machen beim Fressen schlingende Bewegungen, wobei man dann ihren Mund und die Speiseröhre sich erweitern sieht. Im Vorbeigchn schnappen sie die Nahrung weg, ohne sie durch die Erzeugung eines Strudels mit den Mundwimpern herbeizuführen, wie viele andere Infusorien es thun. Besonders ihre vordre Partie (der Hals) ist bisweilen iusserst dehnbar, fährt lebhaft nach allen Richtungen herum, kann sich fast ganz einziehn, und wieder auf die zehnfache Länge ausdehnen, und dient vielleicht als Tastorgan. Bei einigen kommen noch eigenthümliche Organe in ihren Innern vor, die wir bei den einzelnen Gattungen erwähnen werden. Sie haben eine grosse Fähigkeit sich zu incystiren, d. h. sich zusammenzuballen, und unter beständiger Drehung eine feste Membran um ihren Körper auszuscheiden. Dieses geschieht besonders häufig beim Verdunsten des Wassers unter dem Mikroskop; indess scheint dieser Process auch willkürlich eingeleitet zu werden, z. B. nach Verschlingen eines grössern andern Infusoriums, und ist die Cystenbildung oft als Vorbereitung zu einem sich einleitenden Theilungsprocess anzusehen. Im Uebrigen vermehren sie sich durch Theilung auch ohne vorhergehende Einkapselung.

Wir vermeiden es hier, eine analytische Uebersicht der zahlreichen Gattungen zu geben, denn solche Tabellen haben für die Bestimmung nur Werth bei ruhenden Körpern, wo alle Augenblicke ein Vergleichen möglich ist, z. B. bei Insectensammlungen. 
Bei den lebhaften Bewegungen der Infusorien aber ist diese Methode des Bestimmens nicht anwendbar, und man wird die Thiere viel leichter an der Hand von Abbildungen kennen lernen, als mit analytischen 'T'af'eln.

\section{a. Mund endständig.}

1. Gatt. Lacrymaria. Spec. Olor. Dieses grosse Infuso- III. 3. rium mit flaschenförmigem, sehr dehnbarem Körper, kriecht häufig an Wasserpflanken herum, und trägt seinen Mund an einem kleinen conischen Fortsat\%, der etwa dem Korke in einer Flasche entsprechen würde. Um dicsen Conus herum ist eine Reihe etwas stärkerer Flimmerhatre in beständiger Pewegung. Der schlanke Hals ist äusserst ductil, und kann sich bis auf dic fünflache Iünge des Thieres ausclehnen. Dic Körperoberflache ist mit regelmässig gereihten Höckerchen besetzt und gleichmässig bewimpert. Melurere (3) contractile Blasen und ein doppelter Kern sind in Innern sichtbar. Die Bewegungen dieses dehnbaren 'Thieres sind sehr elegant.

Eine rerwandte Art (vermiculuris) hat rorn einen breiten, cylindrischen Anhang und ist etwa mit einer Puderbüchse zu vergleichen, man hat daraus eine eigene Gattung, Phialina, errichtet.

2. Gatt. Trachelophyllum. Spec. apiculatum. In der III. 4. Form der vorigen Gattung sehr ithnlich, unterscheiden sich die hierher gehörigen Infusorien durch die starke Abplattung ihres Leibes. Sie bewegen sich daher nicht wie die Vorigen, indem sie sich um ihre Längsaxe drehen, sondern sie kriechen auf einer Flachseite. Auch sic haben vorn an Hals einen pfropfartigen Fortsatz, aber ohne stärkere Wimpern. In dem sehr dünnen, langen Hals sieht man eine dunkle Linie, welche den geraden Oesophagus darstellt.

3. Gatt. Enchelys. Eiförmige Thiere mit abgerundetem, brei- III. 5. tem hintern und spitz auslaufendem Vorderende, an welchem der Mund sitzt. Der After ist auf der entgegengesetzten Seite. Gewöhnlich sind sie etwas um ihre Lüngsaxe gedreht. Die sehr feine Cilienbekleidung erlaubt ihnen nur sehr langsame Bewegungen, während welcher sie sich bestïndig drehn. Mehrere Arten.

4. Gatt. Enchelyodon. Gleicht ganz der rorigen Gattung, nur III. 6. hat ihre Schlingröhre einen eigenthümlichen Reussenapparat. Wir 
werden eincn solchen bei mehreren folgenden Gattungen wiederfinden. Bei dieser Gattung bildet der Nucleus ein langes Band.

III. 7. 5. Gatt. Holophrya. Dic Körperform dieser 'Thiere ist ähnlich der vorigen, aber vorn nicht verengert, sondern abgerundet, wie hinten. Also ellipsoìd. Um den Mund bildet ein kleiner Vorsprung cine Art Lippe. Spcc. Ovum ist eine häufige, grüngefürbte Art aul Conferven. Aus einer andern Art, die hinten ein schiefgestelltes, langes Seidenhaar hat, womit sie sich fortschnellen

II. 8. kann, hat man die Gattung Urotricha errichtet.

III. 9. 6. Gatt. Prorodon hat ebenfalls eine ovoïde Körperform, wie die vorige Gattung. Der Mund ist nicht genau endständig, und der Oesophagus besitzt cinen seitlich comprimirten Reussenapparat. Ihre Cilien sind ziemlich stark, und sie drehen sich im Schwimmen um ihre Längsaxe.

\section{b. Mund seitenständig.}

7. Gatt. Nassula. An dem clliptischen Kiörper verrïth der scitlich sitzende Stäbchenapparat die Lage des Mundes. Diese Thiere nährcn sich von Oscillarien und Algen. Bei dcr häufigsten Spec.

III. 10. $\mathrm{flava}$, ist der Schlingapparat am Ende kugelig aufgetricben, und im Inncrn des Körpers sieht man nebst zwei contractilen Blasen viele violette Körner.

III. 11. 8. Gatt. Loxodes. Der lünglich ovale Körper ist meist C förmig gebogen, hat in seincr lintern Partie eine Anzahl grosscr Blasen, dic vielleicht ein contractiles Organ sind. Ebcuso stchen eigenthümliche Blasen mit einem stark lichtbrechenden Körper in einer langen Reihc dem Rücken entlang. Der Stïbchcnapparat fehlt, aber der sichelförmige Oesophagus wird durch seinc braune Färbung leicht bemerkt (L.rostrum). Die dehnbarc rordere Partie ist mit zahlreichen Stäbchengebilden beklcidet.

III. 12. 9. Gatt. Trachelius. Der Mund sitzt bei dieser Gattung an der Basis eincr rüsselförmigen Verlängcrung, und führt in einen verzweigten Nahrungscanal. Man darf sich indess diescn nicht als cinen Darmcanal mit cigenen Wandungen vorstellen, sondern muss sich denselben als eine buchtigc Aussackung des dünnern Innenparenchyms erklären.

III. 11 10. Gatt. Amphileptus. Wie bei der vorigen Gattung sitzt der 
Mund an der Basis einer sehır dehnbaren, halsförmigen Verlängerung. Verdauungshöhle nicht verzweigt. Zahlreiche und häufige Arten. Sind arge Raubthiere.

11. Gatt. Loxophyllum. Blattähnlich abgeflacht, können sich III. I5. zwar diese Thiere durch liressen auftreiben, aber immer bleibt ein flacher. durchsichtiger Rand, gebildet durch eine Zone des äussern hörperparenchyms, wohin keine Nahrung eindringt. Dadurch sowohl, als auch, dass sie sich nie beim Schwimmen um ihre Längsaxe drehen, unterscheiden sie sich von der vorigen Gattung.

\section{Anhang.}

12. Gutt. Coleps. Viele bilden aus dieser Gattung eine eigne III. 16. Familie, da ilı Körper formbeständig ist; sie ist indess jedenfalls sehr nahe mit den Trackelinen verwandt. Die häufigste Art C. hirtus ist ein kleines, mit einem eigenthünlichen, festen Gitterpanzer bedecktes Infusorium, das in jedem sumpfigen Wasser rorkommt. Hinten ist der P'anzer mit 2 - 3 Spitzen bewaflnet, und vorn regelmïssig gezithnclt, und hat ungefïhr die Form eines kleinen Fässchens. Das 'Thier ist gleichnüssig mit feinen Cilien bedeckt, schwimmt lebhaft herum und schnappt in Vorbeifahren seine Nahrung weg, wie die Trachelinen. Die Vermehrung geschieht durch Quertheilung, wobei jedes Thier eine Hälfte des alten Panzers behält, der in der Mitte nicht fest verbunden zu sein scheint.

Da es bei geringen Vergrösserungen oft schwer wird, den Sitz des Mundes zu erkennen. so wollen wir zur Erleichterung noch ein anderes Merkmal, die Dehnbarkeit des Körpers, verwenden, und finden als Gattungen mit sehr dehnbarem, stets sich änderndem Leibe: Lacrymaria, Trachelophyllum, Amphileptus; wenig dehnbar ist der Körper ron Tiachelins, Enchelys. Enchclyodon, Loxodes und Loxophylhem, und ganı formbeständig ist er bei Holophrya, Prorodon, Nassula und Coleps.

\section{Fam. Colpodina.}

Diese Familie besteht aus meist ovalen oder nierenförmigen Infusorien, deren Mund und Oesophagus weit offen steht, und nicht erweitert werden kann. Sie sind über die ganze Oberflïche gleich- 
mässig mit feinen Flimmerhaaren bedeckt, und der Mund hat keinen stärkern Winpcrbesatz als die allgemeine Körperbekleidung ist. Bci sehr starker Vergrösserung sieht man diese Wimpern sich in die Schlingröhre hineinerstrecken, was bei der vorigen Familie nie vorkommt. Finigc haben um den Mund herum, der in einer seitlichen Körpcreinbuchtıng liegt, einen oscillirenden Hautsaum, oder kurze, fcinc Seidcnhaare, die eine Art ron Lippe bilden. Der After liegt meist auf der Bauchseite, wie der Mund, in wenigen Fïllen ist cr terminal. Es gehören hierher die häufigsten Infusorien, die man in jcder Infusion trifft. 1)ies hängt wahrschcinlich zusammen mit ihrer grossen Fiihigkcit sich zu incystiren.

Ihre Vermehrung findet auf' dem Wege der Quer- und Längstheilung statt; die oft bei ein und derselben Art in beiden Richtungen beobachtet worden ist. Indess hat man bei einigen auch eine Fortpflanzungsweisc durch Embryonen entdeckt, wobei sich der Kern zu betheiligen scheint. Die kleinen, bewimperten Embryonen bilden sich in dessen Nähc in einer eignen Höhle aus, welche in der Gegend des Mundes einen Ausgang erhält und ihren Inhalt dadurch entleert. Schon im Mutterthier sind sie mit Kern und contractilcr Blase verschen und besitzen häntige Anhängsel mit kleinen Knöpfen. Einige Forscher sehen in diesen Embryonen eine parasitisch lebende Acinetenform und da ihr weiteres Schicksal noch unbekannt ist, so ist ihr Wesen zur Zcit noch nicht enträthselt.

IV. I 2. 1. Gatt. Paramecium. Pant offelthierchen. Ueberall gleichmässig bewimpert, ohne Lippen und ohne Seidenhaare am Mund. Dcr Mund liegt in ciner trichterförmigen, seitlichen Furche. Einige sind mit Trichocysten bcwaffnet, jenen stäbchenförmigen Organen der Haut. Sie gehören zu den hänfigsten Infusorien und beleben in zahlreichen Arten alle Gewïsser. P. A urelia mit sternförmigem contractilem Organ ist dic häufigste Art in dieser Gattung.

IV. 3. 2. Gatt. Colpoda. He uthierchen. Ebcnso häufig wie die Vorigen, unterscheiden sich diesc durch einen Büschel kurzer Seidenhaare am Mund, der eine bewcgliche Lippc vorstellt. Während die Vorigen mehr die Form einer Schuhsohle haben, zeigen die Colpoden einen nicrenlörmigen, etwas comprimirten Leib. Bei der 
gemeinsten Art (C.Cucullus) ist der vordere Theil wie eine Kuppel stark nach vorn gekrümint.

3. Gatt. Cyclidium. Körper oval, etwas comprimirt, nebst den IV.4.5. Wimpern mit langen, feinen Seidenhaaren bewaffnet, welche die Thiere zn grossen Sprüngen befühigen. Man hat ans den Arten, deren Seidenhaare um den Mund herum eine Art Fangnetz bilden, die Gattung Plearonema errichtet. Diese Springhaare stchen oft wie ein Strahlenkranz nach allen Richtungen stariend 1 m das Thier, wenn es unbeweglich liegen bleibt.

4. Gatt. Glaucoma. Kleine, ovale Thierchen, deren Mund zwischen zwci stets flimmernden, häutigen Lippen liegt. Spec. scintillans.

\section{Unterordnung Heterotricha.}

Wir errichten für diese Unterordnung . deren Mundcilien bedeutend kräftiger sind als die feincn Cilien des ïbrigen Körpers, nur eine Familie, Bursarina.

\section{Fam. Bursarina.}

Diese grossen Infusorien sind wie die Vorigen über den ganzen Lcib gleichmässig bewimpert, aber um den Mund tragen sie einen stärkern Cilienkranz, der theils zum Schwimmen, thcils zur Erzcugung eincs Strudels benutzt wird, wodurch fremde Körper herbeigeführt werden. Der stets gähnende Mund sitzt oft in einer tiefern Grube und ist bald scitenständig, bald endständig. Die Körperform der Thiere ist sehr verschieden und bietct uns bequeme Anhaltspuncte für die Systematik. Einige leben als Schmarotzer im Darm höherer Thiere, dic meisten schwimmen frei herum, oder sitzen zeitweise nit ihrem hintern Ende an fremden Körpern fest. Auch bei dieser Familie ist die gewöhnlichste Vermehrung die durch Längstheilung; aber auch Embryobildung ist bci einigen beobachtet worden, wobei sich der längliche Nucleus einschnürt und in einzelne Kerne zerfällt, aus denen die Embryonen herrorgehn.

1. Gatt. Metopus. Der langgestreckte Körper ist abgeflacht, IV. ?. 
S förmig. Der Mund liegt in einer seitliehen Grube, wie bei Paramecium.

IV. 8.9. 2. Gatt. Spirostomum. Thicre von verschiedencr, meist langgestreckter oder ovaler Fïrperform, deren tiefe Mundfurche fast. über die vordre Hällte des Thieres sich erstreckt, und mit cinem kräftigen Ciliensaun bewaffinct ist. Man hat eine Reihe von Gattungen errichtet, je nael der Körperform und der Gestaltung dieser Mundlı̈hle (Plugioloma, Balantidium, Lembadium). Wir rerweisen zur Unterscheidung derselben auf die beigefügien Figuren. Viele leben parasitiseh im Darminlalt anderer Thicre, oder in Schleim, welehen die Mollusken ausscheiden, vicle schwimmen froi im Wasser herum. Diese beiden Gattungen bilden den Ucbergang zu der vorigen Familie und könnteu ebenso gut in derselben untergebracht werden, da ihre Mundeilien nieht sehr viel stärker sind, als die Wimpern der Körperbedeckung.

IV. 10. 3. Gatt. Bursaria. Diese grossen, urnenförmigen Infusorien besitzen eine breite, triehterförmige, init starken Cilien bekleidete Mundhöhle. Im Innorn derselben sieht man eine liante verlaufen, die mit kräftigen Wimpern besctzt ist. Zahlreiehe zerstreute contraetile Blasen, und ein langer hakenförmig gebogener Nuclous.

IV. 2. 4. Gatt. Leucophrys. Der weitgeöffnete, endständige Mund steht mit einen bewimperten Oesophagus in Verbindung. Der ovale Körper ist wenig eontraetil und kann sich nieht festsetzen, wie bei der folgenden Gattung der Fall ist. After hinten.

IV. 13. 5. Gatt. Stentor. Spee. polymorphus, 'Trompetenthierchen. Dic Form dieser grossen und häufigen Infusorien ist die einer Trompete oder eincs Hornes, an dessen weiter Oeffnung der Mund auf einom abgestutzten Conus sitzt. Ebendaselbst befindet sieh der After. Um den Mund herum zicht sich cine Spirale von schr kräftigen Cilien. U'eber den ganzen Körper sitzen feine Wimperhaare auf kleinen Wär\%chen in Lüngsreihen gestellt, wodureh eine Streifung des Thieres hervorgerufen wird, Der Körper ist sehr dehnbar und kann sich urnenförmig zusammenziehn und wieder als langes Rohr ausstreeken. Der Nucleus bildet cin langes Band, und die contraetile Blase steht mit einem langen, varieösen Gefässe in Verbindung. Oft sieht man deutlieh lange, stcifc Seidenhaare von dem Körper ausstrahlen; indess dienen diese nicht 
zu springenden Bewegungen. Dieses Thier schwimmt rasch herum, kann sich aber mit seinem hintern Theile an fremde Körper festsetzen, was oft in grossen Gesellschaften geschieht. In diesen Zustande scheidet es zuwcilen eine gelatinöse: durchsichtige, sehr hinfällige Hülle aus. Eigenthümlich ist die Art der Theilung. Hiebei behält das eine der zwei neuen Individuen die vordere Partie, mit dem Munde des ursprüngliclien 'Ihieres, während das zweite Individuum die hintere Hälfte belailt und daran einen neuen Mund bildet. Es ist eine schräge 'Theilung.

\section{Un terord nung Hypotrichar.}

Wir zerfällen diese Unterordnung der nur auf der Bauchseite mitCilien bewaffneten Infusorien am besten in zwci Familien: Die erste, Chilodina, besitzt auf der untern Seite feine Wimpern als Bewegungsorgane, und in ihren Oesophagus ist ein aus steifen Stäbchen bestehender Reussenapparat eingeschaltet; die zweite Familie, Oxytrichina, trägt auf der untern Seite keine feinen ('ilien sondern sparsame, in regelmässige Reilıen gestellte stärkere Borsten, oder rerschieden geformte Haken und griffelartige Anhängsel. Ihr stets weit offenstehender Mund besitzt keinen Reussenapparat und liegt in einer tiefen Grube auf der Bauclsseite.

\section{Fam. Chilodina.}

Wegen des Stäbchenapjparates, den diese Infusorien in ilırem Oesophagus tragen, hat man sie früher gewöhnlich mit den nahverwandten Formen Nassula, Prorodon etc. in der Familie der Enchelina vereinigt. Aber der Umstand, dass sie nur auf ihrer Bauchseite Wimpern tragen, wïhrend die Rückenseite nackt ist, zwingt uns nach dem Vorgange von STEx, dieselben aus der Unterordnung der holotrichen Infusorien in die der Hypotrichen zu versetzen.

1. Gatt. Chilodon. Diese spity eiförmigen Infusorien kriechen V. 1. behende auf der feinberimperten Bauchseite herum, und ihre vordere, ausgezogene Körperpartie scheint als ein sehr dehnbares 'Tastorgan zu dienen. Der Mund mit dem Stäbchenapparat sitzt im vordern Dritttheil der ganzen Körperlänge. Ch. cucull u s ist ein sehr verbreitetes Infusorium, das lebhaft an Wasserpflanzen herumkriecht, und in dessen Innern man oft verzehrte Algen und andere Pflanzenreste erblickt. 
V. 2. 2. Gatt. Phascolodon. Achnlich der vorigen Gattung, aber weniger von oben nach unten zusammengedrüclzt, sondern mehr rundlich.

V. 3. 3. Gatt. Ervilia. Die kleinen Infusorien dieser Gattung haben hinten an ihrem rundlich ovalen Leib einen schwanzartigen Anhang, mit dem sic rasch wirbelnde Bewegungen machen können, und sich zeitweise auch an fremden Gegenständen anheften. Die meisten Arten sind marin, nur eine Art, E. flu viatil is findet sich hie und da im Wasser langsam fliessender Bäche unter Wasserpflanzen. Des sehwanzartigen Anhängsels wegen hat man eine eigene Familie für dieselben crrichtet. Auch sie haben einen steifen, röhrenförmigen Schlingapparat im Oesophagus eingeschaltet, und nur ein schmaler Streifen auf ihrer Bauchseite ist mit feinen Cilien bedeckt.

\section{Fam. Oxytrichina.}

Die Borstenfüssler bilden eine grosse, deutlich charakterisirte Familie der Infusorien. Sie besitzen nirgends feine, zarte Wimperhaare, sondern um den seitlichen Mund steht eine langgezogene Spirale krüftiger, steifer Cilien, und über die untere Seite des Kiörpers sind Borsten, Stacheln, Haken verbreitet, womit sie mehr gehn und laufen als schwimmen können. Die Stellung und Gruppirung dieser Borsten gibt uns das Eintheilungsprincip für die Gattungen, während ihre Zahlenverhïltnisse mehr für die Arten charakteristisch sind. Da aber das Zählen bei so lebhalten 'Thieren sehr schwierig ist, so werden wir uns wenig mit den Arten befassen, wo die äussere Form uns nicht unterstützt. Die grossen kräftigen Infusorien beleben als Raubthiere alle fliessenden und stehenden Gewässer, indem sie bald auf Pflanzentheilen herumgehn, bald mit den Seitenborsten schwimmen und dabei die hinten befindlichen Styli oder Ruderplatten wie ein Steuerruder benützen; oft auch bleiben sie auf der Stelle ruhig und wimpern nur mit ihrem starken Mundbesatz; aber selten sind alle diese verschiedenen Anhängsel in gleiehzeitiger Bewegung, wie die Cilien der übrigen Infusorien. Man sieht, das Flimmerhaar hat sich hier differenzirt, mehrere Haare sind zu einer Borste zusammengetreten, die eine besondere Form und Function hat, wie z. B. das Horn des Ochsen, 
die Kralle des Vogels aus ursprünglich gleichen Oberhautgebilden herangewachsen sind. Mund und Oesophagus der Borstenfüssler liegen in einer langen, seitlichen Furche und stehen immer weit offen. Ihre Vermchrung geschieht gewöhnlich auf dem Wege der'Theilung, indess ist bei cinigen auch Embryobildung beobachtet. worden. Der Korper ist steif, wenig dehnbar, und die ziemlich feste Haut widersteht mit ihren Anhängen oft einige Zeit der Zersetzung, während der weiche Inhalt schon zerfiossen ist; nie aber bildet sie einen eigentlichen Panzer. Wir könnon die Borstenfüsslcr eintheilen nach dem Vorkommen oder Fehlen ion steifen, wenig beweglichen Haken.

\section{a. Ohne Hakenfüsse.}

1. Gatt. Oxytricha. Diese grossen, länglichen Infusorien sind V. 8.9. mit kräftigen, geraden Borsten bedeckt, die in fünf regelmässigen, schieflaufenden Längsreihen stehn. Am hintern Ende sitzen mehrere flache Ruderfüsse. Gewöhnlich fünf. Wie alle Oxytrichinen haben sie nur eine contractile Blase, hingegen einen doppelten Kern. Einige haben nach vorn einen halsförmig verdünnten Körper und diese bilden die Gatt. Stichochaeta und Stichotricha.

2. Gatt. Aspidisca. Sind viel kleiner als die Oxytrichen und zeichnen sich sowohl durch ihre bizarre Körperform, als durch das Fehlen ron Seitenborsten aus. Sie haben eine derbere Hant, die der Zersetzung einige Zeit widersteht.

\section{b. Mit Hakenfüssen.}

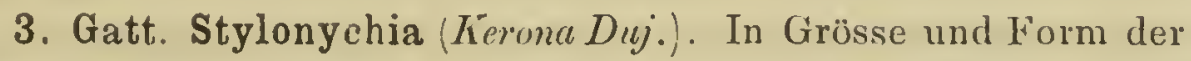
Gattung Oxytricka :ihnlich, unterscheiden sich diese Thiere durch das Vorhandensein kriftiger Haken und die unregelmässige Vertheilung der Borsten, welche hier keine regehnisssigen Reihen bilden. Von der Bauchfläche stehen hinten fünf Ruderfüsse heraus, an deren Wurzel der After sitzt.

St. Mytilus ist eines der grössten und häufigsten Infusorien aller Gewïsser.

4. Gatt. Enplotes (Plrescomia Bory). Kleiner als die vorige V. 7. Gattung, rundlich. mit derberer Haut. Die Ruderfüsse stehen in einer Querlinie am Bauch. Der Mund liegt in einer grossen rhom- 
bischen Grube auf der Bauchseite, die mit zerstreuten, starken Hakenf'üssen besetzt ist.

Andere haben die Gattungen Oxylricha und Stylonychia vereinigt wegen ihrer dünnern Haut, und Aspidisca und Euplotes als mit einem der Zersetzung widerstehenden Panzer versehen, in eine gemeinsehaftliche Gruppe gebracht. Gegenwärtig theilt man die Oxytrichen in Gattungsgruppen ein, die bedingt werden durch die Lïnge der Seiten- und Stirnborsten, je naehdem diese nämlich die Contour des Leibes überragen oder nicht; wir müssen aber aus praktischen Rücksiehten auf' solche untergeordnete Merkmale verzichten.

\section{Unterordnung Peritricha.}

Die Unterordnung der peritriehen Infusorien besteht aus drehrunden Thieren, die nur um den Mund einen stärkern Cilienkran\% tragen, am übrigen Körper aber unbewaffnet sind, oder wenigstens keine feinere Cilienbekleidung besitzen. Wir trennen sie in zwei Familien. Eine erste, Strombidina, hat einen starken Cilienkranz, der unmittelbar dem kreisförmigen Mundrande angeheftet ist, während bei der zweiten Familie, Vorticellina, der Mund in einer eigenthümlich gestalteten Grubē liegt, die wir bei der Charakteristik der Familie näher bespreehen wollen

\section{Faur. Strombidina.}

Der drehrunde Körper dieser kleinen, kugeligen Infusorien ist ganz naẻkt; nur um den Mund finden wir einen krältigen Kranz starker Cilien als vorzügliches Bewegungsorgan, einzelne Formen besitzen daneben noch einen zweiten Cilienkranz, etwa um die Mitte des Leibes, orler um ein hinteres Segment; andere hingegen sind mit einer Zone sehr langer, steifer Seidenhaare versehen, welehe sie zu grossen Sprüngen befühigen. Wir haben hier nur drei kleine Gattungen namhaft zu maehen, die leieht von einander zu unterscheiden sind, und von denen die letzte bald unter den Vorticellinen, bald als selustständige Familie figurirt hat. Die kleinen Thierehen maehen meist so rasche Bewegungen, dass es sehwer liült, ihre Form genau zu erkennen; wesshalb auch die meisten Abbildungen schlecht ausgefallen sind. 
1. Gatt. Strombidium. Kleine topfähnliche Thierchen, die VI. 1. vermittelst eines sehr starken Wimperkranzes lierumschwimmen, ohne springende Bewegungen zu machen.

2. Gatt. Halteria. Spec. grandinella. Runde 'Thiere von VI. 2. ähnlicher Körperform, mit starken Mundcilicn. Zudem besitzen sie um ihren Aequator einen Kranz steifer, langer Suidenhaare, womit sie sclır grosse Sprünge machen. Obgleich sie schr häufig in allen sumpfigen Wassern rorkommen, gclingt es doch sclten, ihre wirkliche Form zu erkennen. Mcist erscheinen sie wie eine Kugel, die auf der einen Seite dickere, auf der andern feinere und längere Cilien besitzt.

3. Gatt. Urocentrum. Spec. 'T urbo. Diescs häufige, aber VI. 3. wegen seincr raschen Bewcgung schwer zu beobachtende Thierchen hat einen urnenförmigen Körper mit starker Wimperkrone am Rand. Hinten trägt es einen kleinen, sehr beweglichen Schwanz, womit es sich oft festheftet. Der Mund liegt in einer seitlichen Furche.

\section{Fam. Vorticellina.}

Die Glockenthierchen bilden unstreitig die höchste und interessanteste Familie der bewimperten Infusorien. Denke dir eine kleine Glocke oder Urne, um dcren Mündung ein lebhaft wimpernder Saum einen beständigen Strudel erzeugt; an der entgegengesctzten Seite sei das Glöckchen an einem elastisclıen Faden angehängt, so hast du einen annähernden Begriff ron der häufigsten dieser Thierformen. Bald schnellt der Faden rasch in eine Spirale zusammen, und zielıt das beutelförmig zuklappende Thierchen zurück; bald dehnt er sich wieder langsam aus, während der Kelch seinen ausgeschweiften Wimperkranz entwickclt und zu strudcln beginnt; oder der Stiel ist nicht elastisch, sondcrn nur die hinterste Partie der Urne macht eine rasche Einknickung, und sie stellt sich dadurch zum Stengel in einen Winkel, etwa wio eine zerknickte Blumc. Darin besteht die einzige unmittelbare Ortsbewegung der festsitzenden Glockenthierchen. Eine mittelbare und sehr ausgicbige Bewegung aber erreichen sie, indem sie sich auf andern Thieren, wie Muscheln, Sclnecken, Krebsen, Wasserinsecten festsetzen, unci von diesen überallh in mittragen lassen. Die Nahrung ergreifen sie nicht mit dem Munde, sondern tühren sic in kleinen Moleciulen durch 
die Erzeugung eines beständigen Strudels in die weitc Ocffnung dcs

VI. 5. Peristomes. So einfach aber ist der Bau der Vorticellinen nicht, und wirwollen sie bei stärkerer Vergrösserung etwas genaucr bctrachten. Dcr 'Typus ihres Körpers ist die Form einer Urne, welche an ihrem vordern Ende abgestutat und cingestülpt ist. In dieser Einstülpung liegt der offene Mund und nalıe dabei der Aftcr. Der Mund setzt sich in eine ebenfalls offene Speiscröhre fort, welche in die Körperhöhle fülırt. Von der Wand der Urne nun erhebt sich eine Hautausstülpung in Form eines umgekchrten Kcgels nach aussen; es ist dies das sogenannte $\mathrm{W}$ im perorgan, an dessen oberm, scheibenförmigen Theile (Discus) ein kräftiger Cilienkranz sitzt. Dic Cilien ziehen sich von da am Kegel des Wimpcrorganes in einer Spirale bis in den Mund und Oesophagus hinein. Das Innere des Körpers besteht aus gleichmässiger Sarcode mit eingestreuten feinen Körnchen, und in dem Verdauungsraum finàet man vicle of gefürbte Nahrungsballen. Die ganze Urne ist also nackt und nur das Wimperorgan trägt in ciner doppelten Spirale Cilien.

Dieser Theil kann sich deckelförmig auf die Trnenöffnung (das sog. Peristom) schliessen, wobei die Wimperhaare clem Auge verschwinden.

Alle Vorticellinen haben nur eine eontractile Blase in der Nähe des Mundes, und einen länglichen bandartigen Nucleus. Diese urnenförmigen Körper sitzen nun gewöhnlich an einem Stiele fest. Bei einigen ist der hohle elastisehc Stiel mit einem spiralig verlaufenden Muskelfaden durchzogen; zieht sich der Muskel zusammen. so ist ersichtlich, dass durch dessen Verkürzung ein spiraliges Aufrollen des Stieles bedingt ist. Bei andern Gattungen hat der Stiel keinen Muskel, ist nicht contractil und dient also nur als stützende Säule. In dicsem Falle hat der hintcrste Theil der Urne die Fähigkeit sich zuckend zusammenzuziehn.

Von besonderm Intercsse ist die Fortpflanzung der Vorticellinen. Einmal kommt eine Längstheilung hïufig vor; dabei zieht sich das Thier kugelig zusammen, und las Peristom verschliesst die Urne fest; die sich berührenden Hauttheile, Wimperorgan, Speiseröhre und Lirnenrand verschmelzen miteinander; der Körper wäehst in die Breite und der Fiern lagert sich quer, nun beginnt die Einschnürung von vorn, und wenn sie bis gegen den Stiel hinreicht, 
so ist auch schon ein neues Wimperorgan gebildet. Alsdann streckt sich ein Thier gerade aus, und nimmt den Stengel allein in Beschlag, während das andre sich rechtwinklig abbiegt, hinten sich einschnürt, und an dieser Stelle einen kräftigen Wimperkranz erhält. Durch das Arbeiten dieser Cilien reisst es sich endlich rom Sticle los, und schwimmt, mit den hintern Wimpern voran, frei im Wasser herum. Man hat diese Form Theilungssprössling genannt, und früher dafür eigene Genera errichtet. Ganz ähnlich ist die Bildung des Knospungssprösslinges, nur ist dieser viel kleiner als das Mutterthier. Hiebei bildet sich am hintern Leibessegment eine höckerige Auftreibung, die wälırend ihres Grösserwerdens sich abschnürt, und einen hintcrn Cilienkranz erhält. Bei diesem Process nimmt der Nucleus keinen Antheil, sondern in der fertigen Kinospe hat sich ein eigener Kern gebildet.

Endlich ist bei einigen die Fortpflanzung durch Embryonen entdeckt worden, die wir am Schlusse noch näher betrachten wollen.

Auch der Process der Einkapselung sowohl am Stiel, als ron demsclben getrennt, kommt bei den Vorticellinen vor.

Der Vollständigkeit wegen müssen wir hier noch einer besonders im Meere verbreiteten Gruppe von Vorticellinen erwähnen, die sich durch einen hyalinen Panzer oder eine Art Schale auszeichneu, worin das eigentliche Thier sitzt. Auch im süssen Wasser kommen einige dieser Thiere hier und da ror.

Wir theilen folglich die Vorticellinen ein nach ihrer Lebensweise und der Art ihrer Anheftung. Eine erste Gruppe bilden die stets frei herumschwimmenden Trichodinen, wclche immer mit einem hintern Wimperkranze versehen sind. Alle übrigen sind wenigstens eine Zeit lang festsitzend und zcrfallen wieder in zwei Gruppen, je nachdem sie mit einem Panzer versehen, oder ohnc einen solchen sind. Von den nackten ist nur eine Gattung ohne Stiel, und sitzt mit einer Art Saugnapf auf fremden Körpern fest (Scyplidia). Die gestielten zerfallen, je nachdem ihr Stiel contractil ist oder nicht, oder je nachdem er verzwcigt ist, oder einfach, in rerschiedene Gattungen. 
Wir erhalten also folgende Uebcrsicht der Gattungen:

I. Unt erfamilie (Trichodinea).

Zeitlebens frei schwimmend.

1. Gatt. Trichodina.

II. Unterfamilie (Vorticellinea).

Ungepanzert, die grösste Zeit des Lebens festgeheftet.
A. Ohne Stiel, mit Saugnapf
2. Gatt. Scyphidia.
B. Mit Stiel.

1. Stiel nicht contractil

3. Gatt. Epistylis.

2. Stiel eontraetil, mit einem Muskel vcrsehen.

a. Stiel vcrzweigt, Colonien bildend.

$\alpha$ ) Jeder Ast hat einen eignen Muskel

4. Gatt. Carchesium.

$\beta)$ Ein einziger verzweigter Muskel verläuft durch alle Aeste der Colonie 5. Gatt. Zoothamnium.

b. Stiel einfach, nie verzweigt 6. Gatt. Vorticella. III. Unterfamilie (Vaginicolea).

Mit hyalinem Panzer versehene Vorticellinen.

1. Das Thier am Grunde der Sehale fixirt.

a. Panzer gestielt.

7. Gatt. Cothurnia.

b. Panzer mit der hintern Fläche festsitzend.

8. Gatt. Vaginicola.

2. Das Thier sehwebt frei in der Schale, mit dessen Oeffnung es verwachsen ist.

9. Gatt. Lagenophrys.

\section{a. Nackte Vorticellinen. \\ I. Freie Vorticellinen.}

V1. 4. 1. Gatt. Trichodina. Dicse nieht gar häufigen Vorticellen schwimmen stets frei im Wasscr herum, indem sie mit ihrem hintern Ende, das einen Cilienkranz besitzt, vorausgehn. Die einzige eontractile Blasc und den bandartigen Nucleus haben sie mit den übrigen Thieren dieser Familie gemein. 


\section{Festsitzende Vorticellinen.}

2. Gatt. Scyphidia. Spec. physarum. Die wurmförmigen VI. 6. Thiere sitzen vermittelst eines sphincterartigen Apparates häufig an der Haut von Wasserschnecken (Physa fontinalis) und weichen in ihrer Körperform am meisten von den Glockenthierchen ab; indess haben sie das charakteristische Wimperorgan init jenen gemein.

3 Gatt. Epistylis. Aul einem steifen, dichotom verzweigten Stiele sitzen dic langgestreckten, urnenförmigen Körper dieser Thiere. Durch die Verzweigung des Stieles entstehen baumartige Colonieen. Der hintere Theil des 'Thierkörpers ist gewöhnlich etwas gefaltet und kann sich in einer raschen Bewegung umknicken, was durch feine Muskelfassern bewirkt wird. Sowohl durch Theilung, als durch Knospung werden freic Sprösslinge erzeugt, die, nachdem sic einige Zeit herumgeschwärmt haben, sich an einer passcnden Stelle wieder festsetzen und durch fortgesetzte Theilung eine neue Colonie erzeugen. Die zahlreichen Arten bestimmt man am leichtesten nach ihrer Körperform, der Form des Peristoms und des Stieles. So ist z. B. die E. brevipes, die sehr häufig auf VI. $\boldsymbol{g}$. kleinen Krebschen vorkommt, sehr leicht kenntlich durch ihren äusserst kurzen Stiel, der kaum 1/6 der Länge des Thieres erreicht. Die E. berberina kennzeichnet sich durch die feine Querstrei- VI. 8. fung und die cylindrische Form der Glocke. E. plicatilis, eine VI. 9. der hïufigsten Arten, durch den etwas wulstig ausgeschweiften Peristomrand, der bei den meisten andern Epistylisarten sonst ganz zart und nicht ausgeschweift ist. Mehrere Spec. z. B. berberina, articulutu etc. haben einen geglicderten Stiel. Bei E. articulata VII. 1. umgibt eine feine Hautfalte mauschettenartig das dünne und lange Wimperorgan. Man hat dieser Eigenthümlichkeit wegen die Gattung 0percularia errichtet.

4. Gatt. Carchesium. Diese Gattung besteht aus Vorticellinen, die eine verzweigte Colonie bilden, worin jedes Individuum seinen eignen Stielmuskel besitzt. Alle Individuen der Colonie sind gleich gross und ziehn sich einzeln zusammen, ohne ihre Bewegung den übrigen 'Thieren der Colonie mitzutheilen. 'T'heilt sich ein solches Thierchen, so behält die eine Hälfte den alten Stiel, während die 
VII. 2. andere einen eignen, neuen secernirt. C. poly pinum und epistylis sind Süsswasscrarten.

VII. 3. 5. Gatt. Zoothamnium. Auch diese Formen bilden eine stark vcrzweigte, baumartige Colonje, durch deren Aeste ein einziger, gemeinschaftlicher Muskel sich hinzieht. Es ist daher natürlich, dass auch die plötzliche Zusammenziehung der Aestchen gemeinsam ist für das ganze Bäumchen. Einzelne Thiere, die zerstreut in den Bifurcationen sitzen, werden viel grösser als die übrigen der Familie, bekommen einen hintern Wimperkranz und schwimmen fort, um die Gründung einer neuen Colonie anderswo anzulegen. Z. affine und Z. parasita findet man auf dem Flohkrebs, die meisten übrigen Arten sind marin.

VI1. 6. Gatt. Vorticella. Der Stiel dieser häufigen, glockenför-

4. 5. 6. migen Geschöpfe ist stets einfach, unverzweigt und von einem deutlichen, spiralig verlaufenden Muskel durchzogen. Ihr Nucleus bildet ein gekrümmtes Band. Auch sie sitzen oft in grosser Gesellschaft bei einander, bilden aber nie eine zusammenhängende Colonie. Sic kommen in den meisten Infusionen vor und fehlen überhaupt keiner Flüssigkeit, in der andcre Infusorien gedeihen.

Viele leben nur in Wasser, das in Fäulniss überzugehn beginnt, wie V. microstoma und convallaria, andere gedeihen nur in ganz klarem Wasser, z. B. V. nebulifera, häufig auf den Wurzeln der Wasserlinse. Durch Aufnahme von Nahrung oder andre Verhältnisse erscheint dieselbe Art oft verschieden gefärbt. Ueberhaupt ist es schr schwer, bestimmte Artenunterschiede bei dieser Gattung aufzufinden, und man muss sich darauf beschränken, Zeichnungen zu entwerfen, die den Habitus der Thiere einigermassen wiedergeben. Als Anhaltspunct für die Bestimmung aller Vorticellinen dient überhaupt die Beobachtung ihres Aufenthaltsortes. Die einen nämlich sitzen nur an bestimmten Pflanzen, anderc, obgleich sie keinc Schmarotzerthiere sind, pflegen sich vorzüglich, oder gar ausschliesslich auf der Oberfläche ganz bestimmter höherer Thiere aufuhalten, von deren Bewegungen ihre Lebensweise theilweise abhängig ist. 


\section{Gepanzerte Vorticellinen.}

Die meisten Repräsentanten dieser Gruppe gehören dem Meere an und nur foldenge seltenere Formen sitzen auf Wasserpflanzen oder lírebsthicren der süssen Gewässer.

7. Gatt. Cothurnia. Diese Gattung zeichnet sich durch eine VII. 8. hyaline, urnenförmige Schale, in deren Grund die Vorticelle angeheftet ist, aus. Die Schale sitzt mit einem kurzen Stiel auf dem Panzer unsrer Flusskrebse fest, und das Thierchen zieht sich bei Erschiitterungen ganz in dicselbe zurück (C. Astaci und Sieboldi).

8. Gatt. Vaginicola. Hat einen ähnlichen, aber ungestielten Panzer. Auch hier sitzt das 'Thier im Grunde der urnenförmigen Schale fest und kann sich in dieselbe zurückziehn. (An Wasserlinsen V. decumbens).

9. Gatt. Lagenophrys. Die topfartige Schale dieser Geschöpfe VII. 9. ist mit einer Seitenwand kleinen Süsswasserkrebschen (Cyclopsine) angeheftet, und das frei an der Schalenöffnung hängende Thier kann sich nicht in dieselbe zurückziehn ( $\mathrm{L}$, vaginicola und ampulla).

Schliesslich erwähnen wir noch kurz einiger seltener Vorticellenformen, um die Reichhaltigkeit dieses eigenthümlichen Infusorientypus darzuthun. Oft trifft man auf dem Flohkrebs (Gammarus pulex) eine merkwürdige Vorticellinenform von cylindrischer Gestalt, die kein eigentliches Wimperorgan trägt, sondern deren Peristom in mehreren spiraligen Windungen $\mathrm{nm}$ eine Mittellinie aufgerollt scheint. Es ist dies die wimperlose Spirochona gemmipara, deren Speciesname von dem constanten Vorkommen von Knospen an dem Mutterthier herrührt.

Endlich erwähnen wir noch des Ophrydium versatile, dessen VII.. hintere Partie sehr beweglich und dehnbar ist, während die rordere Partie des langgestreckten Cylinders in nichts ron dem gewöhnlichen Vorticellentypus abweicht. Dies 'Thier sondert eine gallertige hinfällige Hülle um seinen Körper aus, die man fälschlich für einen eigentlichen Panzer angesehen hat. Zahlreiche Gesellschaften sind dann colonieenweise in solchen Gallertmassen. 


\section{Ordnung Suctoria.}

Saugende Infusorien.

\section{Cinzige Familie Acinetae.}

Die Infusorien der vierten und letzten Ordnung sind erst kürzlich von den übrigen getrennt worden, nachdem man ermittelt hatte, dass ihre feinen, strahlenförmigen Anhängsel wahre Saugröhren bilden, die an ihrem Ende einen kleinen Saugnapf in Form einer geknöpften Anschwellung tragen. Bisher hat man diese Thiere bald zu den Rhizopoden (Actinophrys), bald zu den Vorticellinen gerechnet. Im erwachsenen Zustand sind sie ganz unbeweglich und nähren sich vermittelst der zahlreichen Saugröhren, mit welchen sie den Inhalt anderer Infusorien aussaugen. Fährt ein kleines Infusorium, z. B. eine unvorsichtig springende Halteria an den Röhrenkranz, welcher eine solche Acinete umstrahlt, so ist es sogleich gefangen, stellt seine Bewegungen ein und stirbt.

Es hat diese Erscheinung viel Aehnlichkeit mit dem Verfahren des früher beschriebenen Actinophrys Sol. Auch hier scheint ein Gift lähmend auf das gefangene Thier zu wirken, aber der weitere Verlauf ist ein ganz anderer. Während sich beim Sonnenthierchen die Strahlen mitsamt der Beute in die Körpersubstanz einziehn, und darin verschwinden, biegen sich dieselben bloss ein wenig bei den Acineten; einige Röhren werden sichtlich weiter und man sieht durch dieselben einen Strom feinkörniger Flüssigkeit vom Gefangenen zum Räuber übergehn; die andern Strahlen bleiben dünn, und scheinen nur zum Festhalten der Beute zu dienen. Das gefangene Thier verliert immer mehr an Inhalt, und zuletzt fällt seine leere Hülle als unkenntlicher Klumpen von den Saugröhren ab. Da die Acineten sehr gefrässig sind; so bildet ihre Umgebung oft ein wahres Schlachtfeld von getödteten Infusorien. Ist. die Beute zu gross und zu kräftig, so bleibt die Acinete daran hängen, wird fortgerissen und womöglich abgestreift; oft aber erliegt auch ein grosses Infusorium diesen Blutsaugern, wenn es ihm nicht gelingt, den lästigen Feind durch Reiben loszuwerden. Im übrigen haben die Acineten mit den Ciliaten die contractile Blase und den 
länglichen Nucleus genein, nur ist natürlich nicht nur ein Mund rorhanden, sondern so viel Nahrungsöffnıngen, als sie Saugröhren haben. Durch diesc Saugröhren strömt der Körperinhalt der getödteten Thiere rasch bis zu einem bestimmten Puncte im Parenchym der Acinete und von dort fängt er an, langsam mit der übrigen Blut- oder Nahrungsflüssigkeit des Leibes zu cireuliren.

Der Process der Theilung scheint seltener vorzukommen, als der der Enbryobildung. Die Embryonen entstehen aus Segmenten des Kernes und wachsen zu riemlich grossen, mit einem Cilienkranz versehenen Infusorium aus, die, unbeschadet für das Mutterthier, dessen Hülle durehbreehen, um frei in der umgebenden Flüssigkeit herumzuschwimmen. Haben sie einen, ihrer Entwiekelung günstigen Ort gefunden, so setzen sie sich fest, und erhalten Saugfäden, indem sie nach und nach die Form des Mutterthieres annehmen. Die Acineten haben aueh eine grosse Fähigkeit sich einzukapseln, wobei ihre Saugarme verschwinden.

Zur Bestimmung der zahlreiehen Arten sowolıl, als auch für das Studium der merkwürdigen Lebensweise dieser 'l'hiere, ist es von grosser Wichtigkeit, sieh den Fundort oder Standort derselben zu merken. Wie bei den Vorticellinen leben auch hier die einzelnen Arten vorzugsweise auf ganz bestimmten Pflanzen oder höhcren Thieren, von denen sic herumgetragen werden. Viele werden in Gesellschaft von Epistylis, Carchesium etc. so constant getroffen, dass ihre Beziehung zu diesen Vorticellinen als wesentliche Lcbensbedingung erschien, und so entstand dann, basirt auf nicht ganz genügende Untersuchungen, die Theoric der Acinetenphase der Vorticellen, die wir kurz berühren wollen. Oft findet man gewisse Acinetenformen, an den Stämmchen bestimmter Vorticellinen angeheftet, Cysten von beiden liegen in der Umgebung und Embryonen und Knospungssprösslinge durchziehn das Sehfeld. Man hat daher geglaubt, die Vorticellinen erzeugten Enbryonen, die sieh zu Acineten entwickeln, und aus diescn enstünden dann, durch eine eigenthümliche Metamorphose wiedcr Glockenthierehen. Indess ist das Verhältniss in der That ein ganz anderes, und die Nachbarsehaft der Acineten ist für die Vorticellinen gar keine so freundschaftliche, da sie dieselben als Weideplätze benutzen und ihre Sprösslinge und Urnen gierig aussaugen. 
Ueberhaupt seheinen die festsitzenden Vorticellinen ein beliebter Aufenthaltsort für Schmarotzer zu sein, und ehe man den wahren Saehverhalt kanute, wurden begreiflicher Weise viele Formen der Parasiten mit denen der Glockenthierehen selbst verweehselt. Jede Art von Acineten hält sich hiebei an eine ihr besonders convenirende Vortieellenart, ist aber leieht von ihr zu unterseheiden, da der Stiel der Acinete viel feiner, nie gestreift oder elastisch ist, und aueh nieht an derjenigen Stelle des Vorticellenbäumehens angeheftet erseheint, die dureh eine dichotome Theilung angezeigt wäre; sondern sie ist unsymmetriseh an irgend einem beliebigen Aste der Colonie befestigt. Aueh andere Infusorien setzen den Vorticellinen stark zu: so z. B. eine Art Amphileptus (Meleagris), welcher die Glocken der Epistylis plicatilis fressen, und sieh oft am Stiele der Epistylis einkapseln soll. Diese runden Kapseln haben viele contractile Blasen und lassen einen Amphileptus auskricehen, den man bei ungenügender Beobachtung ebenfalls für eine Entwieklungsstufe der Epistylis ansehen könnte.

Für die Eintheilung in Gattungen ist es massgebend, ob die Thiere nackt oder besehalt, und ob sie gestielt oder ungestielt seien.

\section{a. Nackte Acinetinen.}

VIII. 1. Gatt. Podophrya. Diese häufigste Gattung hat einen mehr

1. 2. 3. oder weniger ovalen Körper, der einem kurzen Stiel aufsitzt. Die Saugstrahlen gehen gewöhnlich nur von einzelnen Stellen büsehelweise $a b$, und starren nach allen Richtungen hin. Hat ein solehes Thier sich vollgesogen, oder entwickelt es in seinem Innern grosse Embryonen, so seheinen die Strahlen mehr gleichmässig über eine bestimmte Körperfläche vertheilt. Die rersehiedenen Arten sitzen meist an Wurzeln der Wasserlinsen (Lemna) oder auf bestimmten Vorticellinenbäumchen als Schmarotzer. So z. B. P. eothurnata, auf Wasserpflanzen, P. eyelopun auf einem kleinen Krebschen (Cyclops quadricornis), P. quadripartita auf Epistylis plicatilis u. s. w.

VIII. 4. 2. Gatt. Sphaerophrya sind ganz kleine, rundliche, ungestielte Acinetinen, die sieh mit ihren wenigen kurzen Saugröhrchen oft an grosse Infusorien wie Zeeken ansetzen, und ron ihnen herumgetragen werden. Z. B. Sph. pusilla häufig an Oxytrichen. 


\section{b. Geschalte Acinetinen.}

3. Gatt. Acineta. Auf einem zarten Stiele sitzt eine äusserst VIII. 5. feine, becherförmige Schale, in welcher der 'Thierkörper von kugeliger Form liegt und nach allen Seiten feine Saugrŏhren aussendet. Die Mehrzahl dieser 'Thiere ist marin.

4. Gatt. Solenophrya. In einer sehr zarten, schüsselförmigen VIII. 6. Schale, die mit ihrem breiten Boden an fremden ISörpern befestigt ist, liegt der schleimige Leib dieser 'Thiere, welcher in mehreren vereinzelten Büscheln kurze Saugröhren aussendet.

\section{Anhang. \\ Entwickelungsgeschichte.}

Wir können diese Uebersicht über die mannigfaltigen Infusorienformen nicht schliessen, ohne noch einen kurzen Blick auf die geschlechtliche Fortpflanzung dieser Thiere zu werfen.

Schon bei den Flagellaten haben wir einige Verhältnisse kennen gelernt (Volvox globator), welche die grösste Analogie zur geschlechtlichen Vermehrung höherer Thiere darbieten; in neuerer Zeit hat eine Reihe von Forschern (besonders BaldBIANI und Steir) bei den Ciliaten verschiedener Familien ganz auffallend ihnliche Fortpflanzungsprocesse verfolgen können, die wahrscheinlich in Bälde als allgemein verbreitet befunden werden möchten.

Bei Gelegenheit der Conjugation haben wir oben (Seite 19) schon gesehen, dass sich bei vielen Iufusorien das Kernkörperchen in feine Stäbchen auflöst, die nach lebhaft schwingenden Bewegungen scliliesslich in die Substanz des Kernes einzudringen, und sich mit derselben gänzlich $z u$ verbinden scheinen. Man hat darin eine Art von Selbstbefruchtung gesehen. Möglicherweise ging in vielen Fällen diesem Processe eine Conjugation vorher, indess möchte aus so vereinzelten Beobachtungen, wie sie bisher vorliegen, 
schwerlich eine allgcmeine Schlussfolgerung berechtigt sein. Nun aber treten eine Reihe vcrschicdener Entwicklungserscheinungen auf, die wir bei einigen bckanutcn Formen näher betrachten wollen. Wir wählen zuerst eine der grossen Oxytrichen (Stylonychia mytilus), bei welcher von verschicdenen Beobachtern eine Embryobildung entdeckt worden ist. Man sieht die zwei Kerne mit einer Furche oder Spalte durchzogen, in welche die stäbchenförmigen Spermatozoen aus dem seitlich am Kernc sitzenden Kernkörperchen eingedrungen sind. Dann dehnt sich der Nucleus in die Länge, einzelne Theile desselben schnüren sich ab und bilden kleine Kügelchen, die sich mit eincm hellern Hof umgeben, und nach und nach als grosse, rundliche Zcllen mit eincm dunklern centralen Körper erscheinen. Dieser letztere wächst in die Lünge, fängt an sich hin und her zu bewegen und zu drehcn, und schliesslich bemerkt inan an ihm einen feinen Ueberzug von Wimperhaaren, nebst einigen stärkern geknöpften Tentakelı, ganz ähnlich den Saugröhrchen der Acineten. Die umhüllende Membran zerreisst, und der junge Embryo bewegt sich frei im Parenchym des Mutterthicres. Schon früh ist dann an diesem Sprössling eine kleine pulsirende Blase und ein dunklerer Kern zu beobachtcn. Nach einiger Zeit nähert cr sich der Körperoberfläche und schlüpft dann durch einen feinen Riss in der Nähe des

VIII. 9. Mundes heraus, um sich lebhaft im freien Wasser herunıutummeln. Aehnliche Vorgänge hat man bei Oxytricha, Pleurotricha, Urostyla, Chilodon, Paramecium, Colpoda, Nassula, Bursaria und Stentor gefunden; bei allen schlüpft ein bewimperter, mit einigen Tentakeln versehener Embryo aus. Bisher konnte eine weitere Entwicklung des dem Mutterthier so unähnlichen Sprösslings noch nicht verfolgt werden. Es würde sich fragen, sind jene 'Tentakeln blosse Hautläppchen, oder wirklich gestielte Saugnäpfe, wie bei den Acineten, und gingen diese Embryonen durch Mangel an Nahrung zu Grunde? EBerhard will nämlich die gänzliche Entwicklung der Embryonen von Bursaria truncatella, einem sehr grossen, an Wasserlinsen lcbenden Infusorium, rerfolgt haben. Sie setzten sich fest, verloren ihre Tentakeln und entwickelten allnühlich eine deutliche Peristombewimperung, wie sie das Mutterthier hatte; indess bedarf eine einmalige Beobachtung so schwer zu verfolgender Vorgänge noch der weitern Bclege. 
Wie schwierig solche Untersuchungen aber sind, erhellt schon daraus, dass die verschiedenen Forscher die Anzahl und Grösse der beobachteten Embryonen ganz ungleich angeben: während der Eine nur wenige grosse Embryonen sah, fand der Andere bei demselben Infusorinm eine Menge kleiner, und möglicherweise existiren bei demselben Thier verschiedene Entwicklungsurten. Auch über das wcitere Schicksal des Mutterthicres lauten die Berichte verschieden; dasselbe geht nach einigen Beobachtern bald nach der Geburt des Embryo zu Grunde, während andere ianden, dass der Embryo aus einer frei sich bildenden Spalte heraustrete, die sich sogleich ohne irgend welche Narbenbildung schliesse, und dass dieser Process die übrigen Lebenserscheinungen des Mutterthieres in keiner Weise becinträchtige.

Eine etwas abweichende Embryobildung wurde bei den Vorticellimen beobachtet. So berich tet Clapariene von Eipistylis plicatilis, dass er oft Exemplare mit einem seitlichen kleinen Höcker oder einer Warze gefunden, welch letztere nach aussen eine feine Oeffnung gehabt habe. In diesen Glocken fand er stets einzelne eiförmige Embryonen in verschiedenen Entwicklungsstadien, die aber nackt und nur mit einem zarten Wimperkranz bewaffnet gewesen seien. Diese Embryonen, die ebenfalls aus abgeschnürten Segmenten des bandförmigen Nucleus entstanden, hätten sich dann in die Nähe des obenerwähnten seitlichen Höckers bewegt, und seien dort einige Zeit wie in einem Uterus liegen geblieben, um zu wachsen und endlich durch dic feine Oeffnung der Warze frei heraus zu treten. Ihr weiteres Schicksal konnte nicht verfolgt werden. Sie unterscheiden sich also wesentlich von den oben erwähnten Embryonen der übrigen Infusorien durch den Mangel eines allgemeinen Wimperkleides und die Abwesenheit von geknöpften Tentakeln, gleichen also ganz den sofort zu beschreibenden Embryonen der Acineten, was die Entstehung der auf Scite 55 erwähnten Theorie von der Ancinetenphase der Vorticellen veranlasst haben mag.

Bei den Acineten endlich, jenen fast unbeweglichen, mit Saugröhren versehenen Infusorien, hat man eine ahnliche Embryobildung beobachtet, wie bei den Vorticellinen. Ein oder zwei grosse Embryonen entstehen im Innern des Muttcrthieres; sie sind nackt, VIII. I. nur mit einem kräftigen Cilienkranz um dic Mitte des Kö̈pers ver- 
sehen, und in ihrem Innern ist ein Kern und eine contractile Blase zu erkennen. Sie sind also dem Mutterthier ganz unähnlich, und treten nach einiger Zeit durch einen schnell sich schliessenden Riss des mütterlichen Leibes in das freie Wasser heraus, um nach stundenlangem lebhaften Herumschwimmen sich an einem passendem Orte festzusetzen. Dann verlieren sie ihre Cilien und treiben allmählich jene feinen geknöpften Saugröhrchen hervor, die sie als Acineten charakterisiren. Es ist also eine den übrigen Infusorien gerade entgegengesetzte Entwicklungsform, welche hier zu Tage tritt.

Schwerlich wird ein Anfänger genügende Geduld haben, so verwickelte Verhältnisse zu verfolgen; sie durften aber nicht unberührt bleiben, da sie uns einen wichtigen Fingerzeig geben, wie die Natur unter den verschiedensten Lebensformen sich stets derselben Mittel und Wege bedient, um den gleichen Zweck zu erreichen. Wenn auch das massenhafte Auftreten und die allgemeine Verbreitung der Infusorien gewiss wesentlich durch die hohe Theilungsfähigkeit dieser Geschöpfe bedingt wird, so scheint doch auch bei ihnen eine geschlechtliche Fortpflanzung ein nothwendiges Element zur dauernden Erhaltung der einzelnen Thierarten zu bilden.

Seite 27, Zeile 2 v. o. lies Anthophysa. 


Hololricha.
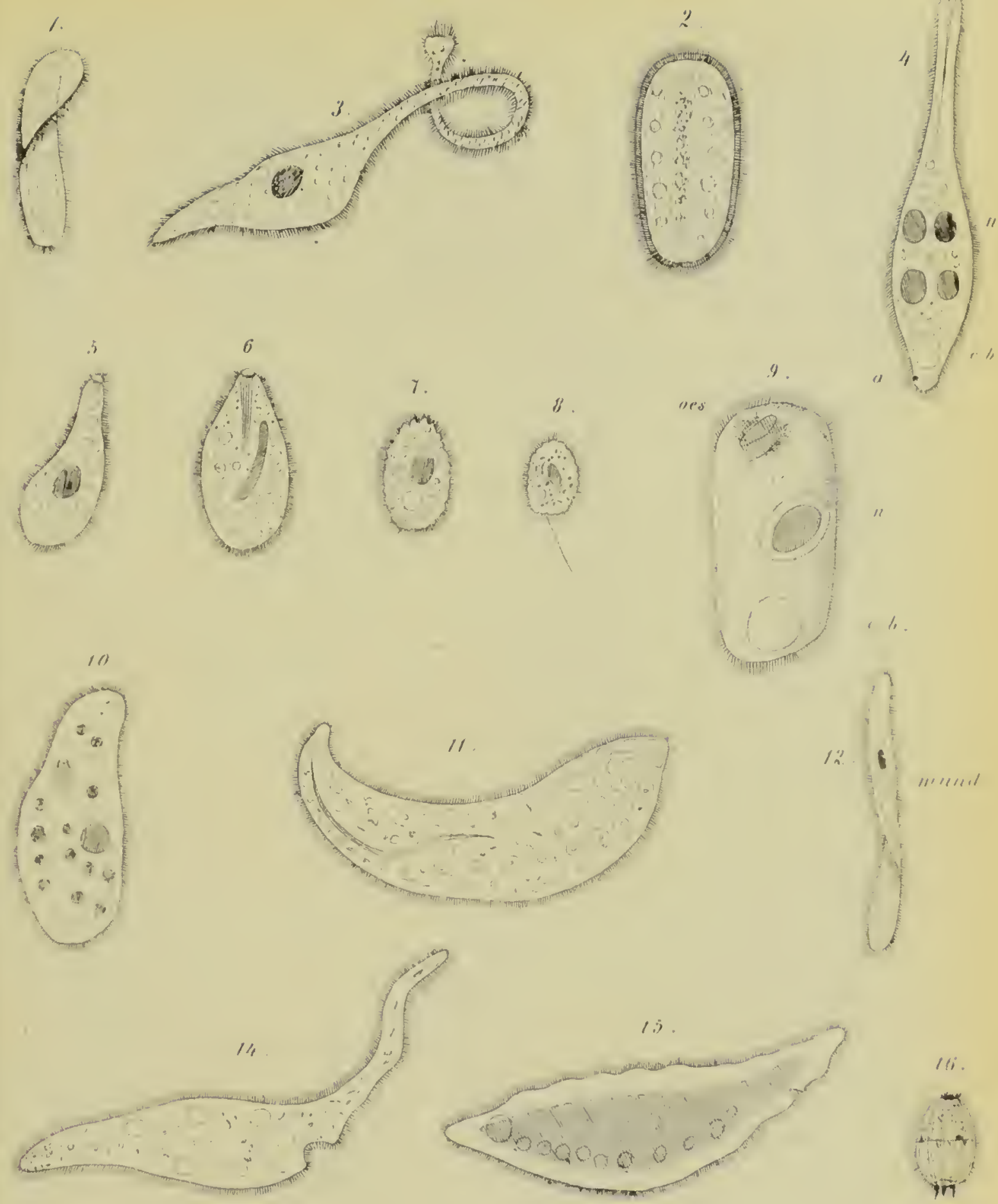

Lith Hoter "Zürn.

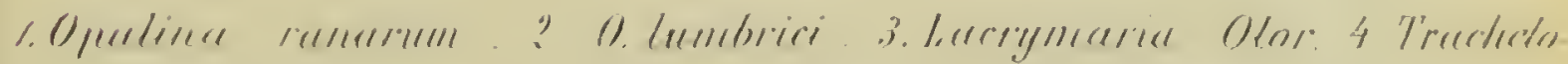

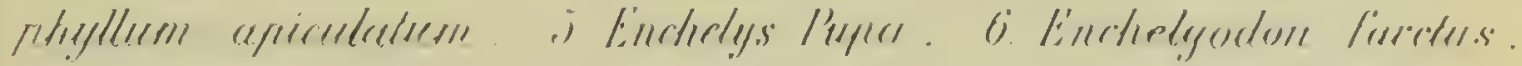

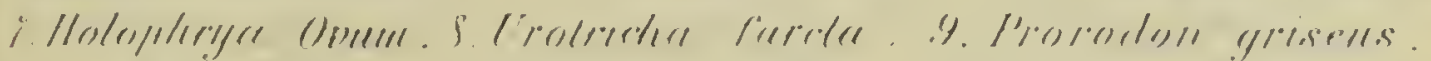

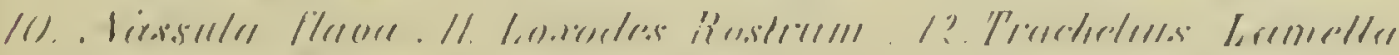

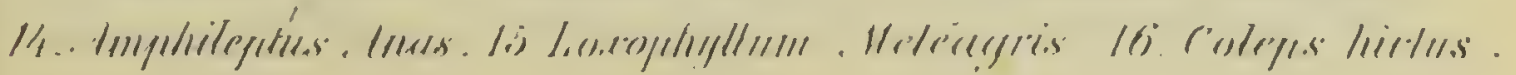





\section{Heterotricha.}

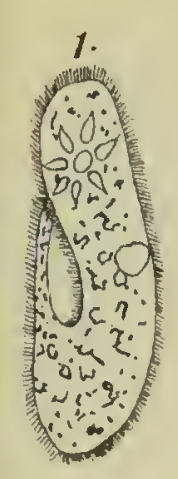

2.
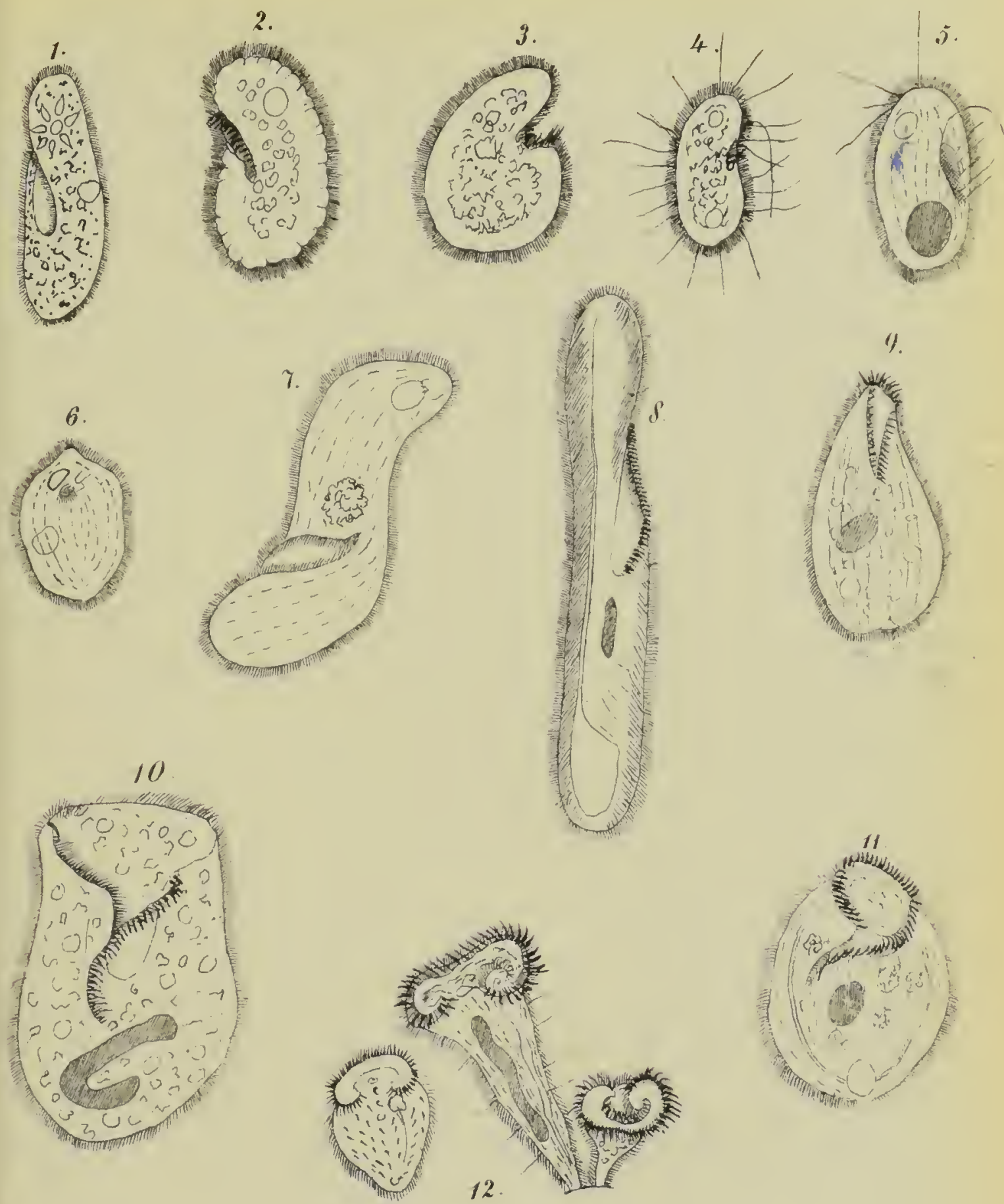

With Hofer, Zürich.

1. Parameaum Aurelex. 2. P. Bursarna. 3. Colnada Curdullus 4. Cyclidum'saltaus. 5. Oyclidum Chrysalis 6 Ophryoglena litron Y hetopus sigmoides. 8. Spirostomum Teres. 9. Balantidium Entoroon 10. Bursarca decora. 11. Leucophrys Patula. 12. Stentor polymnrphus. 



\section{Ilyoutrichat.}
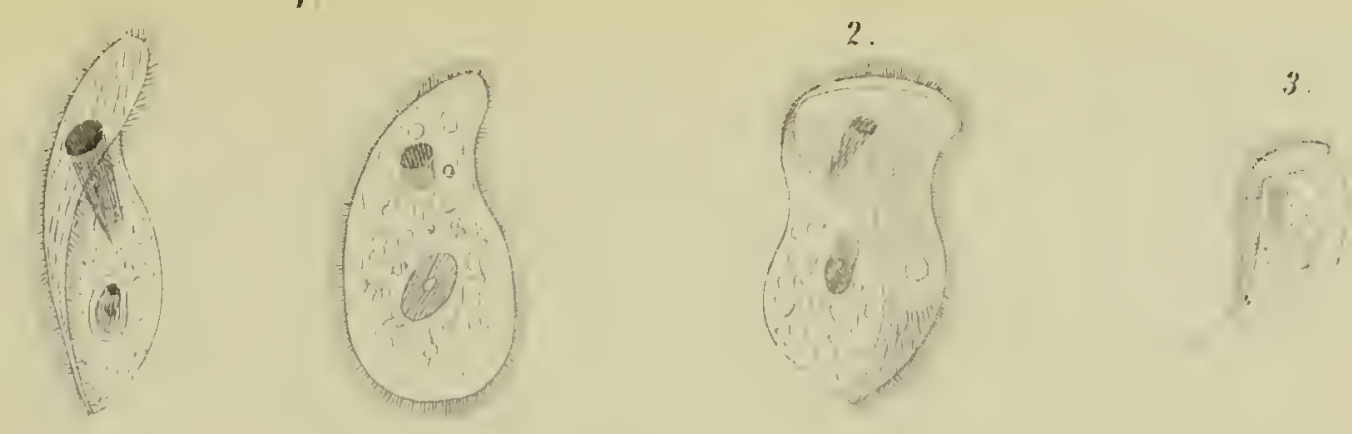

.5.

is
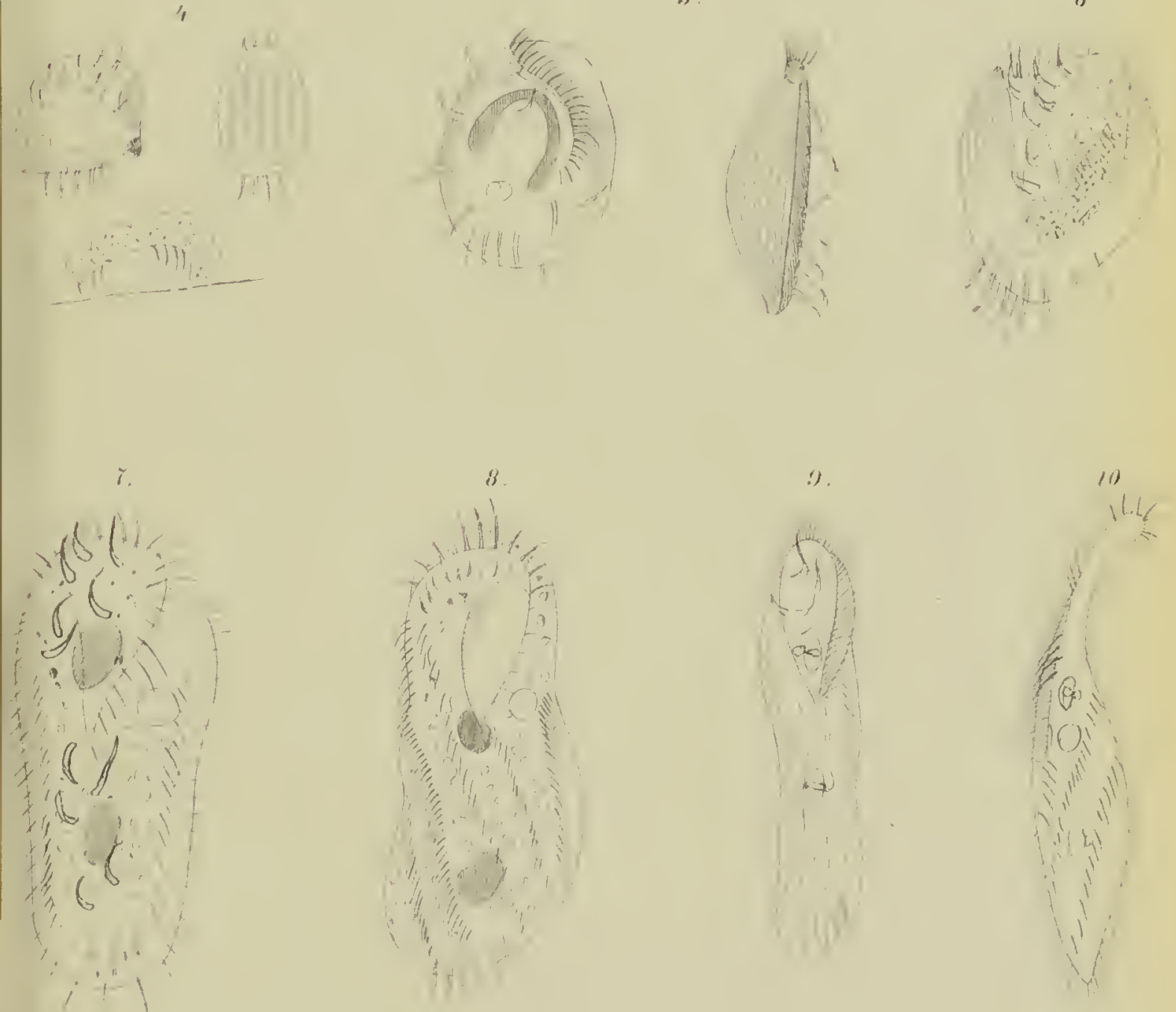

Lith. Hofer, Zuric

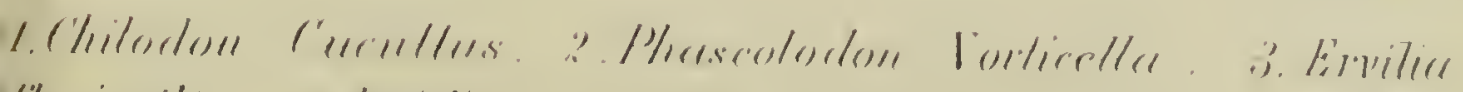

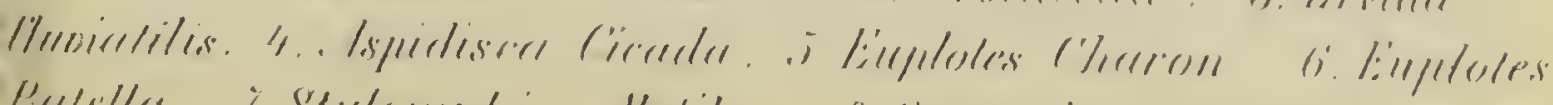

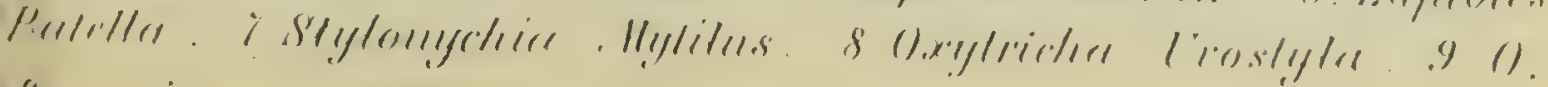

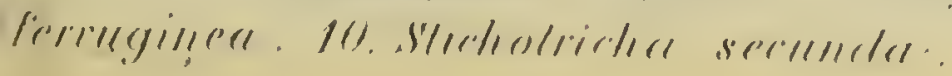





\section{Peritriclai.}

$\stackrel{2}{\wedge}$

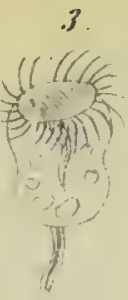

a.

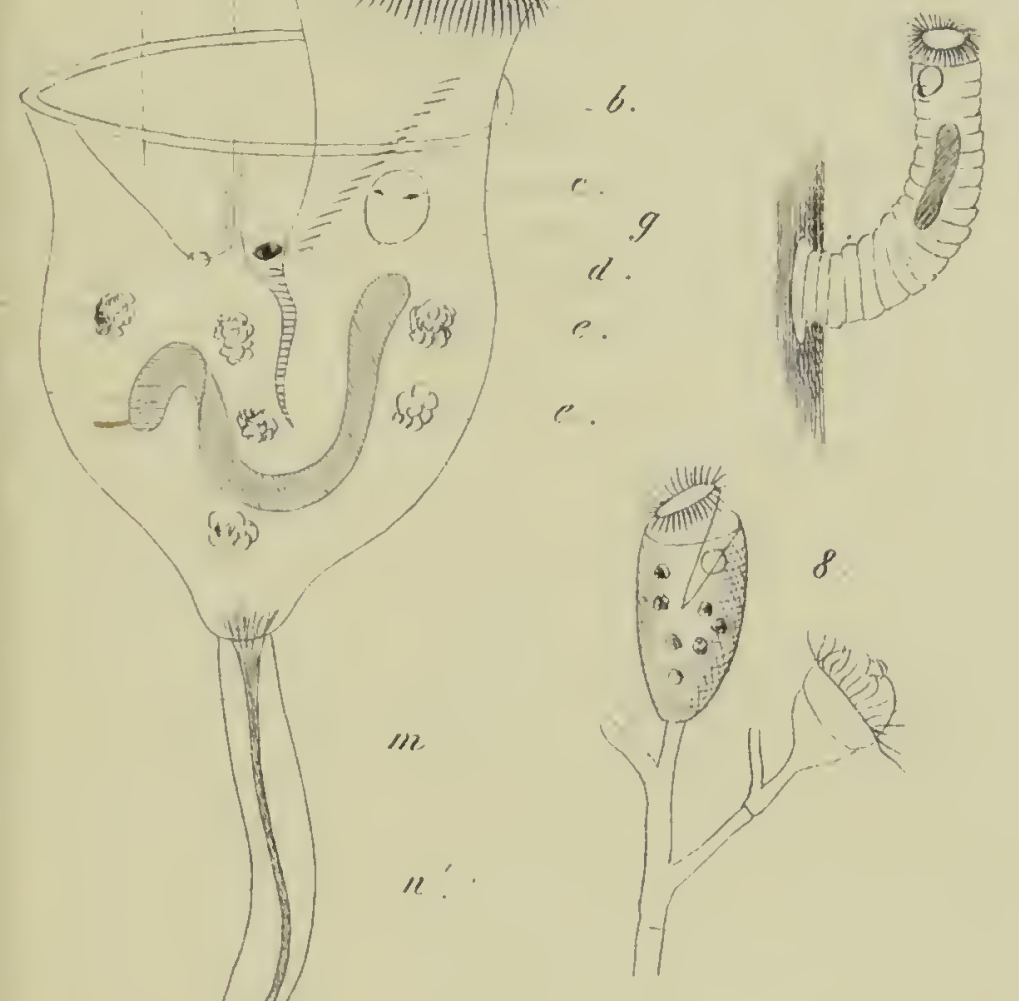

10

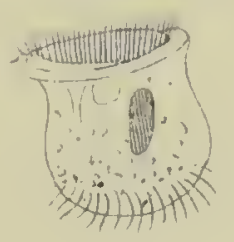

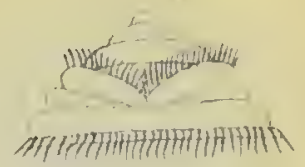

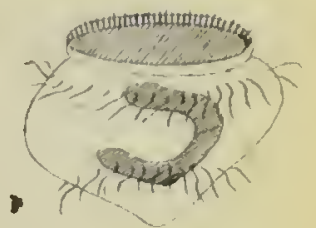

$\gamma$

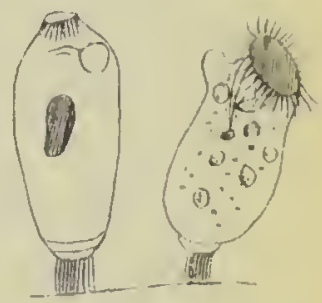

9.

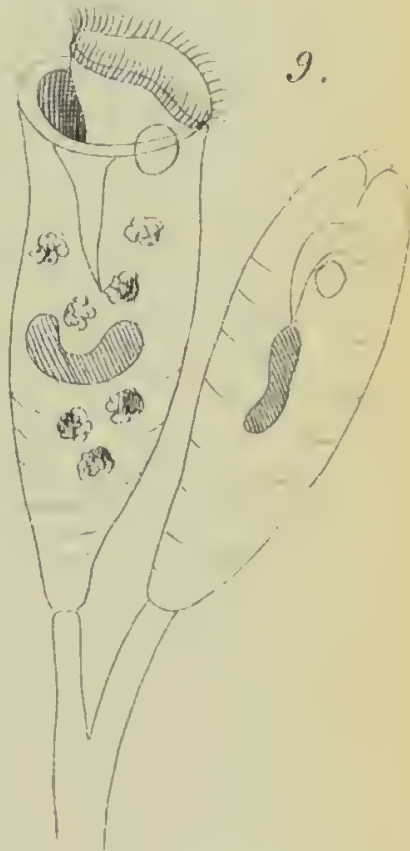

Lith. Hofer, Zurich

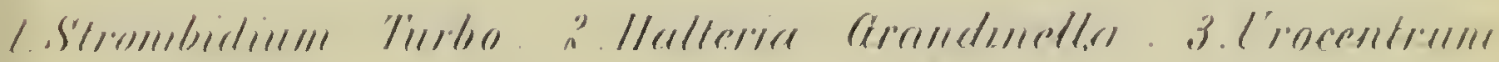

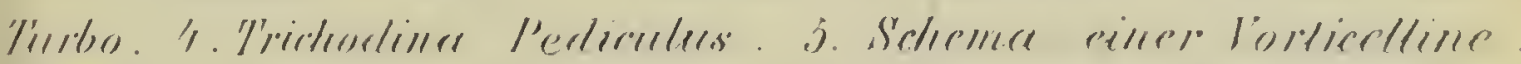

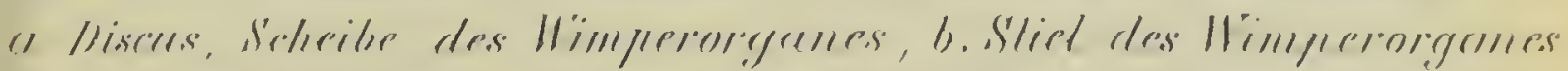

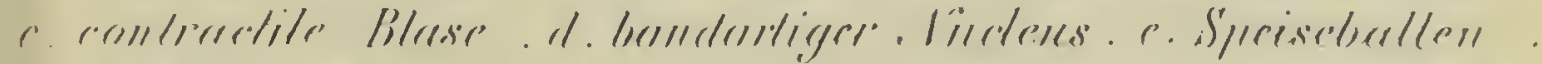

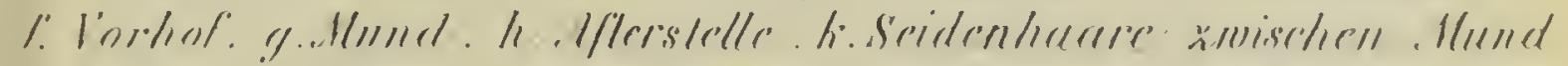

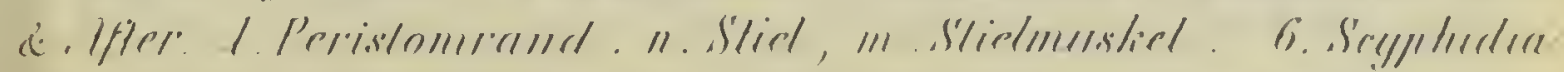

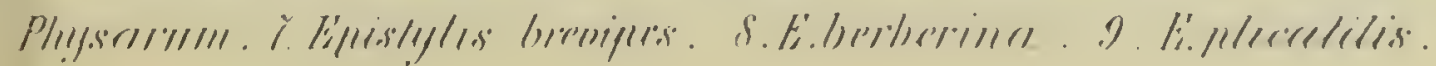

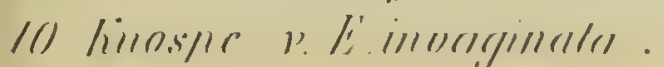





D I E

\section{MIKROSKOPISCHEN 'THIIERE}

DES

\section{SÜSSWASSER-AQUARIUUIS.}

FÜR FREUNHE

DES MILROSROPLS UND DER NATURWLSENSSCHAFTEN,

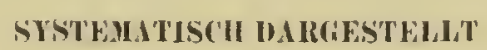

VON

DR. GUSTAV SCIIOCH.

II. $\mathrm{BUCH}$.

DIE RÄDERTHIERE.

MIT ACIT' LITHOGRAPHIRTEN TAFEIAN

I.EIP'ZIG.

VERIAAG VON ARTHUR FELIX.

$1 \times 6 \subseteq$. 



\section{Inhaltsverzeichniss.}

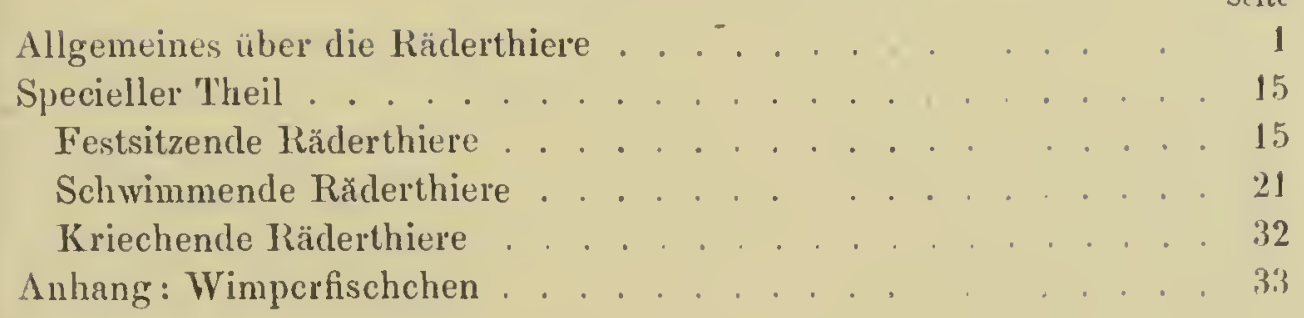

\section{Index generum.}

\begin{tabular}{|c|c|c|c|c|c|c|c|c|c|c|c|c|c|c|c|c|}
\hline & & & & & & & & Seite & & & & & & & & Seite \\
\hline Actinurus & & & & • & & & $\cdot$ & 33 & Floscularia & & & & & & & 16 \\
\hline Anthos & & . & & . & . & & & 20 & Furcularia & & & & & & & 30 \\
\hline Anuraea & . & & & . & . & & & 23 & Hydatina & & & & & & & . \\
\hline Apus & • & • & & 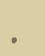 & • & & . & 21 & Ichthydium & 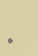 & & & & & & \\
\hline Brachionus & & • & . & 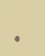 & 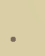 & & & 31 & Lacinularia & & & 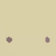 & & & 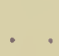 & 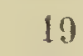 \\
\hline Callidina & & • & • & . & . & & & 33 & Lepadella & & & & & & & \\
\hline Chaetonotus & & . & & & • & & . & 34 & Limnias . . & & & & & & . & $1 ?$ \\
\hline Colurus . & . . & . & . & . & . & & & 30 & zocerca & & & & & & & 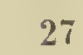 \\
\hline Cycloglena & & . & $\bullet$ & & & & & 26 & Megalotrocha & & & & & & & 2 \\
\hline Diglena . & . . & . & & . & . & & & 26 & Melicerta & & & & & & & 18 \\
\hline haris & & • & & • & • & & & 30 & cerca. & . & & . & & & & 2 \\
\hline Distemma & . . & • & & . & • & & & 26 & labis & & & & & & & \\
\hline plea & • & • & • & . & • & & • & 25 & Monostyla & & & & & & & 2 \\
\hline Eosphora & & & & . & & & & 25 & Monuraea & & & & & & & \\
\hline Euchlanis & & & & & & & & 29 & Noteus. & & & & & & & \\
\hline
\end{tabular}




\begin{tabular}{|c|c|c|c|c|c|c|c|c|c|c|c|c|c|c|c|c|}
\hline & & & & & & & Seite & & & & & & & & & Seite \\
\hline Notommata & & & & • & & & 25 & Salpina & & & & & & • & & 30 \\
\hline Oecistes & & & & & & & 19 & Scaridium & & & & & & & & 30 \\
\hline Philodina & & & & & & & 33 & Squamella & & & & & & 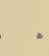 & & 31 \\
\hline Pleurotrocha & & & & & & & 25 & Stephanoceros & & & & & & & & 11 \\
\hline Polyarthra & & & & & & & 23 & Stephanops & & & & & & & & . \\
\hline Pterodina & & • & & . & & & 23 & Synchaeta & & - & & & & . & & \\
\hline Ptygura & & & & • & & & 20 & Theorus . & & $\cdot$ & & & & & & \\
\hline Rattulus & & . & & . & • & & 28 & 'Triarthra & & & & & & : & & \\
\hline Rotifer & & & & & & & 33 & Tubicolaria & & & & & & & & \\
\hline
\end{tabular}




\section{Räderthiere.}

\section{Allgemeiner Theil.}

In dem vielgestaltigen Thierkreise der Würmer hat man von jeher bis in die neueste Zeit eine cigene Klasse für die parasitischen oder Eingeweidewürmer errichtet, obwohl die hierher gelıörigen 'I'hicre nichts mit einander gemein haben, als dass sie Schmarotzerthiere sind und die Eingeweide höhercr Thicre zu ihrem Wohnsitz wählen. Aus ganz demselben, rein biologischen Grunde sind ron jeher dic Räderthiere, mit denen wir uns hicr näher beschältigen wollen, mit den Infusorion und Wurzelfiisslern in cine gemeinsame 'Thiergruppe verschmolzen worden, obwohl sie viel höher organisirt sind, als jene Urthiere.

Und in der That ergicbt sich wenigstens für den Laien, der mit dem mikroskopischen Leben des Süsswassers sich vertraut machen will, die Nothwendigkeit, jene beiden Thierklassen zugleich miteinander zu studiren, so häufig ist das gemeinsame Vorkommen von Räderthicren und Infusoricn in demselben Wassertropfen. Dicse enge Verbindung der sonst sehr verschiedenen Geschöpfe erstreckt. sich aber auch noch auf andere Verhältnisse, als bloss den gemeinsamen Wohnort, weshalb nicht nur Iaien, sondern selbst hochbegabte Forseher sich verleiten liessen, die ähnlichen Lebenscrscheinungen dieser Thiere zur systematischen Grundlage zu machen, und dahin kamen, nicht nur diese getrennten Thierklassen in cinc cinzige zu vercinen, sondern sogar der niederen Gruppe der Infusorien eine höhere, nur den Raiderthieren zukommende Organisation 
zuzuschreiben. In diese Bahn liess sich Ehrenberg, der Begründer der Mikrographie, hinreissen, und es ist unter jenem Irrthume lange Jahrc die weitcre Entwicklung. dieser Wissenschaft gehemmt worden. Machen wir uns daher vorerst ein allgemeines Bild der Aehnlichkeiten der beiden in Frage stehenden Thiergruppen, um nachher um so sicherer die fundamentalen Differenzen ihrer Organisation zu würdigen.

Die Rädcrthiere leben alle im Wasser. Wenige Formen ziehen das Mecrwasser dem süssen vor; am zahlreichsten erscheinen sie in stehenden, mit Wasserpflanzen belebten Teichen, Gräben, sanftfliesscnden Bächen, wo sie in dem Gewimmcl von Algen und Infusorien ein grosses Contingent der Lebensformen bilden; weniger hïufig finden sie sich in Seen, Flüssen, Brunnen oder faulenden Pfützcn; einigc kommen oft in feuchter Erde, Sand und Anschwemmungen allerlei Art vor und bcsitzen die Fähigkeit auszutrocknen und bei Befeuchtung wieder aufzulcben.

Uebereinstimmend mit den Urthieren sind die Räderthiere fast ausschliesslich mikroskopische Geschöpfe, wenn auch durchschnittlich grösser als jene. Die grössten unter ihnen erreichen eine Grösse von $1 / 2{ }^{\prime \prime}-2 / 3 "$ ", während die kleinsten Formen bis gegen $1 / 100^{\prime \prime \prime}$ heruntcrgehen. Ihrc Nahrung besteht, wie die der Infusorien, aus Algen, Pflanzenmoder, Infusorien und andern Räderthieren, wie denn auch sie selbst vielfach den grössern Infusorien zur Beute fallen.

Einige sitzen mit dem schwanzförmigen Körperende an Wasserpflanzen festgeheftet, wie etwa unter den Infusorien die Eipistylisund Vorticella-Arten, und bilden oft ähnliche Colonien; andere schwimmen lebhaft im Wasser herum, wie Bursarien und Stentoren, indem sie mit dem Wimperkranz an Vorderende des Körpers flimmern; einige machen Sprünge oder schwimmen stossweise vermittclst langer Schwanz- und Brustflossen, ähnlich wie die Halterien mit ihren Seidenhaaren, und andere endlich kriechen blutegelartig oder wie Spannerraupen, mit Fuss und Kopfende sich abwechselnd fixirend.

Der symmetrisch gebaute Körper sitzt oft in einer hyalinen oder incrustirten Gallerthülle, wie bei den Infusorien die Vaginicolen, oder bei den Wurzelfüsslern die Arcellen und Diffugien. 
Was aber am meisten zur Verwechslung mit Infusorien reizt, das ist die sehr entwickelte Bewimperung ihres vordern Körperendes, welche zugleich als Bewegungsorgan dient, wie z. B. bei Stentor, oder als Ernährungsapparat, indem dadurch im Wasser ein zuführender Strudel erzcugt wird, wie bei den Vorticellinen. Bei geringer Vergrösserung sieht man auch bei vielen Räderthieren eine dickwandige, periodisch sich contrahirende Blase und oft einen oder zwei rothe Pigmentflecken am vordern Körperende, wie z. B. bci Euglena.

So weit ungelähr gehen die Aehnlichkeiten zwischen Räderthieren und Infusorien, und cs ist leicht begreiflich, dass die ersten Beobachter diese Geschöpfe als zusammengehörig betraclıteten; die charakteristischen Differenzen indess werden uns sogleich deutlich bei der genaueren Betrachtung der Organisation der Räderthiere.

Körperbeschaffenheit und Form. Die formlose Sarcode, welche den Hauptbestandtheil des Körpers der Urthiere ausmacht, bildet allerdings auch im Leibe der Räderthiere cinen integrirenden Theil, aber es treten in dcrselben schon zahlreiche zellige und membranöse Differenzirungen auf, dic sich am Baue der einzelnen Organe betheiligen. Die Räderthiere haben kein eigentliches Blut, sondern eine sarcodenartige Masse von grosser Dehnbarkcit mit viclen feinsten Körnchen crfüllt ihr Inneres, in das dann die Organe eingebeltet sind; es fehlt auch ein Gefässsystem, welches die Ernährungsflüssigkeit in bestimmten Bahnen vertheilcn und mischen soll, und Elemente, die Ehrenberg als Gefässe gedeutet, haben sich spiiter als Muskehn oder Hautfalten erwiesen. Der Körperinhalt ist stets von einer structurlosen Oberhaut (Cuticula) aus Chitin umgeben, unter der eine dünne Lage von Kerngebilden cine zweite Hautschicht darstellt. Dic Haut ist stellenweisc quergerunzelt, in Falten gelegt und gibt dem ganzen Thiere oft das Aussehen eines Gliederthieres. Meist lassen diese Segmentirungen drei Theile deutlich hervortreten: Kopf, Leib und Fuss oder Schwanz, oft aber auch ist der Kopf enger mit dem Leibe rerbunden. Die allgemeine Körpcrform ist entweder eine cylindrische, wurmförmige, und die einzelnen Segmente, zumal an Schwanz, sind ineinander einstülpbar, wie die Theile eines Fernrohres; oder das Thier ist kolben-oder keulenförmig mit verengertem Fussende; 
oder es ist von oben oder von der Seite zusammengedrückt, schildförmig oder prismatiseh; oder endlich hat es die Gestalt eines Sackes, einer Urne. LeYDrG basirt seine Systematik der Räderthiere auf diese allgemeine Körpergestaltung.

Je nach der Resistenz und Dichtigkeit der äussern Chitinhaut erscheinen die Riiderthiere gepanzert, oder mit weicherer, nachgicbiger Bedeckung versehen. Wir haben unter den Infusorien in der Familie der Oxytrichen ähnliche Vorkommnisse gefunden. Auch dieses Moment ist von Errrenberg mit wenig Glück zur Systematik benutyt worden. Der wesentlichste und charakteristische Theil bildct das Räderorgan, welches sämmtliche Räderthiere an ilrem Kopfende tragen. Fs besteht in einer grössern oder geringern, meist lappenartigen Hautausstülpung der Kopf-oder Stimpartie, die an ihrem Rande mit einer doppelten Reihe kräftiger Wimpern besetzt ist. Das Spiel dieser Cilien ist so eigenthümlich, dass der Beobachter oft glaubt, ein rotirendes Rad vor sich zu haben. Die Art und Weise der Wimperbewegung, welche diesen Aspect erzeugt, ist aber noch nicht ganz aufgeklärt: natürlich kann keine Rede ron wirklich sich drehenden Rïdern sein; Dujardor gibt uns

I. 1. eine sehr anschauliche schematische Zeichnung zur Erklärung dieser Erscheinung, während Bergmann und Leuckart der Meinung sind, dass in einer langen Wimper sich nur eine kurze Welle von einem Ende zum andern fortpflanze, während der übrige Theil sich ruhig verhalte.

Die Form des Räderorganes hängt von derjenigen des Stirnlappens $a b$, und wird vielfach in der Systematik benutzt. In mehregen Fällen stehen die Cilien auf mehreren kolbigen oder armförmigen Ausläufern; bei den meisten Räderthieren ïberziehen sie in Continuität den ganzen Stirnrand bis in die Mundhöhle hinein. Ist der Cilienlappen nur ganz kurz, so ist auch das Wimperorgan klein, bildet der Lappen aber einen grossen rundlichen Schirm, so wird der Anblick eines grossen Rades erzeugt; je nachdem der Rand dieses Schirmes eingeschnitten oder ausgebuchtet ist, erscheinen «wei, vier und melır Wimperrïdchen, die aber nie ganz von einander getrennt sind. Durch kräftige Muskeln kann das Wimperorgan meist eingezogen und in den Körper umgeklappt werden, was stets im Kustand der Ruhe gesehieht. 
Verdau ungsaplarat. Von den innern Organen fällt von vornherein jedem Beobachter der scharfbegrenzte Verdauungsapparat in die Augen, was jede Verwechslung mit den Infusorien ausschliesst. Fast immer findet man schon bei mässiger Vergrösserung kauende Kiefer und einen deutlichen, mit fremden Körpern gefüllten Magen und Darm. Betrachten wir günstige Formen unter stärkern Gläsern, so finden wir einen sehr entwickelten Intestinaltractus. Die Mundöffnung befindet sich meist auf der untern, also I. $\mathbf{2}$. Bauchseite des Räderorganes. Durch dieselbe werden die Nalırungstheile vermittelst des Cilienspieles in den weiten, offenen Mundtrichter hineingetrieben; aus diesem können verschluckte Infusorien oftmals wieder entweichen, werden aber meist durch den Cilienstrudel wieder zurïckgeworfen. Bei einigen schliesst sich an diesen Mundtrichter ein zweiter Raum, eine Art Vormagen an, der, an seinem obern Eingang mit einigen borstenförmigen Haaren reussenartig verschlossen, das Entweichen der gefangenen Thicre unmöglich macht. Von da gelangen die Nalırungstheile in den musculösen Schlundkopf, wo sie durch die Kiefer zerkleinert werden. Die Form dieser soliden C'hitinkiefer- ist sehr complicirt: entweder sind es einfache, zwei- bis dreigliedrige Fressspitzen, oder zwei und melr 1. 1. 3. Zälıne sitzen an zwei Armen und arbeiten durch Muskelwirkung gegen festere gekerbte Platten, oder die Kieferspitzen haben die Form cincs Geweihes oder ciner Hand, oder sic sitzen auf lalbrunden Scheiben, die gegen einander gerieben werden. Für die Systematik indess kann man schon der Kleinheit wegen diese DiffeVIII. 8. 9.

VIII.

7. 10. renzen nicht wohl benützen, obgleich sic zur Bestimmung der Art sehr wichtig sind.

Ein röhrenförmiger Oesophagus führt nun in den weiten Ma- 1. 1. 4. gen, der gewöhnlich den grössten Theil kies Verdauungsapparates ausmacht. Er ist meist mit fremden Kïrpern derart gefüllt, dass er I. 1. 5. sogleich deutlich gesehen wird, und verlïngert sich nach unten in den Jarm, der mit einem After in der Nïhe des Schwanzansatzes mündet. Dem Magen liegen an seiner Oberfliiche Zellenlıaufen an, die vielleicht ein Verdauungssecret liefern. Bei vielen Rïderthicren sielit man am obern Theile des Magens zwei helle, blasenformige I. 1. 6. Körper ansitzeu, die in ihrem Innern mehrere Kerngebilde besitzen, 
und durch Muskelfasern aufgehängt, den Verdauungsapparat tragen. Ehrenberg nennt diese Gebilde Pancreas.

Der ganze Verdauungsapparat ist inwendig mit Cilien bekleidet, welche durch ihr Spiel die Rotation der Speisetheile besorgen.

Nicht bei jedem Räderthiere wird man indess alle die einzelnen Theile auffinden können: vielen fellt der weite Mundtrichter und der Vormagen, bei einigen ist sogar der Kauapparat des Schlundkopfes verkümmert, und einzelne haben weder Darm noch After, brechen also die verdauten Speisen wieder durch den Mund. Bei den wenigen bisher mit Sicherheit erkannten Münnchen fehlt merkwürdigerweise jede Spur eines Verdauungsapparates.

Respirationssystem. Als Athemorgan der Räderthiere sieht man gegenwärtig allgemein ein Canalsystem an, das, zu beiden Seiten des Verdauungsapparates verlaufend, nach hinten in eine bla-

I. 1. 8 . senförmige Erweiterung mündet. Bei allen Rotatorien trifft man in der Nühe des Afters eine grosse musculöse Blase mit wasserheller Flüssigkeit gefüllt; sie hat sehr dicke Wandungen und contrahirt sich kräftig in regelmässigen Zwischenräumen, indem sie ihren Inhalt nach aussen entleert. Von dieser Blase geht jederseits ein langer, oft zu Knäueln gewundener Schlauch mit zelligen Wandungen durch den ganzen Körper bis gegen den Kopftheil hin.

1. 1. 9. Diese Respirationsrölr e hat nun mehrere (oft sehr zahlreiche) kleine seitliche Aeste, die offen in das Innere der Leibeshöhle zu münden scheinen, und in ihrem trichterförmigen Ende eine undulirende Membran tragen. Man findet leicht bei den grössern Räderthieren in der vordern Körperhälfte vier bis sechs Stellen mit steter zitternder Bewegung, die schon von den ersten Beobachtern für Kiemen gehalten und mit dem Namen Zitterorgane belegt worden sind; sie entsprechen jenen trompetenförmigen Enden der Aus-

I. 1. 10. läufer von Athemröhren. Man muss sich das Athmen etwa folgendermaassen vorstellen: durch die Haut und den Magen wird stets viel Wasser aufgenommen und mit der Sarcode des Körpers gemischt. Die Zitterorgane saugen das überschüssige Wasser auf und führen es durch die Athemröhren der contractilen Blase zu, welche dasselbe nach aussen entleert. Man könnte dieses excretorische System übrigens eben so gut mit einer Niere wie mit einem Athemapparat vergleichen. Beiläufig müssen wir hier noch erwähnen, 
dass Ehrexberg dieses Organ für ein männliches Geschlechtsorgan ansah, und Tentakeln, welche mohrcre Räderthiere besitzen, fälschlich für Athemröhren erklärte.

Nerven und Sinneswerkzeuge. Bei der Kleinheit und Durchsichtigkeit unserer Thicre ist es wohl leicht zu entschuldigen, wenn so subtile Elemente, wie die des Nervensystems, nur unvollkommen und bei bevorzugten Formen genauer untersucht worden sind. Im Allgemeinen ist wenigstens eine Art Gehirn, d. h. eine im Kopftheile gelegene Ganglienmasse bei den hicrauf untersuchten Arten erkannt, nirgends ist aber ein sogenannter Schlundring oder eine Reihe durch Nervenfasern verbundener Ganglienknoten (Ganglienkette) aufgefunden worden, wie dies Verhältniss z. B. für die Arthropoden typisch ist. Meist sitzen diesem Gehirnganglion ein.I. 1. 14 oder zwei rothe Augenpuncte auf; ebenso gehen an einzelnen Stellen der Körperoberfläche, die wir sofort näher bezeichnen werden, von diesem Nervencentrum feine Fasern $a b$, und vermitteln wahrscheinlich das Gefühl oder die Tastempfindung.

Was die Sinnesorgane anbelangt, so fiel schon den ersten Beobachtern das häufige Vorkommen von rothen oder braunen Pigmentflecken an der Kopfpartic auf, und sie beanspruchten dieselben ohne Zaudern als Gesichtswerkzeuge. Wenn wir auch zugeben, dass so circumscripte Pigmentbildungen immerhin eine optische Beziehung haben mögen, und dass solche Stellen eher zur Perception ron Lichteindrücken belïhigt sind, als die übrige, ungefürbte Körperoberflächc, so müssen wir ron unserm Standpunct aus doch noch einiges Bedenken tragen, jene gefürbten Stellen geradezu für Augen zu erklären; wir sind noch zu sehr an das Postulat von dem gleichzeitigen Vorhandensein cines empfindenden Nerven und eines lichtbrechenden Mediums gebunden. Indess sind in der 'That bei einer grössern Anzahl Räderthiere diese Momente zur Evidenz nachgewiesen worden. Gewöhnlich sitzt der rothe Augenfleck direct dem Gehirnganglion auf, und in diesen Falle ist auch ein lichtbrechender Körper in Form eines wasserhellen Bliischens zu sehen. Für die Systematik hat die Zahl und Stellung der Augenflecke einen grossen Werth, wenn dies auch nicht ron so durchgreifender Bedeutung ist, wie es nach Ehrexberg's Eintheilung scheinen möchte. Bei vielen Formen bemerkt man in dem noch in der Eihülle befind- 
lichen Limbryo und bei den jungen Räderthierchen deutlich jene rothen Augenpuncte, während sie den erwachsenen abgehen. Dies Verhältniss findet sich zumal bei den festsitzenden, die in ihrer Jugend eine kurze Zeit frei herumschwimmen, um ihren zukünftigen Wohnort wählen zu können. Wenn sie sich einmal definitiv fixirt haben, beginnen die Augen zu atrophiren, wie Analogieen hievon in den verschiedensten Klassen niederer 'Thiere beobachtet worden sind.

Für den Gefühls-oder 'Tastsinn scheinen einzelne Stellen der Oberhaut, Höckerchen oder Grübchen, die mit steifen, nicht vibrirenden Borsten versehen sind, zu functioniren, da ron dem Ganglienknoten des Kopfes einzelne feine Nervenfasern an sie herantreten. Diese Stellen sind entweder im Räderorgan oder an den Seiten der vordern Körperhälfte symmetrisch gelegen. Ferner betrachtet man jene armförmigen 'Tentakeln vieler festsitzender' und kriechender Rïderthiere, welche von der Halspartie fühlerartig ausgestreckt und eingezogen werden können, gegenwärtig als Tastorgane, da vom Gehirnknoten feine Fasern bis an ihre stcts bewimperte Spitze verlaufen. Man hielt früher diese Fühler für hohle Röhrchen, die mit dem Athmungsprocess in Verbindung stohen sollten und legte ihnen den Namen von Athemröhren, Sipho etc. bei; es sind aber solide Cylinder mit einer Nervenfaser in ihrer Achse und keine Röhren. Von andern Sinnesorganen hat man bisher keine Kenntniss. -

Geschlechtsorgane und Fortpflanzung. Während wir bei den Urthieren die Vermehrung auf dem Wege der Theilung als die hüufigste Art der Fortpflanzung kennen gelernt haben, ist bei den Räderthieren bisher noch nie ein ähnlicher Process beobachtet worden. Auch die Knospenbildung ist dieser Thierklasse fremd, obwohl viele gesellig lebende Arten, in einer gemeinsamen gelatinöscn Hülle sitzend, den Verdacht auf diese Vermehrungsweise leiten könnten.

Die Räderthiere haben alle eine geschlechtliche Fortpflanzung. Bei den meisten wird es nicht schwer, einen Eiers tock mit Eiern in rerschiedenen Stadien der Entwicklung zu beobachten. Dies Organ umgibt gewöhnlich den Verdauungstractus halbmondförmig, oder liegt seitlich dem Magen und Darme an und mündet durch 
den Eileiter gemeinsam mit dem After aus. Die sogenannte Alteröfnung ist eigentlich eine Mündung der Kloake, da an derselben Stclle Darm, Eileiter und contractile Blase ihren Inhalt nach aussen entleeren. Der Eierstock besitzt eine zarte aber deutliche UTmhüllungshaut und ist mit molecularkörnchenhaltiger Sarcode gefüllt, worin Kerngebilde und Fettropfen vertheilt sind. Der Eier, die darin gebildet werden, sind zweierlei Art bei demselben Thiere; man hat sie Sommereier und Wintereier genannt. Die Wintere ier sind viel grösser als die Sommereier, haben eine dicke, doppelte, oft mit Cilien oder Höckern bedeckte Schale und werden stets vor Entwickelung des Embryo gelegt. Hüllenbewohnende Räderthiere legen dieselben in ihre gelatinöse Umkleidung, einigce tragen sic am Schwanze angeheftet längere Zeit mit sich herum, ähnlich wie die Cyclopsarten ihre Eiersäcke. Beim Ausschlüpfen des Embryo springt das Winterei deckelartig auf. Gewöhnlich werden nur wenige oder nur ein grosses Winterei gebildet.

Die Sommereier sind viel kleiner, zartwandig und zahlreicher und entwickeln schon im Mutterleibe den Embryo, der in vielen Fällen noch im Eileiter auskriecht. Dicse Arten (Notommata, Rotifer, Stephanoceros) sind also lebendiggebürend, während bei andern (Bractionus, Megalotrocha etc.) auch die Sommereier gelegt werden, und das junge 'Thier erst im Wasser ausschlüplt.

Sind im Eierstock mehrere Sommereier gebildet, und kommt das Mutterthier in anomale Verhältnisse, z. B. durch langsames Verdunsten des Wassers auf dem Objecttrïger, so werden erstere wieder resorbirt und der Inhalt des Eierstockes wird zur Bildung eines grossen Wintereies verwendet.

Die männlichen Geschlechtsorgane blieben bis ror circa zwanzig Jahren ganz unbekannt. Ehrrisming suchte sie bald in der contractilen Blase, bald in einem Convolut von Athemröhren. bald in jenen kolbigen Drüsen des Schwanzes, die wir spitter besprechen werden. DaLryupLE entdeckte zuerst das Männchen ron Notommata anglica und hernach LeYnrg das ron Notommata Sieboldi, was vermuthen lässt, dass die Räderthiere insgemein getrennten Geschlechtes, also keine Zwitter sind. Hiebei zeigte sich das merkwürdige Verhältniss, dass diesen Münnchen der gesamnte Verdauungsapparat, also Schlundkopf mit Kiefern, Magen und Darm 
gänzlich fehlt. Ueberdies sind sie kleiner und theilweise von anderer Körpergestalt, als die Weibchen, so dass zu erwarten steht, cinige als Arten beschriebene Thiere werden sich mit der Zeit als Männchen schon bekannter Weibchen herausstellen. (Dies ist z. B. wahrscheinlich für Énteroplea Hydatina, als Männchen von Hydatina scntu, lür Notommate gramularis als Männchen von $N$. Brachionus, Diglena granuleris von Digl. catellina.)

Die Münnchen scheinen daher nur ein kurzes, blos der Fortpflanzung gewidmetes Leben zu füluren, wovon manche Klassen niederer Thiere weitgehende Analogieen zeigen. In ihrem untern Leibesende befindet sich als Samendrüse eine grosse Blase, die mit zelligen Körpern, schlängelnden Fïden oder zitternden Stïbchen prall gefüllt ist und gemeinsam mit der contractilen Blase des Respirationsapparates nach aussen mündet.

Das seltẹne Vorkommen von Münnchen mag theilweise ron der kurzen Lebensdaner derselben herrühren, aber es ist gewiss auch Folge unserer Untersuchungsinethode. Wenn man nämlich ein Räderthier genauer studiren will, so genügt selten ein einzelnes Exemplar, man will ein massenhaltes Beobachtungsmaterial und wählt stets die grössten Exemplare aus, bei denen alle Organe recht deutlich zu Tage treten. Indess ist es auch leicht möglich, dass die Männchen in Wirklichkeit sehr selten sind, oder nur periodisch erscheinen, und dass also cine Parthenogenesis bei dieser 'Thierklasse allgemeine Verbreitung findet, wic man sie für mehrere Insectenarten, deren Männchen noch nic zur Beobachtung kamen, anzunehmen geneigt ist. Der Modus der Begattung oder Befruchtung ist noch unbekannt.

Viele Räderthiere kommen ühnlich dem Mutterthicre aus dem Ei, andere machen eine mehr oder weniger abweichende Metamorphose durch. Schon beim Auskriechen beobachtet man bei den meisten die Kiefer und den Darm, der gewöhnlich mit bräunlicher Bildungsmasse gefüllt ist. Leynig kam auf den sonderbaren Einfall, dies für eine Art Nierensecret zu halten.

Bewegungsorgane. Schon oben haben wir als wesentlichstes Bewegungsmittel der Räderthiere das Räderorgan kennen gelernt. Es kann meist durch Muskelbündel eingezogen werden. Diese Lüngsmuskeln verlaufen, 2 bis 3 an der Zahl, entweder rom 
Fussende aus und theilen sich nach vorn dichotom in mehrere Aeste, oder sie gehen von der seitlichen Körperwandung an das Wimperorgan. Gewöhnlich sind es glatte Muskelfasern, bei einigen aber ist auch eine leichte Querstreifung deutlich zu bemerken. Der Sehlundkopf besteht ebenfalls aus sehr starken Muskeln (Taf. VIII. Fig. 8), die durch ihre Verbindung (ler Kieferïste eine kauende Bewegung ermöglichen. Ferner haben viele Räderthicre cin System querer Muskelfasern, die ihren Körper fassreifartig umspinnen und dadurch oft eine leichte Segmentirung erzeugen.

Die Bewegungen sind sehr verschiedenartiger Natur. Die meisten Rälerthiere schwimmen stetig und ziemlich rasch vorwärts, wenige drehen sich hiebei um ihre Lüngsachse, wie dies bei den Infusorien so hüufig rorkommt; einige schwimmen ruckweise, machen Sprünge mil ihren scitlichen Flossen oder Borsten; Noteus stilrzt sich kopfüber wie ein Argules, Eosphore schwimmt nur auf dem Rücken, wie die Phyllopoden; Pterndina endlich stellt sich bei der Erschuitterung todt und steigt dabei an die Oberfläche des $W$ assers.

Ueber die Stellung, welche man den Räderthieren in der Stufenleiter thierischer Lebensformen anweisen soll, sind die verschiedensten Ansichten geäussert worden. Dass man sie heute nicht mehr bei den Infusorien belassen kann, wohin sie die ersten Beobachter verwiesen, wird Jedem aus dem Vorhergehenden ersichtlich sein. Sie werden daher oft zu den Würmern gebracht und als Ordnung der Klasse der Rundwürmer eingereiht. Leynig, bestimmt durch vielfache Aehnlichkeit der Rotatorien mit den Gliederthieren, will sie als Ordnung der Klasse der krebsartigen Thiere zufügen. C. VoGT weist aber nach, dass eine Reihe den Räderthieren zukommender Charaktere absolut unvereinbar sind mit dem Organisationstypus der Krebsthiere, während sie keine Merkmale besitzen, welche mit den Charakteren des Wurmtypus sich durehaus nicht verbinden liessen, und so möchten wir, ohne hicr auf die nähere Begründung einzugehen, nach VoGT's Vorschlag die Räderthiere am liebsten als eine selbstïndige Klasse des $\mathrm{K}$ reises der IV ü $r m e r$ angesehen wissen.

Der Systematik so kleiner Lebeusformen stehen grosse Schwierigkeiten entgegen, insofern das System nicht blos der Ausdruck 
unseres mitweiligen Wissens sein darf, sondern uns zugleich ein leichtes Mittel an die Hand geben soll, die beobachteten Geschöpfe bequem und sicher zu bestimmen. Die Schwierigkeit, ein in die Augen fallendes Moment zu finden, das gleiehzeitig und constant mit Differenzen der allgemeinen Organisation variirt, ist um so grösser, je kleiner und cinfaeher die Objecte der Betrachtung sind.

Enrenbrig hat dic ersten, wenig glücklichen Versuche zur Eintheilung der Räderthiere auf die Form der Wimperorgane und die Resistenz der Haut gegründet. Er theilt sie in solche mit einfachem und mehrfachem Wimperorgan ein, eine Supposition, die der Natur wenig entspricht und zur Bestimmung gar nicht kann benutzt werden. Ebensowenig haltbar ist seine Eintheilung in gepanzerte und ungepanzerte Rotatorien, da der Ausdruck Panzer nur eine sehr relative Härte der Cuticularbekleidung bezeichnet und vollends unstatthaft ist für die gelatinöse Umhüllung vielcr Räderthiere. Die Stellung und Zahl der Augenpuncte gäbe sehon ein bequemcres Unterscheidungsmittel, wenn sie mehr Hand in Hand ginge mit Verhältnissen innerer Organisation, und überhaupt bei vielen dieser Thiere die Augen nicht blos den Jugendformen zukümen. Ebenso subjectivem Ermessen anheimgestellt ist die ron LEYDIG vorgeschlagene Eintheilung, welche die allgemeine Körperform zur Basis hat. Solche allgemeine Formbestimmungen können sehr wohl zur Besehreibung, nicht aber für präeise Unterscheidung benutzt werden. LEYDIG theilt die Rotatorien in eylindrisehe oder kolbige, in sackförmige, und in von oben oder seitlich zusammengedrückte. Nach dieser vagen Beyeichnungsart wird sich aber wohl Keiner getrauen, eine Bestimmung vorzunehmen.

Viel deutlicher trennt LEYDIG seine Untergruppen je nach der Gestaltung des Fusses, welehes Eintheilungsprineip als leichtestes Merkmal wir mit wesentliehen Modifieationen für die Erriehtung der Familien adoptiren wollen. Für die Ordnungscharaktere halten wir uns am besten an die Systematik Dujardis's, der die Art der Bewegung der Räderthiere zum Ausgangspunet seines Systems maeht. Wir erhalten nach diesem Forscher folgende drei Ordnungen:

1) Räderthiere, welehe in-ihrem ausgewachsenen Zustand mit dem ungegliederten Fussende an fremden Körpern festsitzen.

1. Ordnung. Rotatoria sessilia. 
2) Solehe, die ihre Ortsbewegung nur durch Schwimmen vermitteln.

2. Ordnung. Natantia.

3) Solche, die abwechselnd schwimmen und spannerartig kriechen, indem sie sich nacheinander mit Fuss und Fopfende fixiren.

\section{Ordnung. Repentia.}

Die Form des Räderorganes, die Stellung und Anzahl der Augen und theilweise auch die allgemeine Körpergestaltung werden wir blos zur Errichtung der Gattungsbestimmung, die Gestalt des Fusses aber, die nicht nur leicht in die Augen fällt, sondern zum Theil ron physiologischer Bedeutung ist, indem sie oft die Lebensweise der Rüderthiere becinflusst, ausschliesslich zur Errichtung der lamiliencharaktere verwenden. Wir müssen daher diesem Organ noch eine nähere Betrachtung widmen.

Der Fuss oder Schwanz der Rüderthiere ist sehr verschiedenartig entwiekelt. Einige haben ein stumpfes Leibesende, an dem der After sitzt, sie haben also gar keinen Fuss. Bei den meisten aber ist hinter dem After der Körper in einen Schwanz ausgezogen, in welehen niemals Eingeweide eintreten. Bei den Festsitzenden ist der Fuss cylindrisch, wurmförmig gestreckt, oft quergeringelt, besonders bei der Contraction des Thieres. Meist verlaufen dureh diesen Schwanz 2 bis 3 deutliche Längsmuskeln, die sich dichotom theilend oft den ganzen Körper bis zum Räderorgan hinanl" durchzichen und die Contraction des Thieres vermitteln. Zwischen diesen Muskeln bemerkt man bei vielen grössern Räderthieren 2 bis 3 kolbenförnige, drüsige Organe, deren Bedeutung aber noch ganz unbekannt ist und die früher von EHRevBeng fälschlich als männliche Geschlechtsdrüsen angesehen worden sind.

Bei den kriechenden Räderthieren ist der Fuss am Ende mit cinem zweiklappigen Anhang versehen, der ihnen zum Fixiren dient, sie haben eine kurze Fusszange, die aus zwei gegeneinander bewegliehen Hörnchen oder Blättchen besteht. Die Segmentirung des Fusses ist bei dieser Ordnung stark ausgesproehen, ähnlich wie bei Ringelwïrmern oder Gliederthieren, so dass die einzelnen langen Glieder oft in kleine Fortsätze, sogenannte $\mathrm{N}$ e b e nhörnchen ausgezogen sind. Die Segmente des Fusses werden beim Kriechen fernrohrartig ineinandergesehoben und ausgerogen, was bei den schwimmenden Räderthieren nicht rorknmmt. 
Die schwimmenden Rotatorien haben entweder einen wurmartigen Fuss, der mit einem Büschel feiner Cilien endet, (Ptero-

IV. 4. d in e a e); oder der Fuss fehlt ganz, oder ist sehr klein, aus 1 bis 3 ganz kurzen Gliedern bestehend, und das Körperende trïgt zwei kurze lanzettförmige Schuppen, etwa von der Länge des übrigen

V. Fusses, wenn überhaupt einer da ist. Aus diesen Formen errichten wir die Familie der Hydatineen. Eine andere Familie hat an ihrem Körperende zwei lange stiletartige Fusszangen, die gewöhnlich einem lïngern, gegliederten Fuss aufsitzen; es sind dies die

VII. Euchlaniden. Bei der Familie der Brachioniden endet ein

VI. 7. 8. langer, leichtsegmentirter, wurmförmiger Schwanz mit zwei kurzen, breiten Klappen; und bei der Familie der Mon ureen endlich läuft der Fuss oder der Körper des Thieres in einen einzigen un-

VI. 1-6. paarigen Stachel oder eine Borste aus.

Wir erhalten demnach etwa folgende Uebersicht der Familien:

I. Ordnung. Rotatoria sessilia, festsitzende Räderthiere.

1) Räderorgan besteht aus fünf bewimperten Kolben oder Armen.

1. Fam. Floscularieae.

2) Räderorgan besteht aus einem continuirlich bewimperten Hautsaum.

2. Fam. Melicerteae.

II. O rdn ung. Rotatoria natantia, schwimmende Räderthiere.

I. Körper endet ohne Fuss und Fusszangen. 3. Fam. Apoda.

II. Körper endet mit einem Fuss oder doch mit Fusszangen.

1) Fuss wurmförmig, endet mit feinen Cilien ohne Fusszange.

4. Fam. Pterodineae.

2) Zwei kurze, lanzettförmige K’lappen bilden das Körperende. Sie sitzen entweder an einem ganz kurzen Fuss oder gerade am Hinterleib. Ohne Panzerbildung.

5. Fam. Hydatineae.

3) Körper endet mit einem langen, unpaarigen, griffelförmigen Anhang.

6. Fam. Monureae.

1) Körper endet mit zwei langen Griffehn oder stiletartigen Klappen, die oft an einem langen, mehrgliederigen Fuss sit\%en.

7. Fam. Euchlanida.

5) Langer, wurmförmiger Fuss, der in zwei kurze, lanzettförmige Fusszangen enclet.

8. Fam. Brachioneae. 
III. Ordnung. Rotatoria repentia, kriechende Räderthiere.

1) Kriechen und schwimmen abwechselnd. Fuss lang, gegliedert, kann sich tubusartig rerkïrzen und endet mit \%wei Haken.

9. Fam. Rotiferes.

\section{II. specieller Theil.}

\section{Ordnung.}

\section{Rotatoria sessilia.}

Die Räderthiere dieser ersten Ordnung sind leieht kenntlich, weil sie den grössten Zeitabschnitt ihres l,ebens an fremden Körpern festgeheftet sind; man könnte sie höchstens mit Rotiferen verwechseln, die sich oft für kur\%e Zeit an Wasserpflanzen festsetzen; aber schon der Mangel an Segmentirung des.Fusses bei den wirklich festsitzenden Räderthieren wird diesen Irrthum leicht rermeiden lassen. Die allgemeine Körpergestalt dieser 'Thiere ist kolbenförmig. Sie haben cin sehr grosses, prächtig spielendes Räderorgan und gehören überhaupt жu den grüssten Repräsentanten der ganzen Krlasse, da die Mehrzahl die Lünge ron $1 / 3$ Linie erreicht. Die meisten sit\%en in hyalinen oder inerustirten Hüllen, und mehrere bilden in ciner gemeinsamen Gallerte grosse Gesellschaften. Wir erhalten nach der Beschaffenheit des Räderorgans zwei deutlich zu unterscheidende Familien; die Floseularien mit fünfarmigem Organ und dic Melicerten mit normalem, zusammenhängendem Wimperkranz.

\section{Fan. Flosculariene.}

Diese Familic umfasst nur zwei Gattungen, die aber in der Form ihres Wimperorganes nicht nur ron allen andern Räderthieren, sondern auch unter sich schr abwcichen, so dass man rersucht ist, zwei Familien für sie zu errichten. Die (ilien des Wim- 
perorganes stehen bei der Gattung Floscularia auf fünf kolbenförmigen Armen und bilden sehr lange, zarte, aber nicht vibrirende Haare, während bei der zweiten Gattung, Stephanoceros, die wimpiernden Cilien ron fünf langen Fangarmen getragen werden. Die innere Organisation ist im übrigen bei beiden Gattungen sehr übereinstimmend.

II. 1. 2. 1. Gatt. Floscularia. Blumenfischchen. Die sehr langen, feinen Cilien stehen auf fünf (bis sechs) kolbenförmigen Anschwellungen der Kopfpartie. Sie wimpern nicht, sondern bilden, ausgestreckt, ein reussenförmiges Netz, in welehem kleinere Infusorien sich verstricken und so gefangen werden. In der Mitte dieser Fadenbüschel steht der weit geöffnete Mund, der in einen Mundtriehter und von hier in einen weiten Vormagen führt. Der Vormagen ist an seinem Eingang mit einigen stärkern Cilien bewaffnet, welche das Entweiehen der Beute verhindern. Von da gelangt die Nahrung in den Sehlundkopf, wo zwei doppelzähnige Kiefer (aihnlich wie die in Taf. VIII. Fig. 10 abgebildeten) gegen einander arbeiten. Magen und Darm sind inwendig bewimpert und zeigen nichts vom gewöhnlichen Typus Abweiehendes. Das kolbenförmige 'Thierehen sitzt in einer sehr hyalinen und schwer zu cntdeekenden Hülle. Man muss oft sehr scharfe Linsen anwenden und stark abblenden, wenn man dieselbe sehen will, und DuJardin liat sie gewiss blos übersehen, wenn er behauptet, in Frankreich besässen diese Thierehen keine Hülle. Bei Erschütterung, oder wenn ein Infusorium in ihren Strahlenkranz geräth, klappen die Stirnlappen plötzlich zusammen und die Haare bilden einen steifen Büschel um die gefangene Beute. Die grossen Sommereier werden in die Hülle gelegt und bleiben an dem Fusse und untern Körperende angeheftet. Der Embryo im Ei, sowie junge Thiere haben zwei deutliche rothe Augenflecken, welehe den Erwachsenen fehlen. Fl. or -

1. 1. 2. nata, ctwa $1 / 10$ "' lang, ist überall sehr häufig auf Wasserpflanzen. Ihr Futteral sehr fein, seheint ein solider Cylinder und keine holle Röhre zu sein. Ehrenberg gibt ihr fälschlieh seehs statt blos fünf Höcker mit Cilienbüschelı. ${ }^{1}$ Fl. proboscidea $E$. hat in der

1) Ich habe indess aus cinem kleinen Teiche bei Fehrabtorf eine kurze, kugelige Floscularia mit siehen sehr deutlichen, langen Armen gefunden: indess scheint die $\Lambda r^{2}$ verschieden ron $\mathrm{Fl}$, ornata. 
Mitte der Wimperarme eine dicke, kolbige, mit langen Cilien bekleidete Anschwellung, und Fl. appendiculata Leydig hat im Wimperorgan nebell den Cilienhöckern noch einen bandartigen Fortsatz, der eine Art Tentakel zu bilden scheint.

2. Gatt. Stephanoceros. ${ }^{1}$ Kronenrädchen. St. Eich horni.

Diese seltene Form zeichnet sich durch fünf lange Fangarme am Kopfende aus, an denen wimpernde Cilien in etwa fünfzehn Wirteln stehen. Auch hier ist ein centraler Mund zwischen den Armen des Räderorganes mit weitem Mundtrichter und Vormagen. Ein hyalines Futteral umschliesst das 'Thier, das seine Arme aber nicht zurückziehen kann. Es findet sich selten auf Lemna oder Ceratoplyyllum sitzend und erreicht etwa die Grösse von $1 / 3{ }^{\prime \prime}$.

\section{Fam. Melicerteae.}

Das Räderorgan dieser Formen ist mehr nach den allgemeinen Plane der übrigen Räderthiere gebaut und besteht aus einem lappenförmigen, oft ausgebuchteten Schirm der Stirnpartie, an deren Rand eine doppelte Reihe stark vibrirender Cilien continuirlich verläuft. Diese Wimpern ziehen sich bis in den auf der Bauchseite gelegenen Mund hinein. Der Wimperapparat ist gross und bei der Bewegung meist tellerförmig ausgebreitet, und dadurch entsteht der Aspect eines grossen drehenden Rades. Sie sitzen alle mit einem ungegliederten Fuss an fremden Körpern fest, und die meisten besitzen eine hyaline oder incrustirte Hülle, in welche sie sich zurückziehen können. Ihre Körperform ist die einer Keule, an deren blumenkelchartig erweitertem Ende die Cilien einen beständigen Strudel erzeugen, welcher Nahrungstheile gegen den Mund fülnrt. Man kann sie nach ihrer Hülle bequem in drei Gruppen theilen, 1) in solche, wo jedes 'Thier seine eigene, gesonderte Hülle besitzt (Tubicolae); 2) in solche, wo die Individuen gesellig in einer gemeinsamen Gallertmasse eingebettet liegen (Lacinulariae), und 3) in solche, denen jede Hülle fehlt $(N u d a)$. Die Gattungen werden am besten unterschieden nach der Art, wie die Hülle beschaffen ist,

1) Ueberall, wo nichts Bestimmtes angegeben ist, datiren die Namen yon EHRENBERG. 
und nach der Anzahl der Wimpcrlappen des Räderorganes, 'die durch Einbuchtung entstehen. Zur Bestimmung der Genera erhalten wir etwa folgende analytische Tabelle.

I. Jedes Thier sitzt in einer gesonderten Hülle.

1) Hïlle regelmässig mit linsenförmigen Körpern incrustirt.

Melicerta.

2) Hülle hyalin oder mit verschiedenen Matcrialien incrustirt.

a) Räderorgan vierlappig oder mit zwei seitlich ausgeschweiften Lappen.

Tubicolaria.

b) Räderorgan kreisrund auf der Bauchseite eingebuchtet.

Oecistes.

c) Räderorgan zweilappig.

Limnias.

II. Die Thiere sitzen gesellig in einer gemeinsamen Gallerte.

Lacinularia.

III. Thiere ohne Hülle.

1) Gesellig. Räderorgan hufeisenförmig.

Megalotrocha.

2) Vereinzelt. Räderorgan vierlappig.

Anthos.

II. 1. 3. Gatt. Melicerta. Spec. ringens. Man trifft dicse $1 / 2^{\prime \prime \prime}$ grossen, prächtigen Räderthiere oft auf Lemna und Ceratophyllum, wo sie durch ihre blumenkelchartige, vierblättrige Wimperkrone sich leicht bemerkbar machen. Interessant ist die Bepflasterung ihrer röhrenähnlichen Hülle durch regelmässige, reihenweise $\mathrm{Ab}$ lagerung kleiner, runder Linsen, wodurch dieser Schlauch ganz das Ansehen eines Phryganeengehäuses bekommt. Wahrscheinlich ist auch seine Entstehungsart eine ähnliche, obgleich man das Baumaterial noch nicht genau kennt; es sind aber jedenfalls keine rom Thiere ausgeschiedenen Zellen, sondern irgend eine wenig beobachtete, einzellige Algenform mit dunklcrem Kern. Unter dem viertheiligen Räderorgan treten zwei fühlerartige Tentakeln hervor, und an der Kopfpartie sieht man zwei rothc Augenpuncte.

4. Gatt. Tubicolaria. Die Futteralrïdchen sitzen in einem röhrenförmigen, gelatinősen Futteral, das oft streifig getrübt, oft mit fremden Bestandtheilen rermischt ist, und in welches sie die grossen Wintereier ablegen. Das Räderorgan ist von vorn und hinten

III. 2. tief eingeschnitten und seitlich etwas geschweift bei T. najas, die,

III. 3. etwa $1 / 2$ "' gross, oft an Wasserlinsen gefunden wird; bei 'T. copro- 
phila, deren Hülle mit Kothmassen des Thieres ganz durchzogen zu sein scheint, ist das Räderorgan "vierlappig. ${ }^{1}$

5. Gatt. Oecistes, zeichnet sich durch ein rundes Räderorgan, das nur an der Bauchseite eingekerbt ist, aus. Die Hülle ist meist mit bräunlichen Massen incrustirt, und die Embryonen der Wintereier, sowie die jungen Exemplare haben zwei rothe Augenpuncte. Oe. hyalin us wird $1 / 3$ "' gross.

II. 4.

6. Gatt. Limnias. Die Wasserdütchen haben ein grosses, zweilappiges Räderorgan, und ihre Jugendformen sind im Besitz zweier Augen. L. ceratophyll i, etwa $1 / 2$ "' gross, sitzt in einer II. 5. langen, bräunlich pigmentirten Schale. Eine andere Art, L. do-II. 6. li olum,2 hat eine hyaline, kurze, tonnenförmige Hülle, der die regelmässigen Querstreifen ganz das Bild eines Fïsschens geben.

7. Gatt. Lacinularia. Diese grossen Räderthiere mit dem prächtigen, hufeisenfürmigen Wimperorgan leben gemeinsam in einer gelatinösen Hülle, welche an Wasserpflanzen festsitzt, 20-30 eine Colonie bildend. Die Hülle scheint durch Verschmelzen mehrerer einzelner Futterale entstanden, und in derselben findet man grosse Eier mit Embryonen, die zwei rothe Pigmentflecken tragen, wie auch junge Individuen. Man darf hiebei aber nicht an einen Knospungs- oder Theilungsprocess denken, da diese Vermehrungsweise bisher noch nie bei Räderthieren beobachtet worden ist. L. socialis bildet oft mehrere Linien grosse Colonien. In die III. 5. Hülle können sich die Thiere ganz zurückziehen. (1/3"' einzelnes Thier.) L. volvox (man hat für sie das Genus Conochilus IV. 1. errichtet) sind etwas kleinere 'Thiere von keulenförmiger Gestalt, mit rundlichem, kleinerm Räderorgan, die, wie die vorigen, zu 10-30 eine Colonie in einer kugeligen Gallerthülle bilden, indem

1) Diese nene Art bildet eigentlich der Form des Räderorganes und der Hülle wegen eine eigene Gattung. Ich fand die ovalen, $3 / 4^{\prime \prime \prime}$ grossen $\mathrm{Kap}$ seln häufig in einem kleinen Sumpfe bei Zürich. Das Thier hat einen sehr langen, fadenförmigen Fuss und kaun seine Hülle ganz verlassen Zwei 'Tentakeln, bohnenförmige Eier, keine Augenflecke.

2. Ich fand diese neue Art, die vielleicht auch eine eigene Gattung bilden kann, nur einmal in einem kleinen Sumpfe bei Fehraltorf, Canton Zürich, auf I emnawurzeln sitzend. Mit zwei Tentakeln. Bei der Contraction bildeu sich am vordern Leibesende sechs kleine Zapfen, und in dieser Stellung verharrte das Thierchen oft Tage lang. 
sie mit dem F'ussende im Mittelpunct des Klümpehens sitzen. Das einzelne Kugelfischchen wird etwa $1 / 5$ "' gross und hat zwei, mit ciner langen Borste bewaffnete Tentaceln und zwei rothe Augenpuncte. Die Colonie selbst ist aber nicht an fremden Körpern festsitzend, sondern schwimmt rollend frei im Wasser herum, wie ein Kügelchen des Volvox globrator. Auch sie können sich gänzlich in die unhüllende Schleimmasse zurückzielıen.

8. Gatt. Megalotrocha. Ganz ähnlich den Thieren der Lacimularic socialis in Grösse und Form des hufeisenartigen Räderorganes, sitzen die sogen. Sonnenschirmthierchen in zahlreichen Gesellschaften mit den Fussenden vercint zusammen, haben aber nur an dem Anheftungspuncte eine dünnere, hyaline Schicht von Gelatine.

IV. 2. Meg. a lboflavicaus bildet 1-1"' grosse Klümpchen, deren Einzelthicre ctwa $1 / 3^{\prime \prime \prime}$ sind, und tragen die grossen Eier an ihrem Fusse festgeheftet.

III. 4. 9. Gatt. Anthos, ${ }^{1}$ quadrilobus. Etwa $1 / 4$ "' grossc, cinzeln sitzende Thiere mit grossem, blumenkelchartigem, tief eingeschnittenem Räderorgan und sehr dehnbarem, langem Fuss. Sie laben cinen langen Tentakel, der bei der Contraction des Räderorganes nicht eingezogen wird. Fine Hülle konnte nicht beobachtet. werden. -

An hang. Hier müssen wir noch einer Form erwähnen, dic zwar nicht gerade beständig festsitzend ist, aber mit den Räderthieren dieser Gruppe näher verwandt ișt, als mit den kriechenden, obgleich auch sic blutegelartig kricchen kam, oft aber lange Zeit nit dem saugnapfartigen Fussende sich an andere Körper anheftet.

10. Gatt. Ptygura. Die Körperform ist wie die der übrigen Sessilia kolbig, rorn mit einem einfachen, runden Räderorgan, hinten in einen geringelten Schwanz endend, der einen Saugnapf

IV. 3. an seinem Ende trägt. P. melicerta. Enrenberg stellt dies Thicr merkwürdiger Wcise mit den Ichthydien zusammen, die nicht cinmal Räderthiere sind.

1) Diese Art fand ich hăufig in einem Teiche bei Fehraltorf und benannte sie vorläufig, da mir ausser Emrenberg's, Pelity's und Lerdig's Werken keine bezügliche literatur zu Gebote stand, hier aber solche Formen nicht erwähnt werden. 


\section{Ordnung.}

\section{Rotatoria natantia.}

Die frei schwimmenden Räderthicre bilden weitaus die grösste Gruppe dieser Klasse und zeigen auch in ilhrer Körpergcstaltung die grössten Formverschiedenheiten. Keines derselben sondert cine Hülle un seinen Körper ab; aber dic Obcrhaut ist meist ctwas derber, als bei den Thieren der vorigen Ordnung, widersteht der Kalilauge lïngere Zcit, und bei schr viclen bildet sie. einen resistenten, formbeständigen Panzer. Diese Verhältnisse sind aber mit schwächern Vergrösserungen nicht immer leicht zu erkennen, und es besteht überhaupt ein allmählicher Uebergang zwischen wirklich bepanzerten und weichhiutigen Thieren, so dass man an die systematische Verwerthung dieser Eigenschaften nicht denken darf. Ebenso basirt die Eintheilung nach der Form des Räderorgancs und der Anzahl der Augen auf meist unvollkommenen Bcobachtungen, und wir wählen dalice hier den leicht sichtbaren Fuss oder Schwanz als Kriterium einer Systematik, obgleich dadurch selbstverständliclı nicht immer natürliche Gruppen geschaffen werden, und die Auleinanderfolge der verschiedenen Abtheilungen keineswegs den Ausdruck ihrer Verwandtschaftsbezichungen bildet.

Wir haben oben schon diese Ordnung nach der Fussform in sechs Tamilien zorlegt, und stellen die fusslosen Räderthiere, die allerdings wenig rerwandte formen rereinigen, in die erste Reihe.

\section{Fam. Apoda.}

Ucbersicht der Gattungen :

1. Sacklörmige Räderthicre ohne Fuss und Fusszangen mit einem Nackenauge und zicmlich weicher Cuticula.

Apus.

2. Uruenförmige Thiere mit resistentem, vorn vielfach ausgezacktem Panzer und cinem Nackenauge.

Anuraea.

3. Besitzen seitliche Flossen, die sie zum Springen befähigen.

Polyarthra.

11. Gatt. Apus. In dies provisorische Genus stellen wir zwei Arten, die bisher der Gattung Notommute zugehörten und als 
$N$. Sieboldi Leydig und anglica $D l_{p}$. bezeichnet worden sind. EHrExBERG charakterisirt jene Gattung folgendermaassen: "Panzerlose Räderthiere mit vielfachem Räderorgan, einem Nackenauge und zweifingerigem, gabelschwanzartigem Fuss. Das Räderorgan besteht nur aus Cilien. * Mit dieser vagen Cliarakteristik werden eine sehr grosse Menge von Formen von der rerschiedensten Körpergestalt vereinigt, so dass dies Genus gegenwärtig weitaus das grösste ist. Da unsere beiden Reprïsentanten indess nicht einmal einen Gabelschwanz zeigen, so trennen wir sie von dem grossen Geschlecht Notommata, wie wir auch die Arten mit langen Schwanzzangen später davon sondern werden, um einen etwas cinheitlicheren Typus zu erhalten. Die zwei hieher gehörigen Species sind zugleich die am genausten studirten Räderthiere und bisher die einzigen bei denen mit Sicherheit das Männchen bekannt und gut beschrieben worden ist. Dahrymple entdeckte es zuerst bei der von ihm beschriebenen Art anglica und LexDrg fand es später bei der Art Sieboldi ebenfalls; wir wollen daher einen dieser Repräsentanten an der Hand der Lexpig'schen Figur näher betrachten. Der

IV. 6. sack förmige Körper von A. Sie b old i zeigt beim Weibchen einen weiton Wimperkranz, der in seiner Mitte zwei mit steifen, nicht vibrirenden Borsten versehene Höcker trägt. Auf der Bauchseite ziehon sich die Cilien bis in den Mund hinein, der sogleich in den Schlundkopf führt; es fehlen also Mundtrichter und Vormagen, wie dies bei den meisten schwimmenden Räderthieren der Fall ist. Dann kommt ein dicker Oesophagus mit starker Längsmusculatur und ein weiter, mit Drüsenzellen bedeckter Magen, der mit kurzem 1) armstück in die Kloake endet. Der halbmondförmige Eierstock umgibt den Magen, und der Eileiter ist durch einen noch in der Schale licgenden Embryo sehr ausgedehnt. Aus der contractilen Blase tritt jederseits eine lange, geschlängelte, einfache Athemröhre und neben derselben verläuft an ihrer Basis abzweigend eine andere Athemröhre, die eine grosse Anzahl $(20-30)$ Zitterorgane trägt. Das

IV. J. Männchen von $A$. Sieboldi ist schon in der äussern Form sehr rom Weibchen abweichend, und ist sehr in die Augen fallend durch den Mangel von Schlund und Magen, während die Musculatur des Körpers mehr in den Vordergrund tritt. Das Gehirnganglion mit dem Auge schickt eine Nervenfascr an einen seitlichen Borstenbüschel 
ab. Die Athemorgane sind rom nämlichen Bau, wie die des Weibchens. Im untern Drittheil aber findet sich einc grosse Blase, in der die Spermatozoen liegen, also ein Hoden. Das Männchen bedarf keiner Nahrung, es schwimmt, oft die armartigen Seitenzipfel einschlagend, lebhaft herum und scheint nur ein ganz kurzes, der Fortpflanzung gewidmetes Leben zu führen, ein Verhältniss, das in verschiedenen Klassen niederer Thiere mehrfache Analogien findet. Die schönen, ron LEYDig herrührenden Untersuchungen dieses Thieres liaben uns einen Typus der schwimmenden Räderthiere kennen gelernt, und ermöglichen, um so rascher über die übrigen Formen hinwegzugehen und nur das systematische Interesse derselben zu fixiren.

12. Gatt. Anuraea. Die Sturzrädchen sind schwanzlose, IV.8. schwimmende Räderthiere mit einem ziemlich derben Panzer, der oft gestreift, oft facettirt, oft glatt ist. Ein Nackenauge. Sie tragen an ihrem abgerundeten Körperende die grossen Eier oft mit sich herum. Der Derbheit und comprimirten Form ihrer Hautbedeckung wegen werden sie gewöhnlich in die Nähe von Noteus und Bractioms gestellt, obwohl ihr Räderorgan nicht immer so deutlich in zwei Lappen sich ausbreitet, wie bei jenen Gattungen. Zahlreiche Arten.

13. Gatt. Polyarthra. Diese Gattung ist anf den ersten Blick IV. 5. kenntlich durch sechs seitliche Flossen oder federartige Borsten, mit denen das Thier springende Bewegungen machen kann. Ein Nackenauge. Die Haut bildet keinen soliden Panzer.

\section{Fam. Pterodinear.}

\section{Mit der einzigen}

14. Gatt. Pterodina. Die Flügelrädchen sind runde, von oben etwas zusammengedrückte Thiere, die ron der Mitte der Bauchfläche einen wurmartig geringelten Schwanz mit feinen Endborsten absenden. Sie besitzen zwei rothe Augenflecken unter dem grossen, zweilappigen Räderorgan, und ron diesem letztern gehen zwei sehr starke, quergestreifte Muskelbündcl gerade gegen die hintere Seitenwand. Die mantelförmige, ziemlich resistente Cuticula gibt diesen rundlichen, langsam schwimmenden Thierchen 
einen sehr charakteristischen Habitus, so dass sie schwer mit irgend

IV. 4. einer andern Form verwechselt werden können. Pt. patina ist häufig, etwa 1/10"' gross und stellt sich bei Erschütterung oft Stunden lang todt, was einige Geduld zu ihrer Beobachtung erfordert.

\section{Fam. Hydatineae.}

EHreṇberg charakterisirt diese Familie als panzerlose Räderthiere mit einem vieltheiligen Rüderorgan. Wir haben uns oben schon über die Unzulängliehkeit dieser Merkmale ausgesprochen, und fassen daher alle jene schwimmenden Räderthiere zusammen, die einen kurzen oder gar kcinen deutlichen Schwanz oder Fuss haben, deren Körper aber stets mit zwei deutlichcn bewegliclıen kurzen Blättchen, den sogenannten Fusszangen endet. Ist ein kurzer, ein- bis höchstens dreigliedriger Fuss vorhanden, so sind dic Fusszangen ungefähr gleich lang, wie der Fuss. Die Cuticula ist nieht zu einem rigiden Panzer erhärtet, und der Wimperapparat ist gewöhnlieh etwas höekerig. Die Verthcilung der Gencra lässt sich am leiehtesten dureh die Anzahl und Stcllung der Augen begründen, wobei wir noch zu bemerken haben, dass $\mathrm{Nackenaugen}$ die auf oder hinter dem Sehlundkopf gelegenen, Stirnaugen die vor demselben sitzenden genannt werden. Wir erhalten etwa folgende Uebersicht:

1) Keine Augen.

Gen. Hydatina.

2) Ein Nackenauge.

a) Das Räderorgan nur aus Wimpern bestehend.

Gen. Notommata.

b) Im Räderorgan ragen zwei starke Griffel borstenförmig hervor.

Gen. Synchaeta.

3) Zwei Augen.

Zwei Stirnaugen:

Zwei Nackenaugen:

4) Drei rothe Augenpunete.

Gen. Diglena. Gen. Distemma.

5) Im Naeken ein Haufen rother Augenflerke. Gon. Cycloglena.

6) Jederseits vier bis sechs liehtbreehende Körper aber ohne Pigment, dic vielleicht Augen sind.

Gen.Theorus. 
15. Gatt. Hydatina. Das Krystallfischchen ist eines der bekanntesten Rädcrthiere und seiner Grösse $\left(1 / 1-1 / 5^{\prime \prime \prime}\right)$ und Durchsichtigkeit wegen ein passendes Object zur Untersuchung. Das Rüderorgan besteht aus starken Cilien, die auf höckerigen Wülsten die ganze Vorderpartie überdecken. Der Körper lat eine stark entwickelte Quermusculatur, die vielfach Einschnürungen erzeugt. Die Kiefer haben die Form einer Hand mit ausgestreckten Fingern, sind fünfzahnig, gross; bei verwandten.Formen ist cr nur einzahnig, man hat daher für diese das Genus Ple urotrocha errichtet. Die bekannteste Arst ist die H. senta, die oft in schr grosser Menge V. 5. 6. vorkommt und eine gewisse gesellschaftliche Lebensart zu führen scheint. Die Durchsichtigkeit des Thierchens erlaubt leicht das genauere Studium desselben, wofür wir indess auf die Abbildung verweisen. Sic lcbt ron Euglcnen, die sich oft massenhaft in schlammigem Gcwässer an der Oberflächc entwiekeln und man findet ihren Magen gewöhnlich mit diesen grünen Monaden gefüllt. Eine Art ohne Schlund nnd Magen, die sich oft unter den zahlreichen Exemplaren findet, hat Ehrenberg Enteroplea genannt; dies ist wahrschcinlich das Männchen ron Hydatina senta, von der es sich nur durch ' etwas geringere Grösse, 1/5"', und stärkere Musculatur auszeichnet, welch letztere das genaue Erkennen ciner Samenblasc im untern Theile des Thierchens ziemlich erschwert.

16. Gatt. Notommata. Nur ein einziges Auge im Nacken sitzend, Räderorgan besteht nur aus Wimpern, ohne Stirnhaken oder Griffel, kurzer Zangcnfuss mit kurzen Schwanzklappen. Dic Oberhaut bildet nie eincn Panzer, sondern ist ziemlich weich. Aus dieser grössten Räderthiergattung haben wir die fusslosen Formen ( $N$. anglica und Sieboldi), sowic die mit langen Fusszangen (tigris. longisetu und aequalis) ausgeschicden, um etwas conformere Körpergestaltungen zu bckommen. Der Fuss und seine Bewaffnung scheint bei den Rotatorien überhaupt von grösserer physiologischer und biologischer Bedcutung zu sein, als dies auf den ersten Anblick scheinen möchte. Die zahlreichen noch rerbleibenden Species enthalten mit die grössten Formen freier Räderthiere, so N. myrme-V. 2. lco mit zwei einzahnigen, syrinx mit zweizahnigen und centrura mit dreizahnigen Kiefern und sackförmigem Körper, welche dic Grösse ron 1/3" erreichen. N. $\left\{\right.$ uba $1 / \iota^{\prime \prime \prime}$. Dic N. parasita V. 1. 
lebt parasitisch in den Kugeln ron Volvox globator, in die sie sich hineinfrisst. N. vermicularis Duj. ist lang wurmförmig.

17. Gatt. Synchaeta. Ein Nackenauge. Körperform mehr trichterartig, mit grossem Räderorgan, aus welchem zwei lange Griffel herrorragen.

18. Gatt. Diglena. Zwei Stirnaugen, Zangen des sehr kurzen Schwanzes oft ziemlich lang und breit. Grosse einzahnige Kiefer, die vorschiebbar sind, so dass sie das Kopfende oft überragen. Körperform cylindrisch. Mehrere Arten.

19. Gatt. Distemma. Zwei Nackenaugen. Langgestreckte, cylindrische Körperform. Kiefer ein- bis zweizahnig. Kleinere Thiere.

20. Gatt. Eosphora. Zwei Stirn- und ein Nackenaugenfleck. Die zwei rothen Pigmentflecke der Stirn haben keinen lichtbrechenden Körper, wohl aber das Nackenauge, so dass man diese Form zu Notommala zählen könnte. Indess ist jene Gattung schon gross und die Stirnpuncte sehr constant, weshalb wir sie hier abtrennen.

21. Gatt. Cycloglena hat in der Nackengegend einen rundlichen Haufen rother Pigmentflecken und die

22. Gatt. Theorus jederseits vier bis sechs unpigmentirte Augen oder wenigstens augenförmige, kleine, lichtbrechende Körperchen.

\section{Fan. Monureac.}

In diese Familie vereinigen wir eine Anzahl Gattungen aus den Ehrexiserg'schen Familien Euchlanidota und Hydatinaea, die alle das Gemeinsame haben, dass ihr. Schwanz nicht in zwei Klappen (Fusszangen) endet, sondern dass das Körperende in einen unpaarigen Griffel oder einen starken Stachel ausläuft. So evident dies Merkmal an sich ist, so ist es doch bei kleinern Formen oft schwer zu beobachten, wenn man das Thier nicht in seiner Bewegung und in verschiedenen Stellungen genau verfolgt, und oft ist man gezwungen, stärkere Linsen (etwa Hartnack $\mathrm{Nr}_{\mathrm{r}}$. 7) von 250 350 maliger Vergrösserung anzurenden, was bei diesen lebhaften Thieren seine Schwierigkeiten hat. Einige besitzen eine weichere, andere eine panzerartig erhärtete Oberhaut. Ihre Körperform ist 
entweder cylindrisch, prismatisch, oder schildförmig ron oben comprimirt. Je nach dieser Form und der Anzahl der Augen erhalten wir etwa folgende Uebersicht der Gattungen:

1) Mit einem Augenpunct im Nacken.

a) Körper cylindrisch, weich, ohne Fuss, langer ungegliederter Schwanzfaden.

Gen. Monocerca.

b) Körper prismatisch, panzerartige Oberhaut, mit hohem Rïckenkamm. Fussende besteht aus einem langen, ungegliederten Stachel.

Gen. Mastigocerca.

c) Körper schildförmig ron oben zusanmengedrückt, bepanzert. Schwanz lang, am Finde eine kurze Spitze tragend.

Gen. Monostyla.

2) Mit zwei Augen.

a) Schwanz einen gekrümmten ungegliederten Stachel bildend, ohne scitliche oder Stirnborsten.

Gen. Rattulus.

b) Schwanz zwei- bis dreigliedrig mit einer langen Borste cndigend. Mit einer Stirnborste.

Gen. Monura.

c) Langer Schwanzstachel und zwei seitliche, ebenso lange Sprungborsten.

Gen. Triarthra.

23. Gatt. Monocerca. Diese Räderthierchen bilden kcinen VI. 3. eigentlichen Panzer, ihre Oberhaut ist ziemlich weich. Sie sind dem Genus Notommata nahe verwandt, aber ihr Leibesende geht in einen langen, beweglichen, schnurförmigen Stachel aus, den sic beim Schwimmen oft wellenartig schlängeln. Neben der Wurzel dieses Gebildes sieht man gewöhnlich die zwei in Hörnchen ausgezogenen Hinterleibsspitzen. Dic Kiefer sind einzahnig, sehr stark und aus dem Räderorgan ragt eine längere Spitze oder eine Art Tentakel hervor.

24. Gatt. Mastigocerca. Der prismatische Körper hat eine VI. 2. pranzerartig erhärtete Cuticula, die auf ihrem Rücken in einem hohen Kamm sich abhebt. Die lange Endborste ist so lang, wie das ganze Thier. M. carinata $1 / 12^{\prime \prime \prime}$, mit Schwanz $1 / 6{ }^{\prime \prime}$.

25. Gatt. Monostyla. Diese schildartig oder wappenförmig VI. 1. comprimirten 'Thiere gleichen in ihrer Körperform sehr den Euchlanis- und Lepadella-Arten, aber das Endglied ihres Schwanzes bildet einen langen Griffel, der mit einer kurzen, unpaarigen Spitze bewaffnet ist. 
VI. 4. 26. Gatt. Rattulus. Klcine, dünnhäutige Thierehen ron cylindriseher Körperform, ohne weitere Anhängscl, als einen gekrïmmten Schwanzstachel. Körper weich. R. lunaris.

VI. 5. 27. Gatt. Monura. Kleine, bepanzerte 'Thierchen (verwandt mit Colurus), deren zwei- bis dreigliedriger Fuss in einen kurzen, unpaarigen Staehel endet. Im Räderorgan tritt ein kleines, borstenförmiges Hörnelıen deutlich hervor. M. dulcis.

V. 6. 28. Gatt. Triarthra. Sind grosse, springende Riiderthiere, deren walzenförmiger Leib mit einer selır langen, bauchständigen Borste endet. Von den Seitentheilen geht jederseits eine älınliclıe lange Borste nach hinten, womit die Thiere grosse Slurünge maehen können. Oft schicint es je naeh der Stellung, als wenn drei langc Sehwänze von dem dieken Leibe abgehen würden. Man sielıt häufig die Eier am lintern Körpertheile angeheftet, wo sie an kurzen Füden zu hängen seheinen.

\section{Faul. Fuchlanida.}

Die meisten der liier vereinigten Räderthicre haben einen weiten Panzer, der das Thier mantelartig umhüllt, einige haben aber auch eine dünnere Hautbedeckung und wurden daher von Ehrenberg in der Familie der Hydatinaen untergebracht. Allerdings ist diese Gruppe keine ganz natürliche, was aber bei dem homologen Körperbau der Rotatorien wenig störend wirkt; indess sind die Charaktere, die auf die Form des Fusses basirt sind, aueh mit schwachen Linsen leicht zu constatiren, weshalb besonders zur Bestimmung der grössern Gruppen ihre Vorzügliehkeit Jedem einleuchtet.

Die Euehlaniden haben immer cine langgestreckte Leibesendigung, indem entweder ein langer Fuss aus mchrern gestreckten Glicdern mit zwei borstenförmigen Fussklappen vorhanden ist, oder wenn die Fussglieder fehlen, so sind dic Fusszangen in sehr lang ausgezogene Griffel oder Stacheln umgewandelt. Dic Uebersicht der Gattungen basirt man, wie bei allen schwimmenden Räderthicren, am besten und bequemsten auf dic Stellung und Anzahl der Augen, die hier viel constanter ist, als bei den festsitzenden. Nebenbei werden die Form des Körpers und die Panzerbildung 
passend rerwerthet werden können. Wir erhalten also etwa folgende analytische 'Tafel :

1) Ohne Augeupuncte. Körper schildförmig. Gen. Lepadella.

2) Ein Nackenauge. Gepanzert.

a) Mantelförmiger Panzer auf der Bauchseite der Länge nach klaffend, ohne Anhüngsel. Schildfürmig. Schwanz kürzer als das 'Thier. $\quad 1$ Gen. Euchlanis.

b) Mantelpanzer unten geschlossen, prismatisch, vorn und hinten in Hörnchen ausgezogen. Schwanz relativ kurz.

Gen. Salpina.

c) Mantelpanzer geschlossen, ohne Hörnchen, Schwanz linger uls das übrige Thier. Prismatisch. Gen. Dinocharis.

d) Langer, zweigliedriger Springfuss mit sehr langen Fussrangen.

Gen. Scaridium.

3) Ein Stirnauge. Kurzer Fuss mit langen Fusszangen.

Gen. Furcularia.

4) Zwei Stirnaugen.

a) Räderorgan ohne Schirm. Gen. Colurus.

b) Räderorgan ron einem schirmförmigen Panzerlappen überragt.

Gen. Stephanops:

5) Vier Augenpuncte.

Gen. Squamella.

29. Gatt. Lepadella. Die Schuppenfis ch chen sindkleinere, von oben zusammengedrückte, schildförmige Thiere ohne Augenpuncte. Der Fuss und seine Zangen sind rerhältnissmässig noch kurz, etwa halb so lang, als der Leib. Er besteht aus drei Gliedern und dic schmalen Fusszangen sind fast so lang, wie der Schwanz. Das Wimperorgan ist klein, und der Körper vorn stark rerengert. Der zicmlich feste Panzer hat hinten für den Fuss einen sattelförmigen Ausschnitt. L. ovalis, $1 / 20{ }^{\prime \prime}$, häufig. Mehrere VII. 1. Arten.

30. Gatt. Euchlanis. Die Mantelfischchen zeichnen sich sogleich durch ihren weiten sackartigen Panzer aus, der auf der Bauchseite der Lünge nach klafft, wie wenn er aufgeschlitzt worden wäre. Auch sie sind etwas ron oben zusammengedrückt, leicht schildförmig und nach rorn bedentend rerengert, weshalb auch wenig Raum für das kleine Räderorgan bleibt, dessen Cilien auf mehreren 
höckerigen Stirnausbuchtungen stelıen. E. luna $1 / 12^{\prime \prime \prime}$, macrura

VII. 2. $1 / \mathrm{s}^{\prime \prime}$, Lynceus $1 / 14^{\prime \prime \prime}$, dilatata sind die bekanntesten. Zahlreiche Arten.

VII. 3. 31. Gatt. Salpina. Auch diese Gattung hat, wie die beiden vorigen, einen kurzen Schwanz mit langen Fusszangen. Der Körperpanzer ist prismatisch, etwas von der Seite zusammengedrückt, oder cylindrisch, an der Bauchseite aber stets geschlossen, nicht klaffend. Nach vorn und hinten endet der Panzer in Spitzen oder Hörnchen. Viele Arten.

VII. 4. 32. Gatt. Dinocharis. Von gleicher cylindrischer Körperform, aber keine Hörnchen am Panzer. Der Schwanz ist auch viel länger, als bei der vorigen Gattung und oft mit dornenartigen Anhängseln versehen. D. pocillu m $1 / 10^{\prime \prime \prime}$.

33. Gatt. Scaridium mit einem Nackenauge und

34. Gatt. Furcularia mit einem Stirnauge sind zwei Genera mit weicherer Oberhaut, ohne Panzerbildung, die daher gewöhnlich in die Familie der Hydatinaeen gestellt werden. Ihre sehr langen Gabelschwänze lassen sie aber hier gut unterbringen. Bei Scaridium ist der Fuss aus zwei sehr langen Gliedern und einem ebenso langen pfriemenförmigen Gabelpaare gebildet. Der Körper ist cylindrisch, oft buckelig, wie bei der Gattung Furcularia, wo kein Fuss vorhanden ist, sondern der Hinterleib blos mit einer oft gezähnten, langen, paarigen Fusszange endet. Hieher zählen wir trot\% ihres Nackenauges auch jene Arten der Gattung Notommata, deren. Leib in zwei sehr lange pfriemenförmige Zangenstücke ausläuft (also die

VII. 6. Ehrenberg'schen Arten N. tigris, longiseta und aequalis). Sca-

VII. 7.

VII. 5.

VII. 8. rid. longicaudum, Furcularia gibba.

35. Gatt. Colurus, Sind kleine, bepanzerte Räderthierchen mit «wei- bis dreigliedrigem Schwanz und langen Schwanzklappen. Vorn haben sie oft eine hackenförmige Spitze am Panzer. Ihre Körperform ist meist cylindrisch oder prismatisch, und für die flach von oben comprimirten hat man das Genus Metopidia errichtet.

viI. 9. 36. Gatt. Stephanops. Die Haubenthierchen sind in der Form ihres Teibes den vorigen ähnlich, unterscheiden sich aber sogleich du'ch eine grosse schirmförmige Ausbreitung des Panzers, welche das ganze Räderorgan überragt. Diese Stirnklappe bleibt bei der 
Contraction des Thierchens ausgebreitet. St. lamellaris, lebhalte Thiere ron $1 / 12 "$ ".

37. Gatt. Squamolla. Schildförmig ron oben zusammengedrückt, mit flachem Panzer, vier Augen, zwei- bis dreigliedrigem Fuss und schmalen Fusszangen. Panzer vorn und hinten sattelförmig ausgezchnitten. S. oblonga.

VII. 10.

\section{Fam. Brachioneat.}

Die zwei Gattungen, welche diese kleine Familie bilden, bilden zugleich eine gute, natürliche Gruppe, die leicht ron ähnlichen Formen unterschieden werden kann. Schwanz scharf abgesetzt, lang, mit zwei breiten, kurzen lindklappen. Der harte, schildförmige Panzer ist vorn und hinten mehrfach ausgeschnitten, und das grosse Räderorgan hat zwei stärkere Seitenlappen und mehrere mittlere Höcker.

38. Gatt. Brachionus. Die Wappenthierchen sind stark von oben zusammengedrückt, und sitzen wie Schildkröten in lhrem festen, wappenförmigen Panzer. Der lange Fuss ist quergerunzelt, ohne dentliche Glieder und endet mit breiter, kurzer Fusszange. Vor und hinten ist der Panzer ausgeschnitten und in diverse Spitzen ausgezogen, die zur Bestimmung der Art benutzt werden können. Ein Nackenauge. Sie tragen oft ihre grossen Eier mit sich herum. Die Kief'er haben vier bis fünf Zähne. Das Thier kann sich ganz in seine Schale zurückzielien. B. urceolaris, etwa VI. J. $1 / y^{\prime \prime \prime}$, ist eins der häufigsten Räderthiere. Viele Arten.

39. Gatt. Noteus. Ohne Augen. In seiner Körperform dem Genus Anuraea nahe verwandt, ebenfalls mit stark comprimirter, schildkrötartiger Schale, die auf' ihrer Oberfläche grosse Facetten und starke Punctirung reigt und rorn und hinten in breite Zipfel ausgezogen ist. Der Schwanz hat drei lange Glieder, die mit zwei breiten Zangenklappen endigen. N. quadricornis, etwa $1 / 10^{\prime \prime}$, VI. 8 . ist die einzige Art. 


\section{Ordnung. \\ Rotatoria repentia.}

Die Räderthiere, welche abwechselnd schwimmen und kriechen, bilden eine eigene Gruppe, die sich durch die Gliederung ihres l'usses auszeichnet. Die langen Segmente desselben können sich fermrohrartig in einander einschachteln und ausschieben, wodurch der cylindrische Körper einer bedeutenden Verkürzung unterliegt. Dieser Fuss endet.immer in zwei hakenartige Spitzen, womit sich die Thiere beim Kriechen fixiren. Das Wimperorgan ist relativ klein, meist in zwei Lappen ausgezogen, und wird beim Kriechen eingeklappt, beim Schwimmen aber ausgebreitet. Einige besitzen einen vorstülpbaren Rüssel mit zwei Augenflecken. Die Thiere sind sehr dehnbar, beweglich, ohne härtere Cuticula oder Panzerbildung. Seit mehr als hundert Jahren haben diese weitverbreiteten Geschöpfe viel von sich reden gemacht, wegen ihrer hohen Fähigkeit auszutrocknen, um nach Tagen und sogar Monaten wieder aufzuleben, wenn sie befeuchtet werden. Viele leben auch in der That an Stellen, die nur sehr kurze Zeit und vorübergehend ein wirkliches Leben ermöglichen, z. B. in dem Sande der Dachrinnen, der nur vom Regen befeuchtet wird, während ihn die Sonnenhitze so zu sagen vollständig ausdörrt. Wir haben bei den Infusorien (Colpoda cucullus) etwas Analoges gefunden, aber bei den Räderthieren fehlt jene Hüllenbildung, die bei der Incystirung der Infusorien vorkommt.

Die egelartig kriechenden Räderthiere bilden nur eine einzige, scharf begrenzte Familie.

\section{Fam. Rotiferes.}

Die Uebersicht der drei wesentlichen Gattungen ist eine seh. einfache:

Ohne Augen

Gen. Callidina.

\%wei Stirnaugen, meist auf dem vorstreckbaren Rüssel.

Gen. Rotifer.

Zwei Nackenaugen

Gen. Philodina. 
40. Gatt. Callidina. Aus dem Wimperorgan tritt ein vorn bewimpertcr, augenloser Rüsscl beim Kricchen hervor. Die Fussglieder sind sehr tief ausgeschnitten und bilden daher Nebenhörnchen. Körjer wurmförmig, durch die grossen Eier oft stark bauchig aufgetrieben. Vom Nacken geht ein kleiner Tentakel ab. "Zwei viclzahnige Kiefcrplatten. C. elegans $1 / 6 "$ ".

VIII. 1.

41. Gatt. Rotifer. Ein Rüssel trïgt zwei rothe Augenpuncte und ist vorstülpbar. Fuss mit melıreren Nebenhörnchen. Thier lang cylindrisch. Kiefer zwei zwei\%ahnige Platten bildend. Am Nacken cin dicker 'Tentakel. R. rulgaris ist eines der gemeinsten und bekanntesten Thiere der ganzen Klasse und wurde von Alters her mit dem Namen Rälerthier belegt.

42. Gatt. Philodina. Langgestreckter, cylindrischer Leib VIII. 4. mit zwei Augen ror dem Schlundkopf, der zwei zwei-bis dreizathnige Kieferplatten trïgt. Ein langer Nackententakel und viele lange Nebenhörnchen am Schwanz. Viele Arten.

Beide Gattungen haben zahlreiche Arten, und je nach der Zahhl der Nebcnhörnchen am Schwanzc oder ihrem Fehlen sind neue Gattungen errichtet worden, z. B. Gen. Actinurus, das drei fingerartige Theile am Fussende trägt, Monolabis, wo die Nebenhörnchen fehlen, alles Puncte von untergeordneter Bedeutung.

\section{Anhang.}

\section{Familic der Ichthydina.}

Wir müssen aus biologischen Gründen hier noch eine Familie von Würmern erwïhnen, dic bisher mit demselben Rechte zu den Rïderthieren gezühlt worden ist, mit lem früher die Rotatorien für Infusionsthicrchen crkliirt wurden. Die definitive Stellung der W imperfischehen oder Ichthydina in dem Kreise der Würmer ist bisher noch nicht fixirt, aber jedenfalls gehören sie nicht zu den Rïderthicrchen. Fntweder bilden diese жwei Gattungen eine eigene Ordnung, oder sic gehören zu den rhabdocoelen Tirmatoden. Man findet sie fast in allem stehenden Gewüsser, wo Infusorien und 
Räderthiere vorkommen, und deshalb schon sind sie nieht zu umgehen in eincr Beschreibung der mikroskopisehen Thierformen des süssen VIassers.

Der eylindrisehe, wurmfürmige Körper dieser Gesehöpfe endet mit einem kurzen Gabelselıwanz, was ihnen einige Achnliehkeit mit Riiderthieren giebt. In seinem Innern findet man keine weitern Organe, als eine ganz gerade, fadenförmige Speiseröhre und einen ebenfalls geraden, breitern Darmsack, der naeh hinten mündet. Oft sicht man noch ein grosses Ei mit einen wurmförmigen Embryo. Lin Räderorgan ist nieht vorhanden, sondern die Bauchseite ist bis zum Kopf mit Cilien bekleidet, vermittelst deren die Thierehen schwimmen. Bei einer Gattung hat die Rückenfläche borstenartige, dieke Anhängsel, die aber nicht wimpern. Der sehr kleine, kreisrunde Mund seheint zum Saugen zu dienen, indess sind die Lebenserseheinungen dieser so häufigen Thiere noch wenig bekannt. Man kennt nur zwei leicht sieh unterscheidende Genera:

1. Gatt. Ichthydium mil Fischform, auf der untern Seite VIII. 6. iusserst fein bewimpert. I. podura, etwa ${ }^{1} / 20^{-1 / 30}{ }^{\prime \prime \prime}$, überall häufig, und

2. Gatt. Chaotonotus, von ähnlieher Körperform, meist etwas gebogen und wie roriges einen kleinen Gabelschwanz tragend. Bauchseite mit krïftigen Cilien und der Rücken mit Borsten oder

VIII. 5. Hautlïppchen papillenartig bedeckt. C'h. Larus, etwa 1/20"' gross, häufig an Wasserpflanzen.

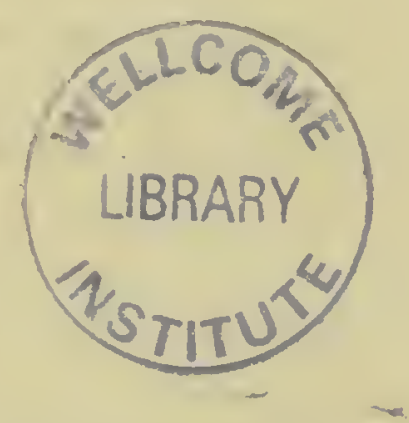

bruck ron Breitkopf und Härtel ir jeiprig. 


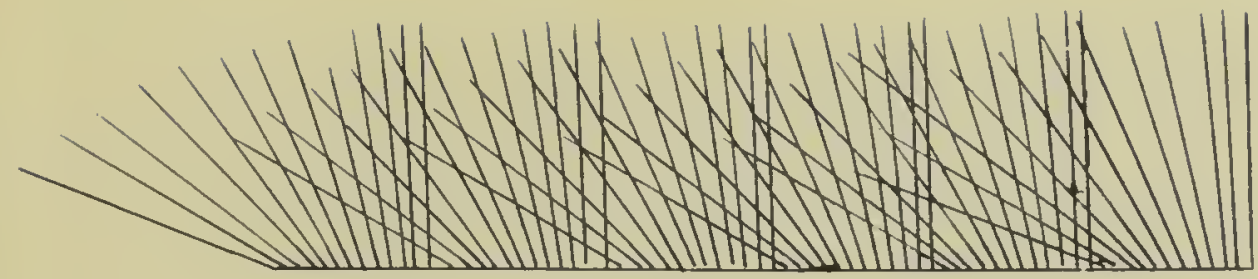

I

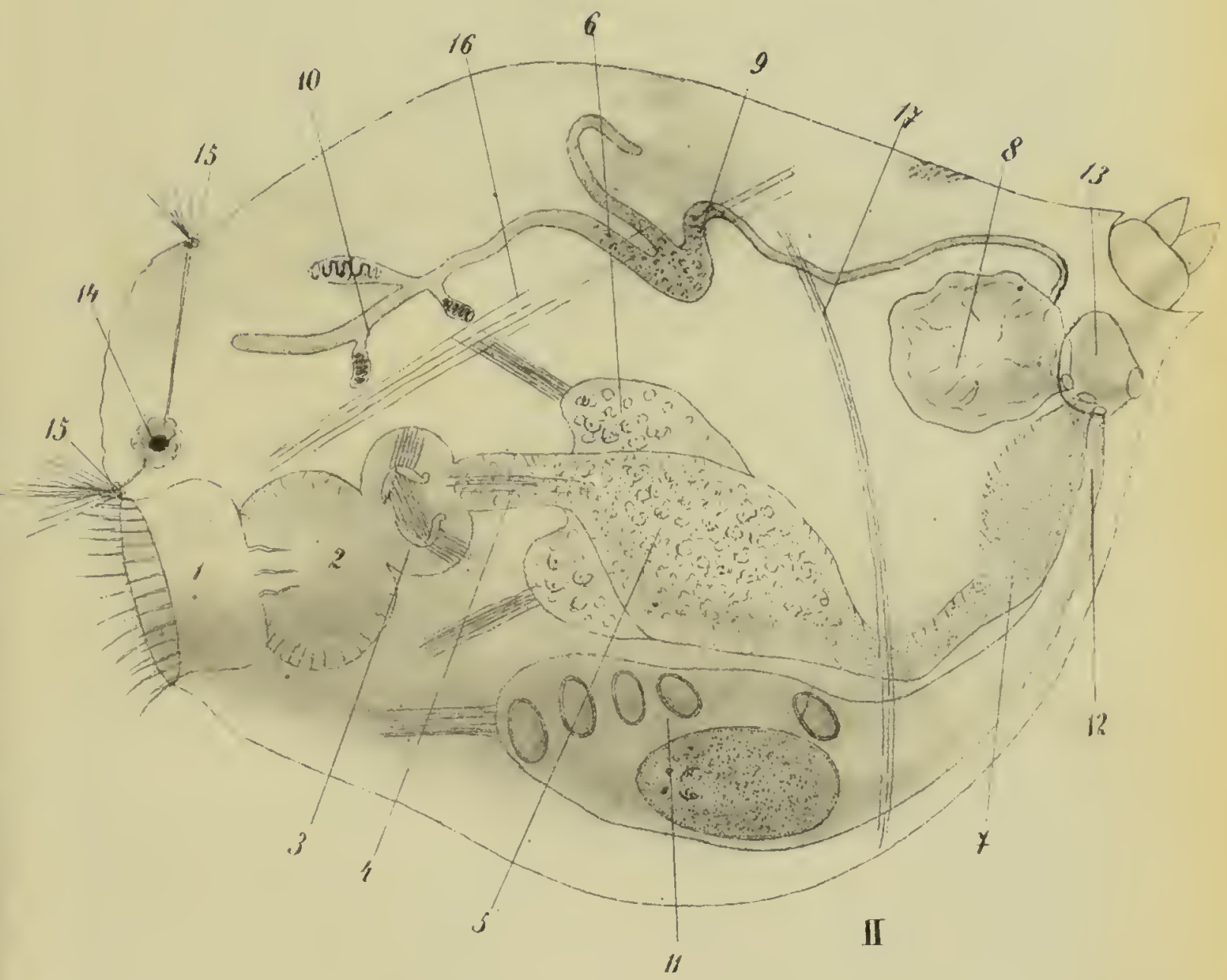

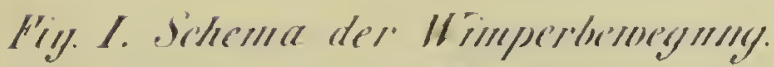

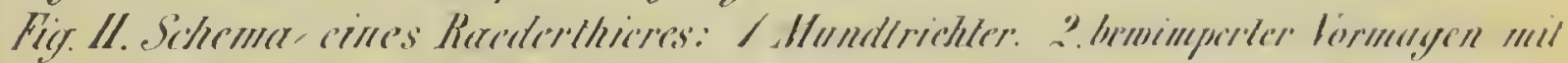

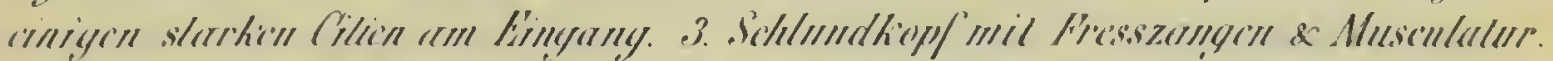

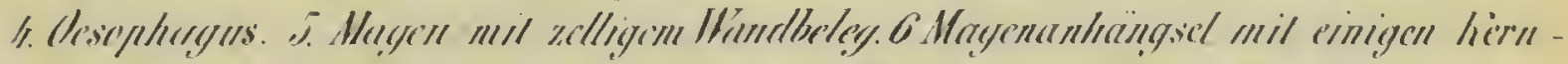

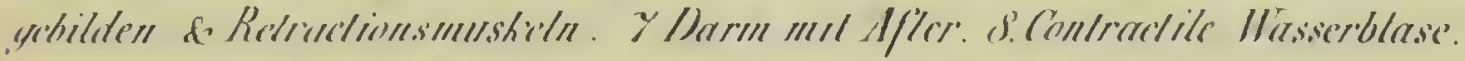

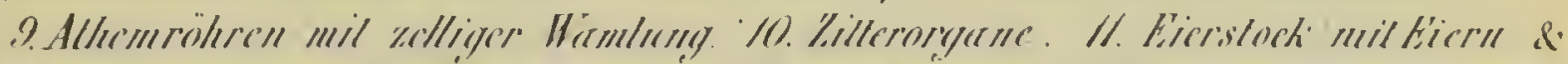

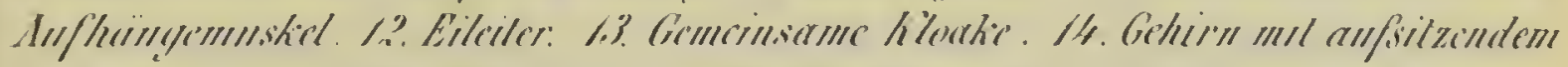

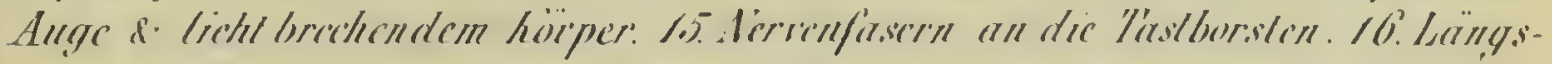

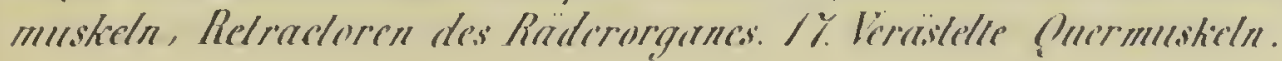




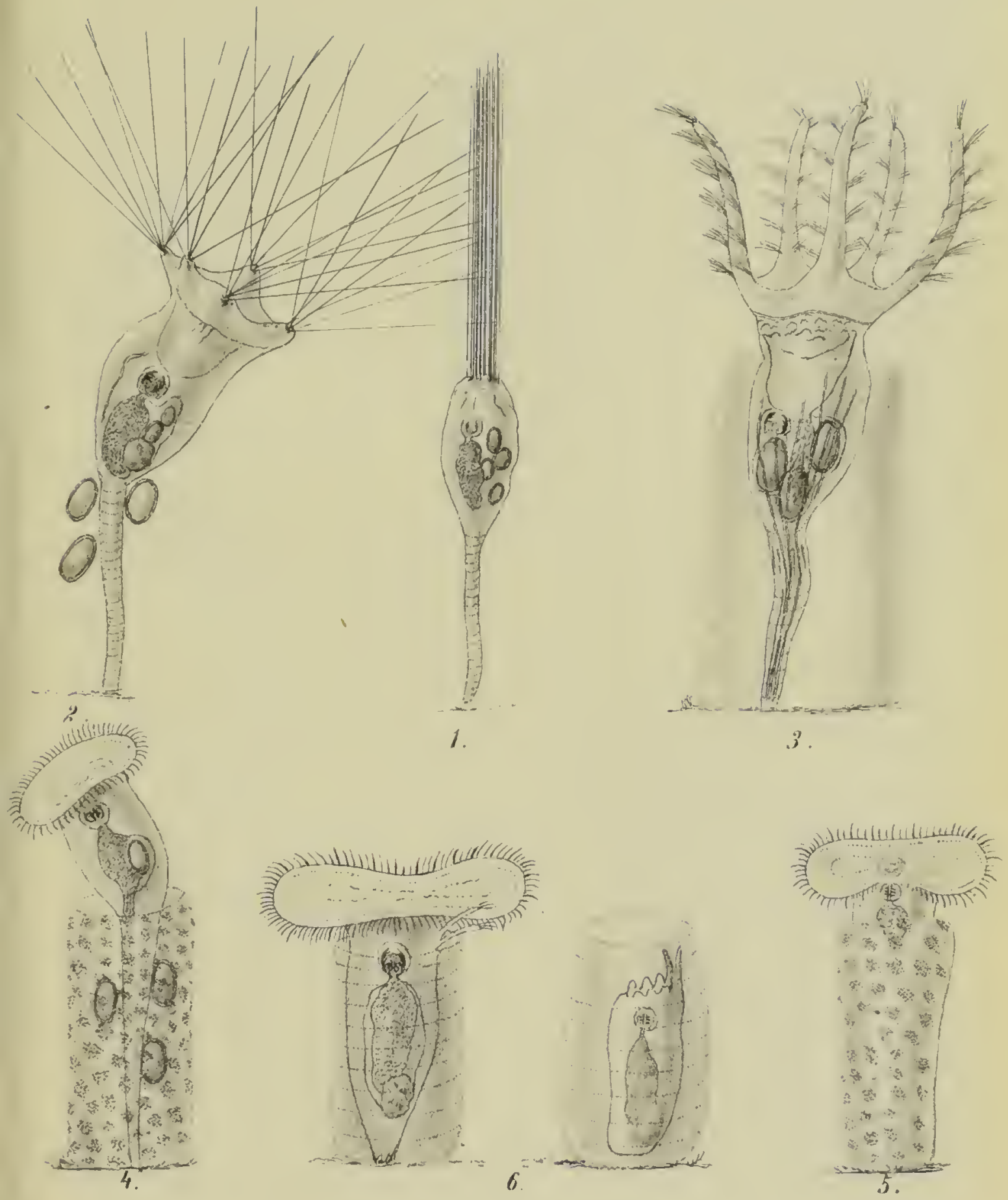

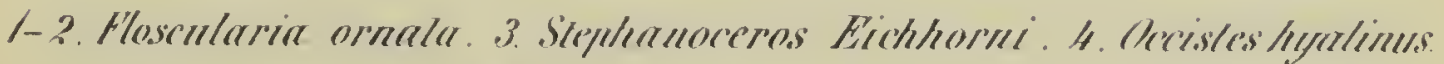

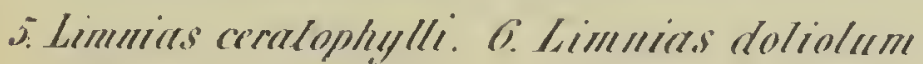



III.
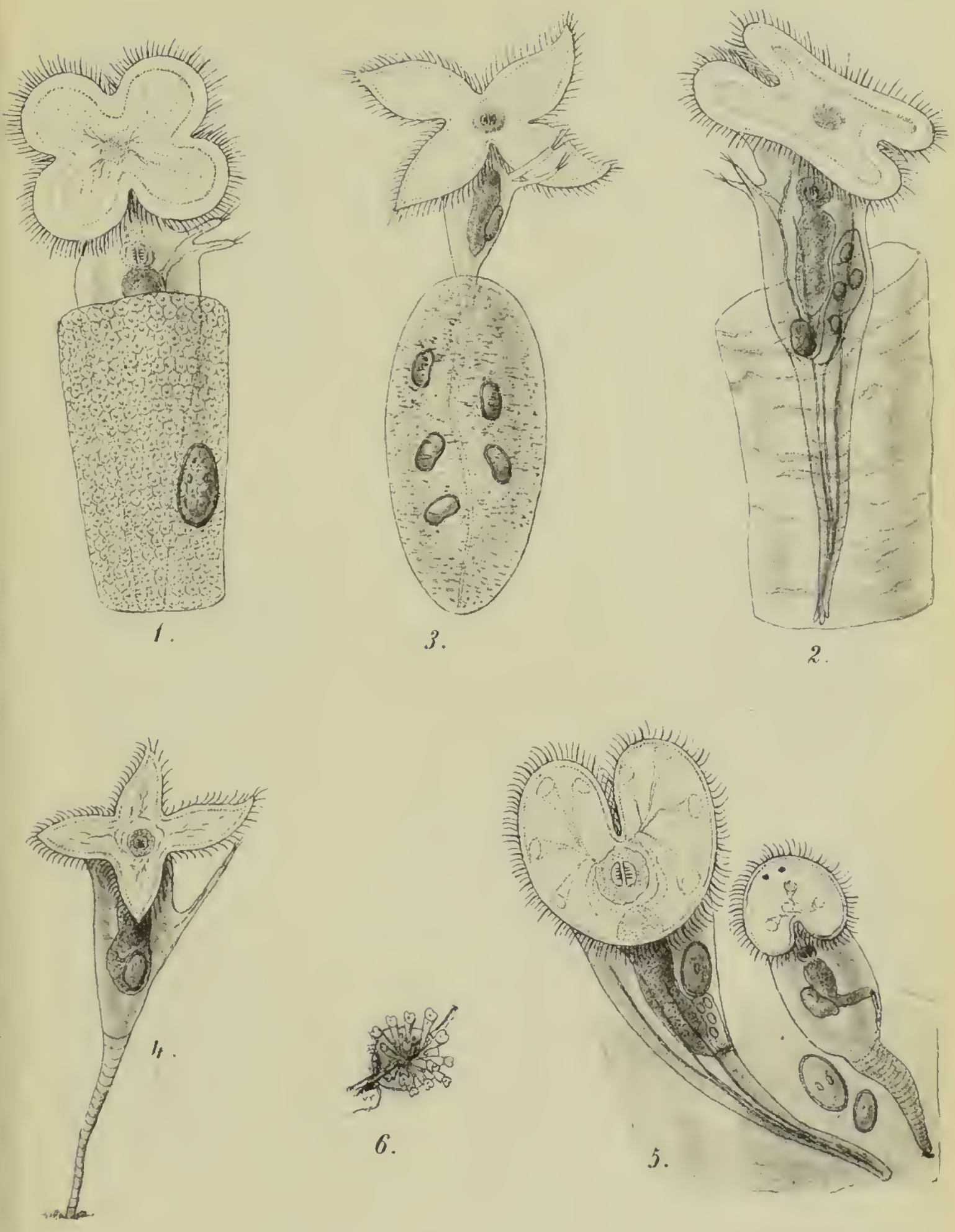

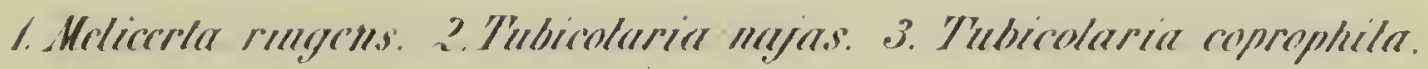
4. Anllios quadtrilobus: Sol G. Lencimularia socialis. 



\section{IV.}
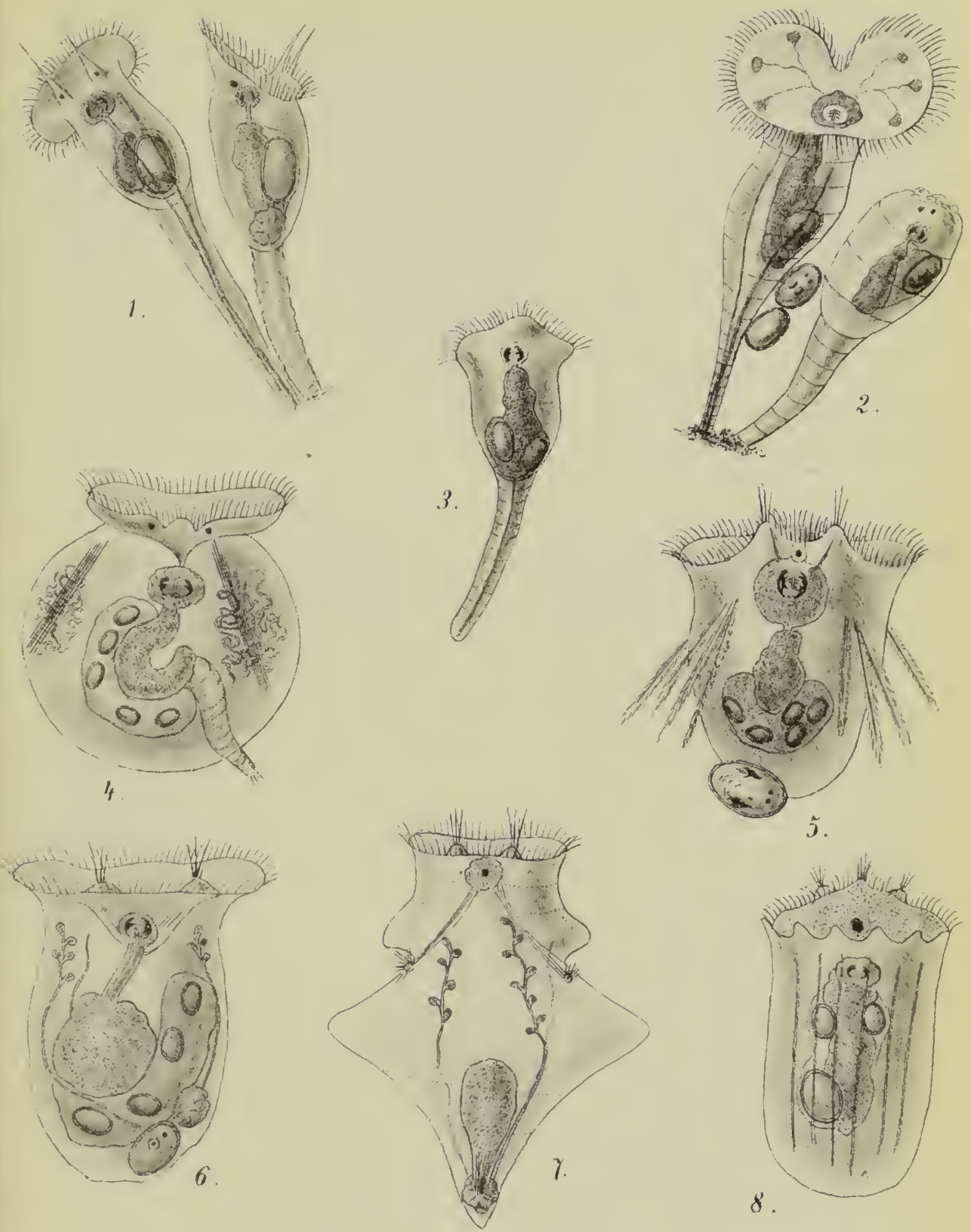

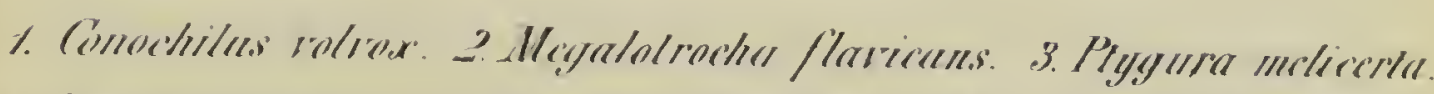

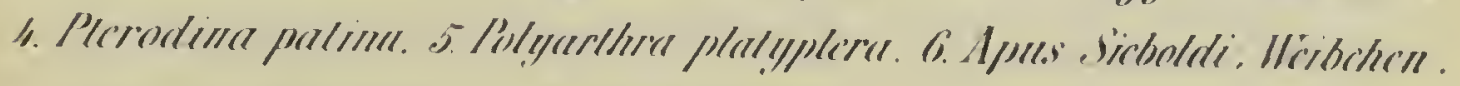

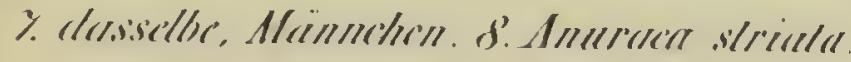




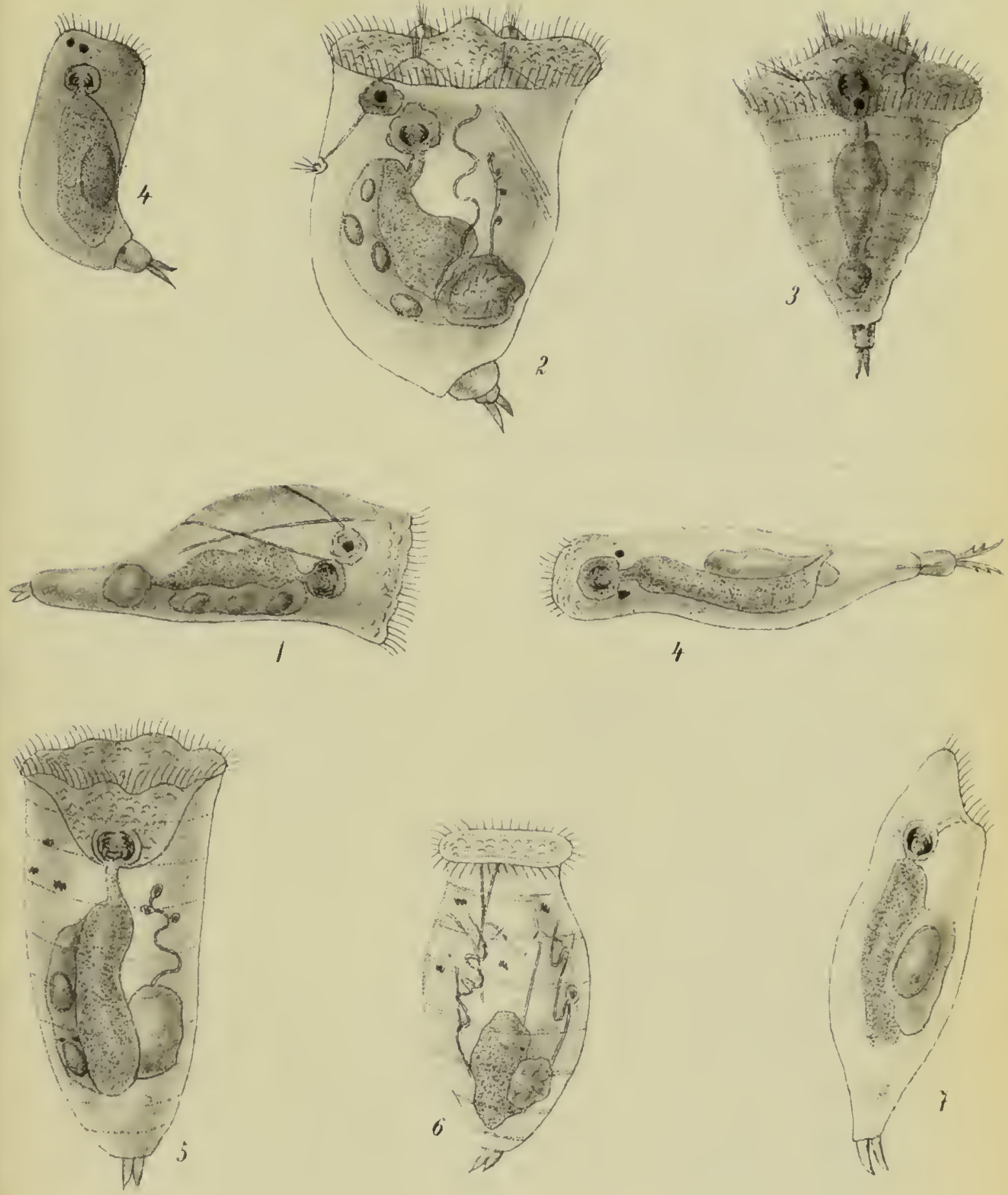

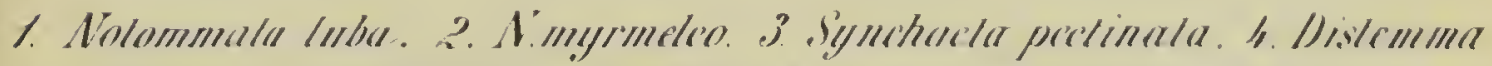

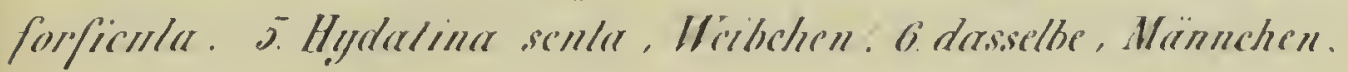

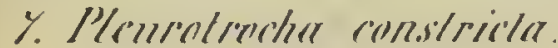





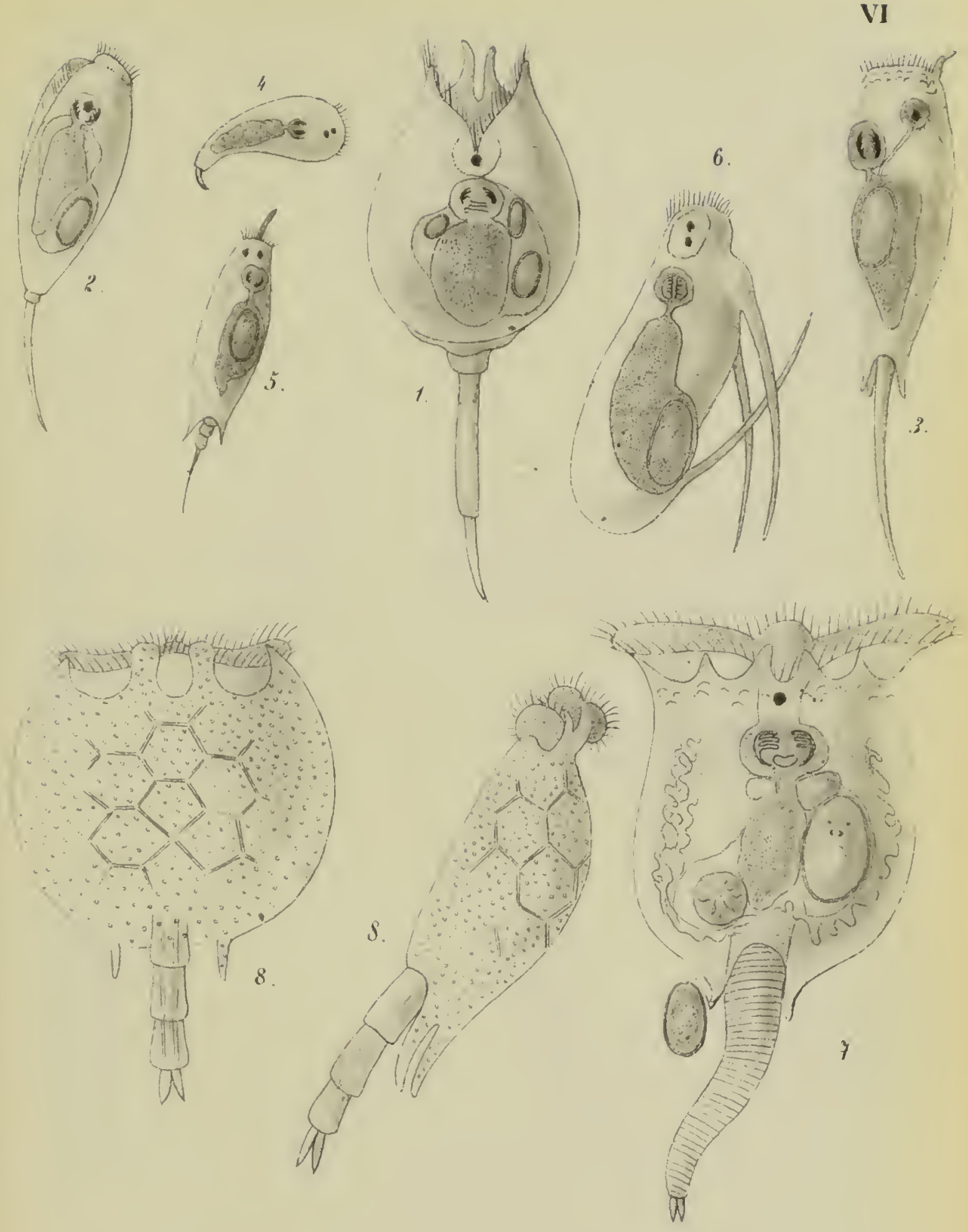

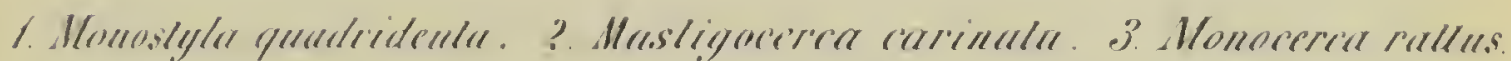

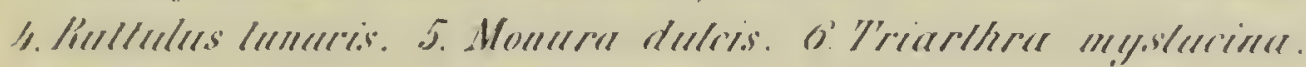

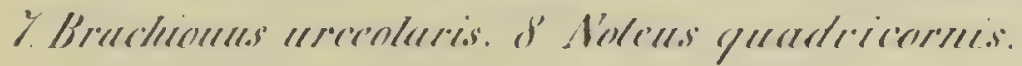



VII.
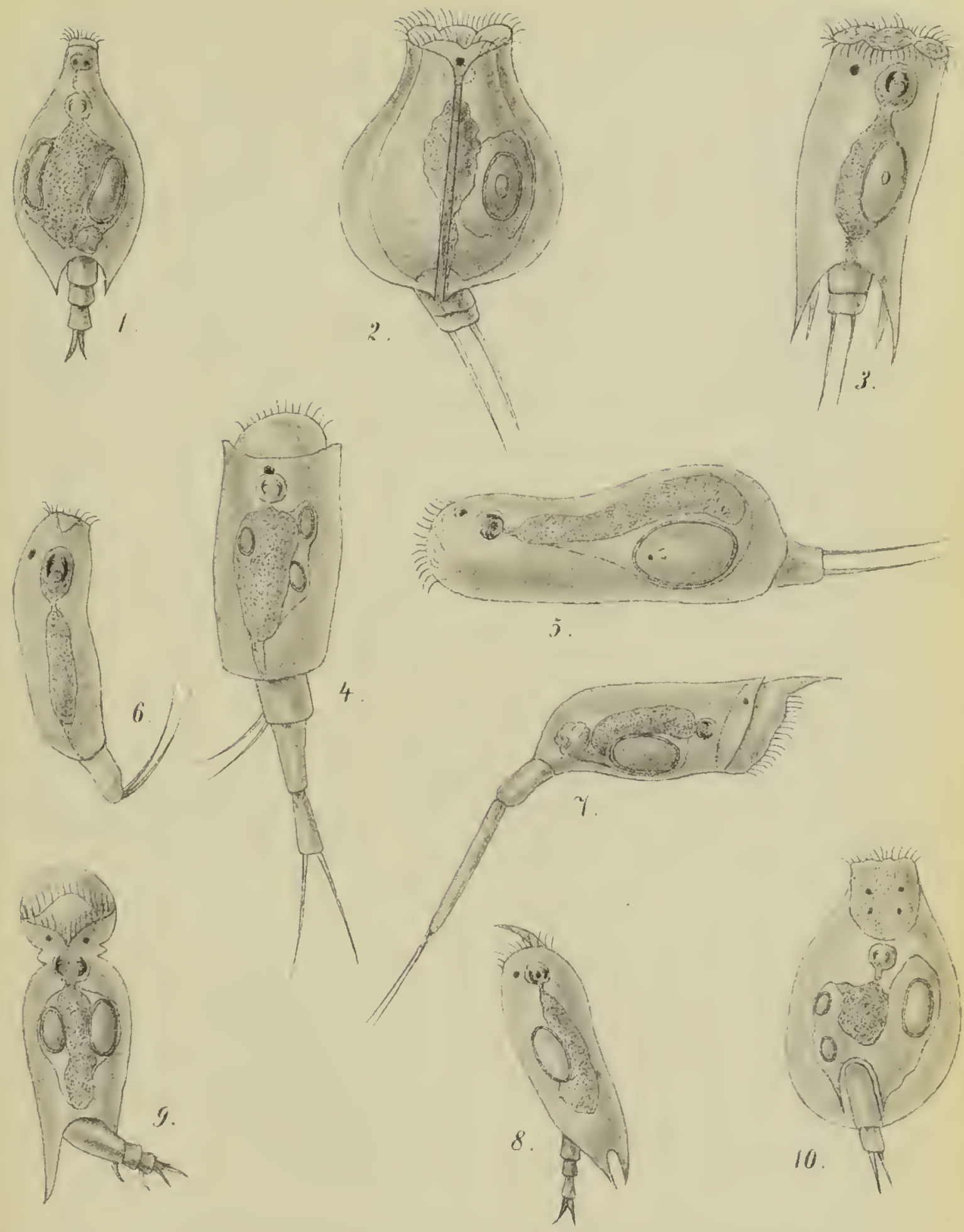

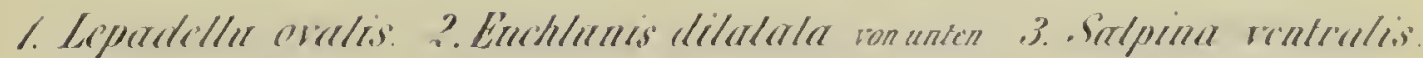

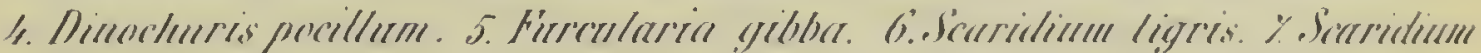

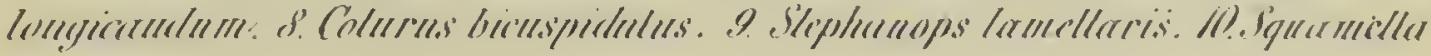
oblonieyur. 







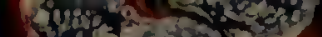

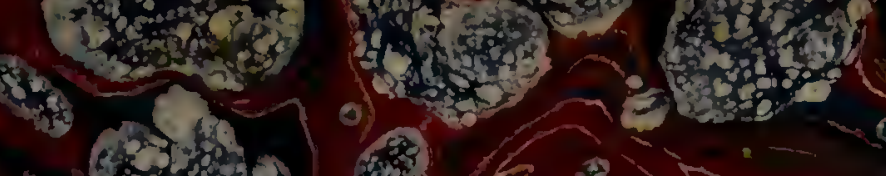

\section{a.

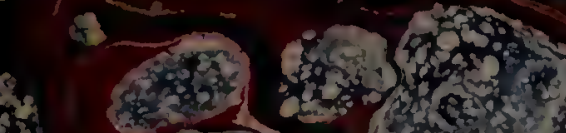

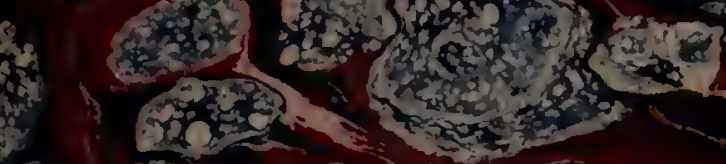

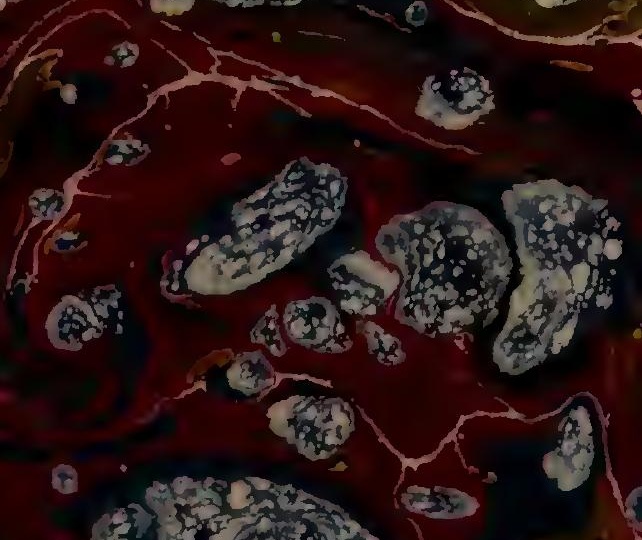

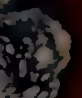

ixta

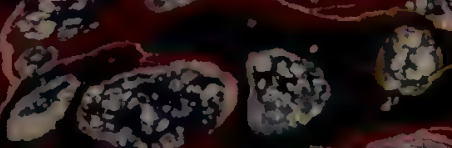

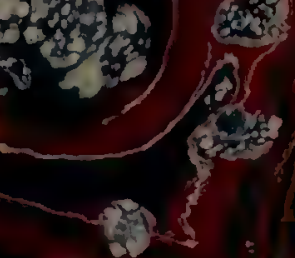

L.

(s)

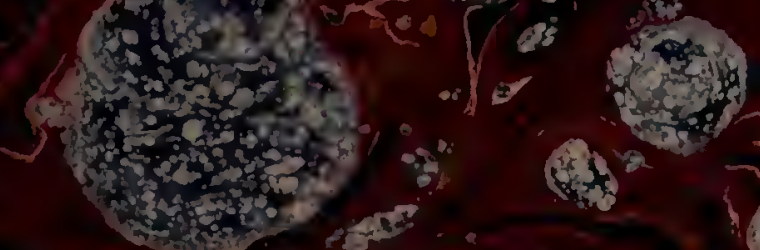

(3)

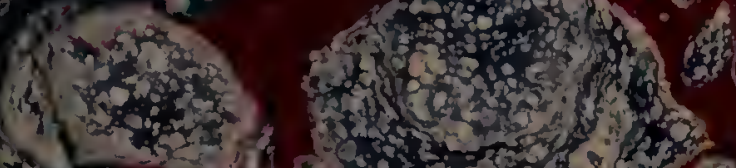

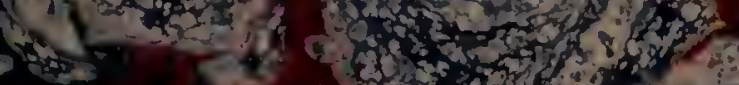

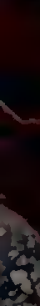

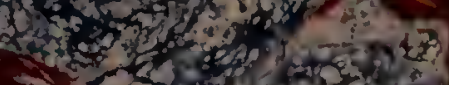

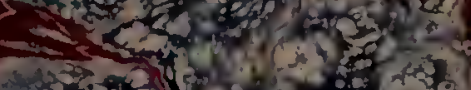

6.1.

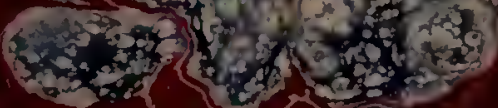

if 1 the

(1)

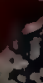

상

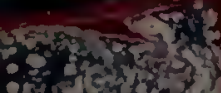

oysosing

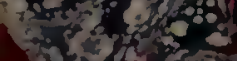

(2)

9

(5)

s?

is

1. 13

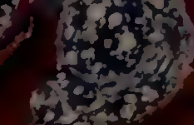

s?

(1)

.

(x) 12

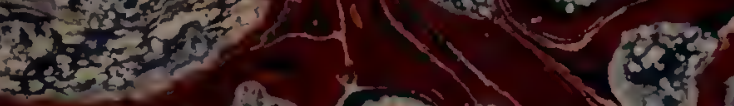

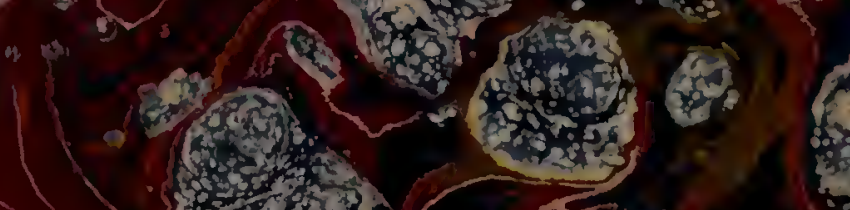

2.

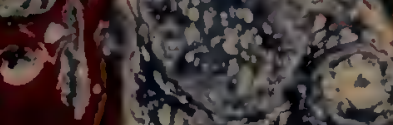

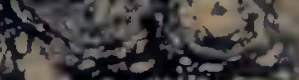

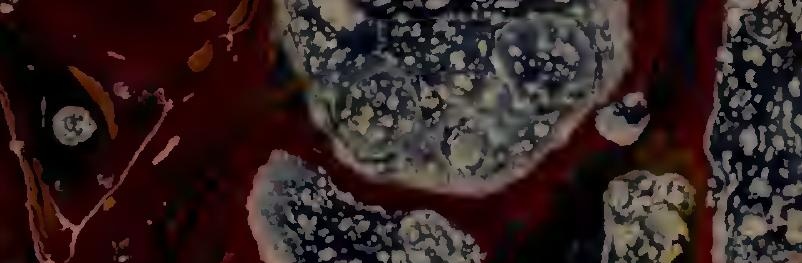

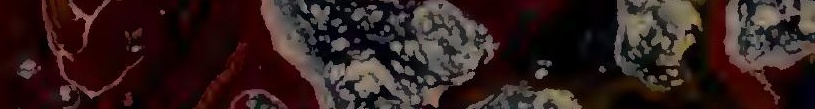

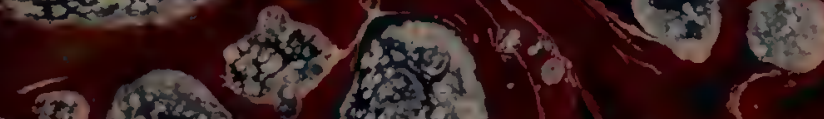

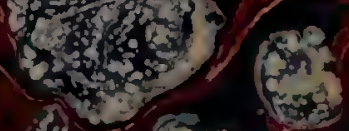

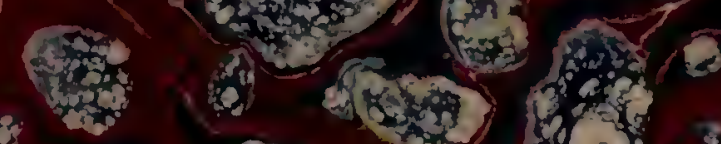

(2) $6 x+5)$ की

as

010 (3)

(1),

3.

texts.

(1) (2)

$466^{3}$

c.

$78{ }^{2}$

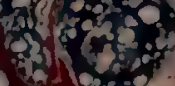

yareces y 
